UNIVERSIDADE DE SÃO PAULO

FACULDADE DE ECONOMIA, ADMINISTRAÇÃO E CONTABILIDADE DEPARTAMENTO DE ADMINISTRAÇÃO

PROGRAMA DE MESTRADO PROFISSIONAL EM EMPREENDEDORISMO

O TEMPO NO LANÇAMENTO DE PRODUTOS DE INFORMAÇÃO

\author{
Autora: Cibele Vegiato de Mello \\ Orientador: Prof. Dr. Martinho Isnard \\ Ribeiro de Almeida
}

SÃO PAULO 
Prof. Dr. Marco Antonio Zago

Reitor da Universidade de São Paulo

Prof. Dr. Adalberto Américo Fischmann

Diretor da Faculdade de Economia, Administração e Contabilidade

Prof. Dr. Roberto Sbragia

Chefe do Departamento de Administração

Prof. Dr. Martinho Isnard Ribeiro de Almeida

Coordenador do Programa de Mestrado Profissional em Empreendedorismo 
UNIVERSIDADE DE SÃO PAULO

FACULDADE DE ECONOMIA, ADMINISTRAÇÃO E CONTABILIDADE DEPARTAMENTO DE ADMINISTRAÇÃO

PROGRAMA DE MESTRADO PROFISSIONAL EM EMPREENDEDORISMO

CIBELE VEGIATO DE MELLO

\title{
O TEMPO NO LANÇAMENTO DE PRODUTOS DE INFORMAÇÃO
}

\author{
Dissertação apresentada ao \\ Departamento de Administração da \\ Faculdade de Economia, Administração e \\ Contabilidade da Universidade de São \\ Paulo como requisito para a obtenção do \\ título de Mestre em Ciências
}

Orientador: Prof. Dr. Martinho I. R. de Almeida

\footnotetext{
Versão Corrigida

(versão original disponível na biblioteca da Faculdade de Economia, Administração e Contabilidade)
}

\section{SÃO PAULO}


FICHA CATALOGRÁFICA

Elaborada pela Seção de Processamento Técnico do SBD/FEA/USP

Mello, Cibele Vegiato de

O tempo no lançamento de produtos de informação / Cibele Vegiato de Mello / Cibele Vegiato de Mello. - São Paulo, 2017. $139 \mathrm{p}$.

Dissertação (Mestrado) - Universidade de São Paulo, 2017. Orientador: Martinho Isnard Ribeiro de Almeida.

1. Inovação 2. Administração de empresas 3. Eficiência organizacional 4. Produtos novos 5. Estratégia organizacional I. Universidade de São Paulo. Faculdade de Economia, Administração e Contabilidade. II. Título.

CDD - 658.4 


\section{AGRADECIMENTOS}

Agradeço aos meus pais, João e Catarina, e a meu marido, Pedro, por todo o incentivo ao longo dessa jornada, pelas recomendações e discussões de tópicos de estudo, pelas revisões de material e pelo auxílio em todas as outras atividades que me permitiram voltar aos estudos neste momento.

Agradeço ao Professor Martinho Isnard Ribeiro de Almeida pelo suporte ao longo de todo o curso, propondo-se a criar um novo curso e ensinando empreendedorismo não só na teoria, mas também na prática interna à Universidade de São Paulo.

Agradeço aos professores e monitores do curso de Mestrado Profissional que estão também inovando no formato de curso e de aulas, propuseram novos modelos de ensino e continuam se empenhando todos os dias a melhorar o ensino de Administração e Empreendedorismo no Brasil.

Agradeço a todos os entrevistados por sua disponibilidade de tempo e pelo valor que aportaram a esse estudo.

Agradeço aos colegas de sala pelas ricas discussões em classe, que ajudam a construir uma perspectiva mais diversa e aplicada dos temas estudados ao longo do curso.

Agradeço à Fabiane Caseiro, que nos ajudou esclarecendo dúvidas e auxiliando todos os processos acadêmicos desde a matrícula até o envio final dos exemplares dessa dissertação.

Agradeço por fim a todos aqueles que estiveram presentes ao longo do estudo, amigos, colegas do trabalho e de estudos que contribuíram frequentemente de modo indireto com os resultados dessa dissertação. 


\section{RESUMO}

Essa dissertação visa elaborar recomendações para agilizar o lançamento de novos produtos de informação em organizações de grande porte, com base em uma pesquisa bibliográfica e entrevistas semiestruturadas. A seleção dos dezesseis entrevistados foi realizada procurando identificar três públicos diferentes: cinco gestores de novos produtos em empresas de grande porte, cinco gerentes de aceleradoras e seis empreendedores. Foram coletados fatos e impressões destas fontes e comparados com a bibliografia pesquisada. Foi constatado que o tempo é o fator primordial no lançamento de novos produtos e que este é inerente a todas as decisões relacionadas a fatores dos aspectos internos da empresa e do ambiente organizacional. As principais recomendações advindas da análise foram: quantificar o valor do tempo, de forma que as decisões comparativas entre o tempo e os aspectos burocráticos de um lançamento em uma grande empresa possam ser balizados; utilizar o produto mínimo viável (MVP) para validar a comercialização do novo produto; criar processos flexíveis, tendo em vista que é fundamental a experimentação com o mercado no momento de lançamento; valorizar a marca e os produtos já existentes no portfólio da empresa no lançamento, evidenciando as vantagens da corporação na comunicação; criar parcerias e incentivar a inovação aberta para não depender apenas do crescimento orgânico; incentivar o envolvimento de colaboradores com o projeto do novo produto, de modo interdepartamental, criando possibilidades de job rotation e adequando a composição da equipe a cada fase do projeto; alocar recursos específicos a cada novo produto, para evidenciar prazos claros e evitar as necessidades burocráticas comuns a grandes empresas; incentivar a mentoria entre dirigentes da empresa e a equipe do novo produto; entender o problema do cliente como o ponto de partida do lançamento; usar métricas ao longo de todo o processo da inovação para avaliar o atingimento dos objetivos e o direcionamento correto das ações.

Palavras-chave: produtos novos, inovação, administração de empresas, eficiência organizacional, estratégia organizacional 


\begin{abstract}
This dissertation aims to elaborate recommendations to accelerate the launch of new information products in large organizations. This research was based on a bibliographical research and semi-structured interviews. The selection of the sixteen interviewees was carried out in order to identify three different audiences: five managers of new products in large companies, five managers of accelerators and six entrepreneurs. The collected facts and impressions from these sources were compared with the bibliography. It was found that time is the primary factor in the launch of new products and that it is inherent in all decisions related to internal aspects of the company and the organizational environment. The main recommendations of the analysis were to: quantify the value of time, in order to validate comparative decisions between the time and the bureaucratic aspects of a launch in a large company; use the minimum viable product $(M V P)$ to validate the new product; create flexible procedures, since market experimentation is fundamental at the time of launch; leverage the brand and the products already existing in the portfolio, highlighting their advantages in the communication; create partnerships and encourage open innovation not to rely solely on organic growth; encourage the involvement of employees in the new product design, in an interdepartmental manner, creating possibilities of job rotation and adjusting the composition of the team to each phase of the project; allocate specific resources to the new product showing clear deadlines and avoiding the bureaucratic needs common to large companies; encourage mentoring between company managers and the new product team; understand the customer's problem as the starting point of the launch; use metrics throughout the innovation process to assess achievement of each objectives.
\end{abstract}

Keywords: new products, innovation, business management, organizational efficiency, organizational strategy 


\section{SUMÁRIO}

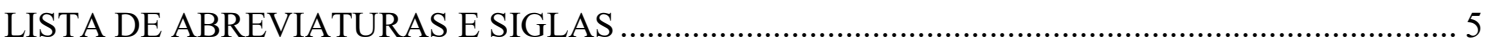

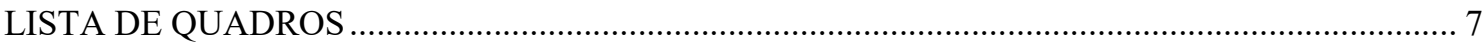

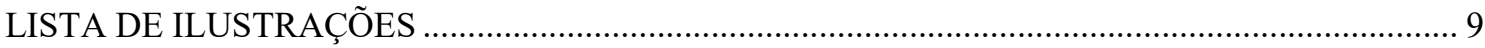

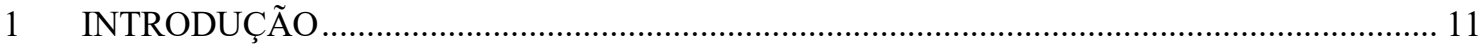

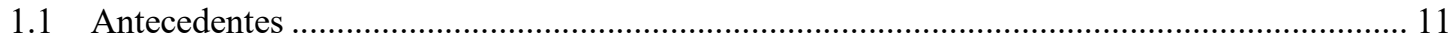

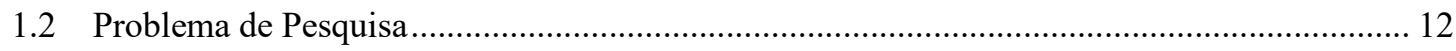

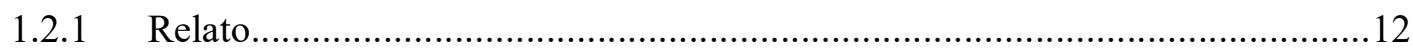

1.2.2 Identificação do tema e do problema de pesquisa........................................15

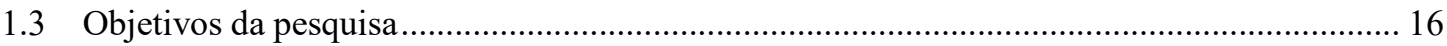

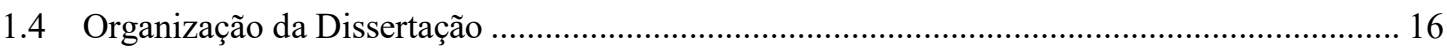

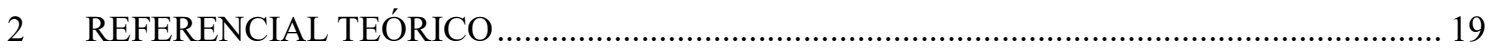

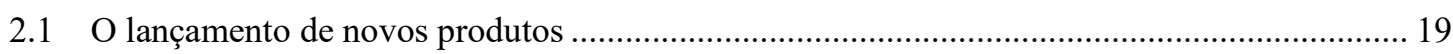

2.1.1 A importância do tempo no lançamento de novos produtos ............................20

2.1.2 Aspectos relacionados ao tempo de lançamento...........................................23

2.2 Modelos de aceleração do lançamento de novos produtos e inovação..................................... 24

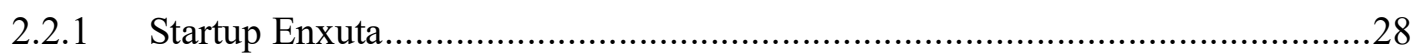

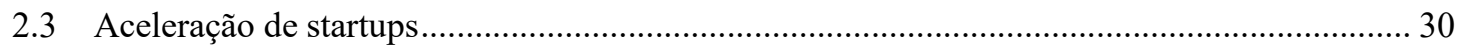

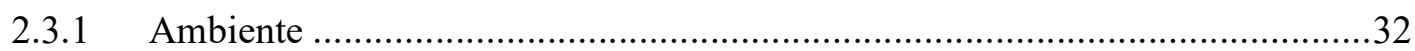

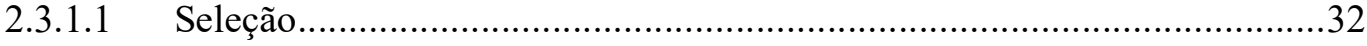

2.3.1.2 Infraestrutura e suporte administrativo.................................................33

2.3.1.3 Investimentos e redes de parceiros.............................................................33

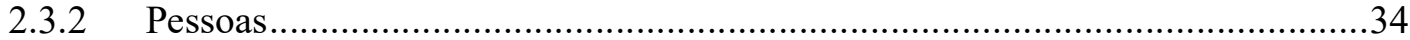

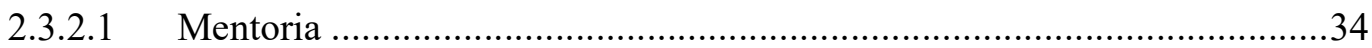

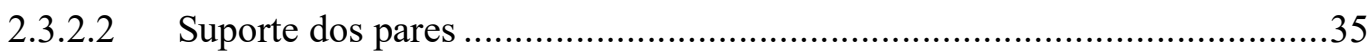

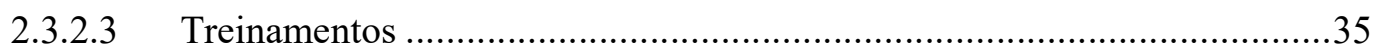

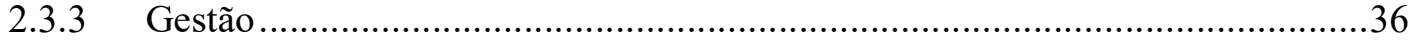

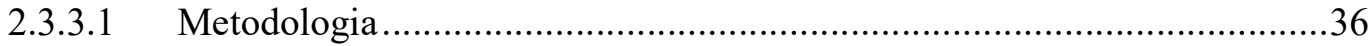

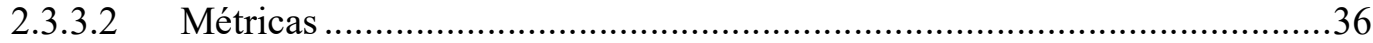

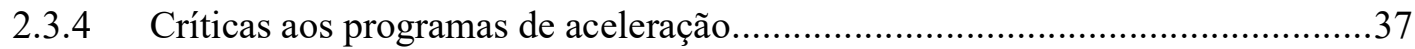

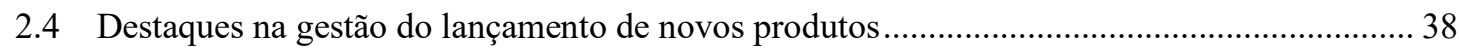

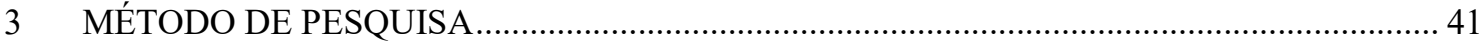

3.1 Caracterização geral do método de pesquisa e coleta de dados ............................................... 41

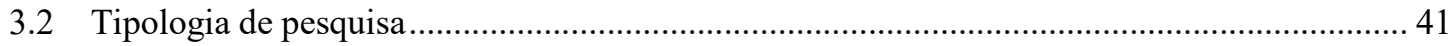


3.3 Estrutura da Pesquisa e Métodos de Coleta e Análise de Dados. 42

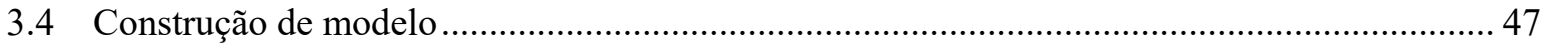

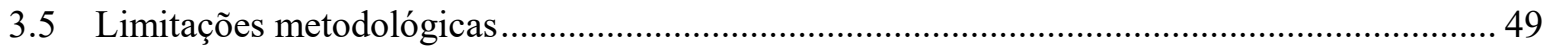

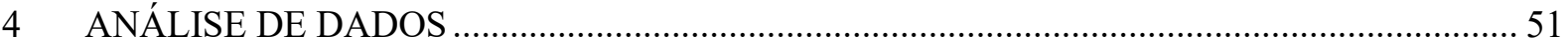

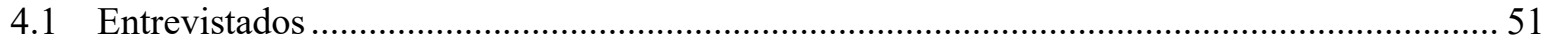

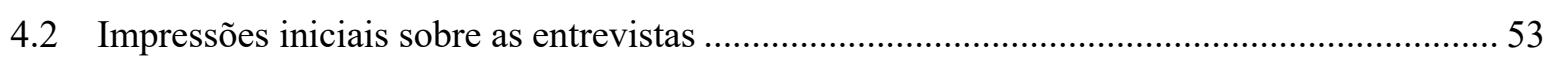

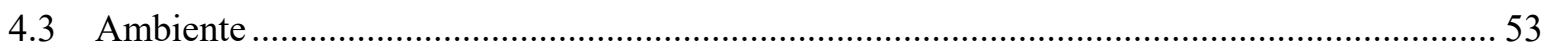

4.3.1 Antecedentes e consequências do lançamento de novos produtos......................54

4.3.1.1 O tempo e a agilidade no lançamento de novos produtos............................54

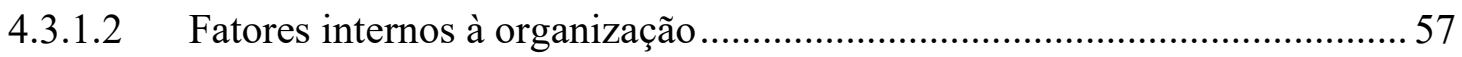

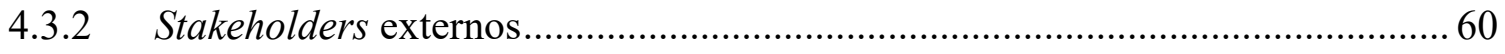

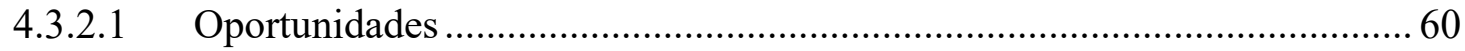

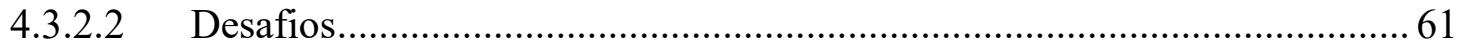

4.3.2.3 Ecossistema: Fornecedores, Pares e Clientes............................................. 65

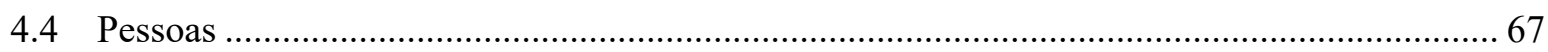

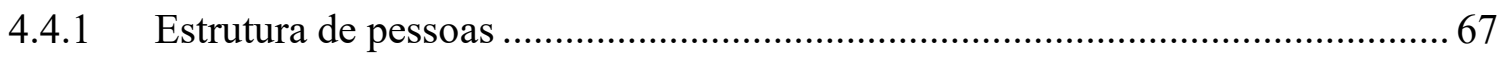

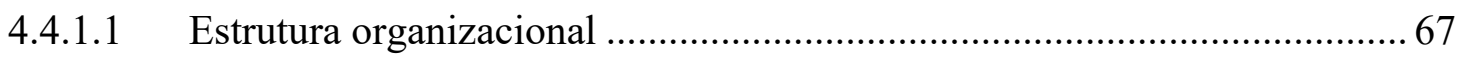

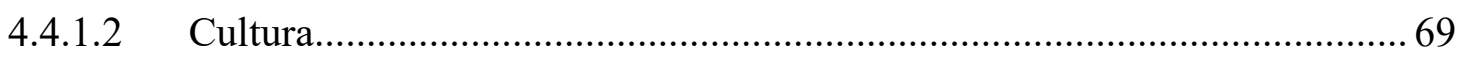

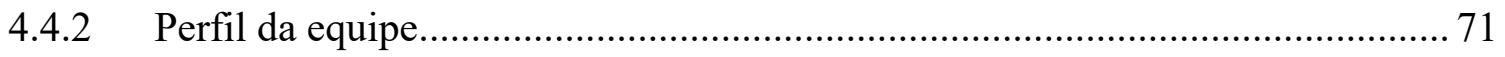

4.4.2.1 Gestão e composição das equipes .............................................................. 71

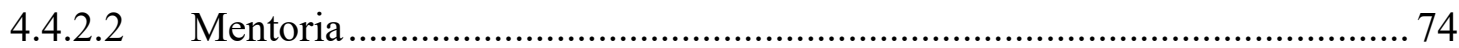

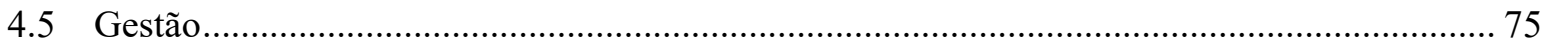

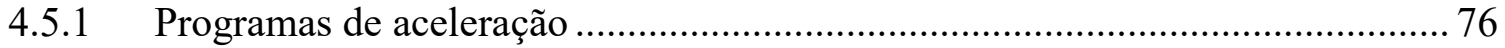

4.5.1.1 Fases e atividades da aceleração .............................................................. 76

4.5.1.2 Limitações dos processos de aceleração ..................................................... 80

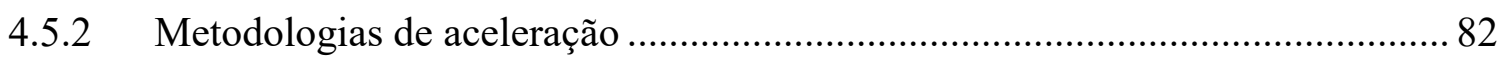

4.5.2.1 Modelos para aceleração de projetos e inovação ........................................ 82

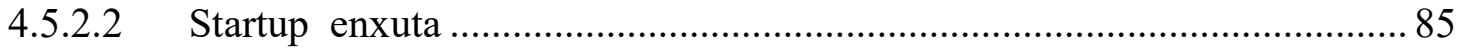

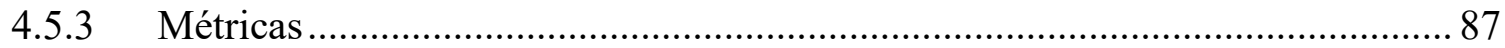

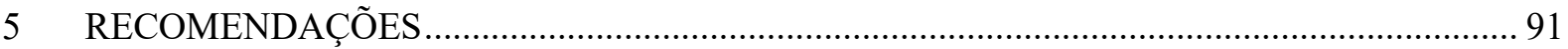

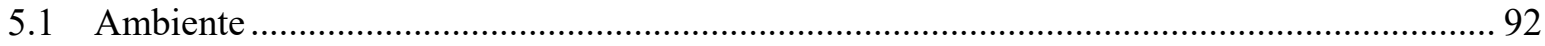

5.1.1 Antecedentes e consequências do lançamento ............................................... 92

5.1.1.1 O tempo e a agilidade no lançamento de produtos ..................................... 92 


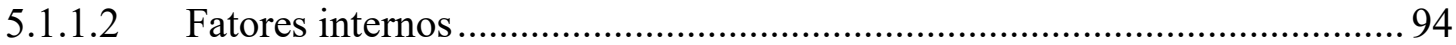

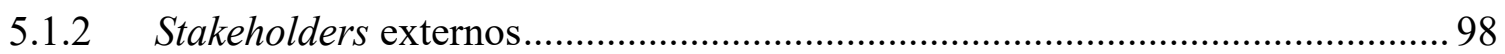

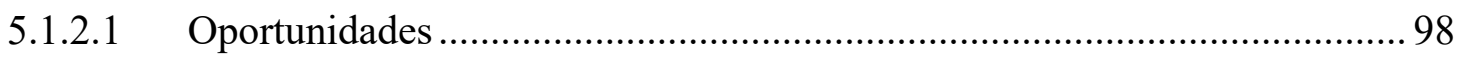

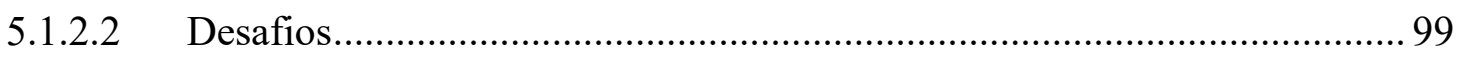

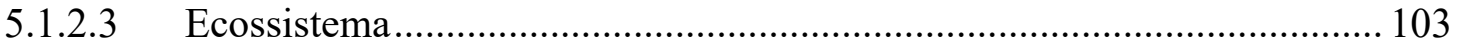

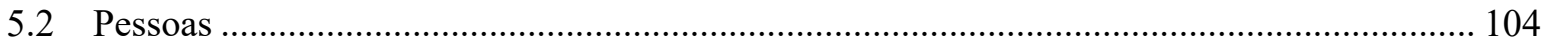

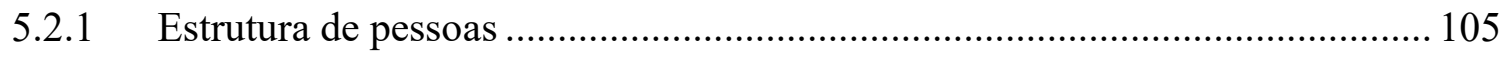

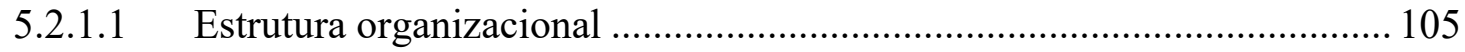

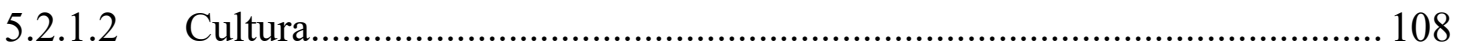

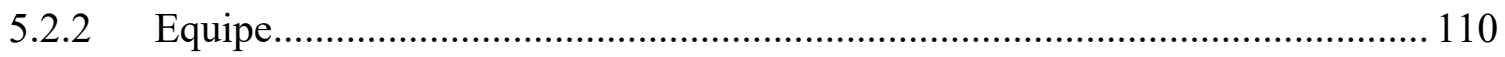

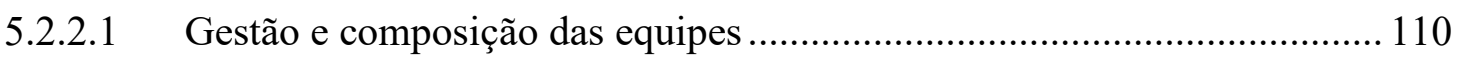

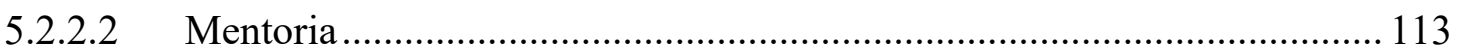

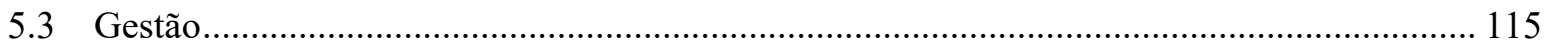

5.3.1 Métodos de gestão de novos produtos........................................................ 115

5.3.1.1 Modelos para aceleração de projetos e inovação ......................................... 116

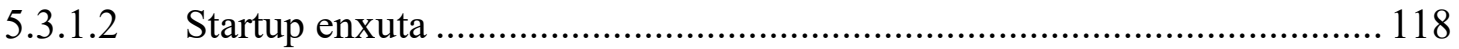

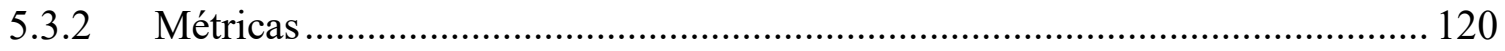

5.3.2.1 Definição das métricas para novos produtos ........................................... 120

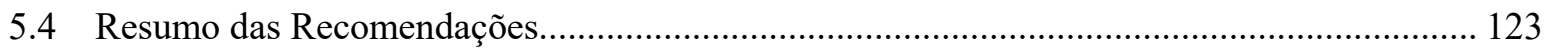

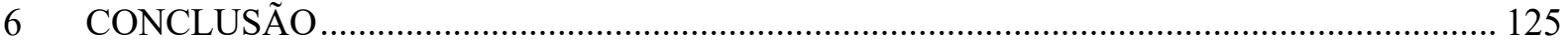

6.1 Limitações do estudo e recomendações para estudos futuros ................................................ 126

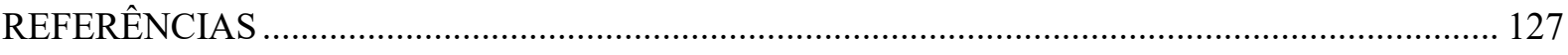

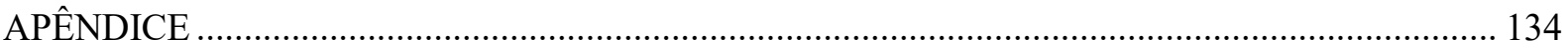

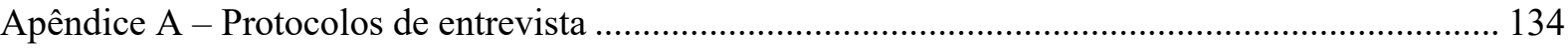

Protocolo da entrevista semiestruturada com gestores de inovação em corporações .... 134

Protocolo da entrevista com empreendedores ou gestores de inovação em startups ..... 135

Protocolo da entrevista com gestores de aceleradoras ou mentores............................. 137 


\section{LISTA DE ABREVIATURAS E SIGLAS}

B2B: Business-to-Business (Empresa a Empresa)

B2C: Business-to-Consumer (Empresa a Consumidor)

IOT: Internet of Things (Internet das Coisas)

KPI: Key Performance Indicator (Indicador Chave de Performance)

MVP: Minimum Viable Product (Produto Mínimo Viável)

OKR: Objectives and Key Results (Objetivos e Resultados-Chave)

P\&D: Pesquisa e Desenvolvimento

PMBoK: Project Management Body of Knowledge

RH: Recursos Humanos

SEO: Search Engine Optimization (Otimização dos Motores de Busca)

TI: Tecnologia da Informação 


\section{LISTA DE QUADROS}

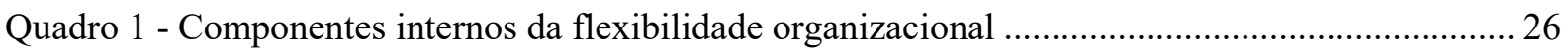

Quadro 2 - Métricas relevantes por componente do canvas ................................................................... 37

Quadro 3 - Componentes subdivididos em famílias e códigos de para análise de dados....................... 45

Quadro 4 - Critérios e técnicas para garantir confiabilidade na pesquisa qualitativa ........................... 49

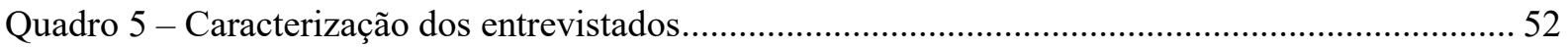

Quadro 6 - Evidências e descobertas relacionadas à unidade de análise de tempo ............................... 93

Quadro 7 - Recomendações relacionadas à unidade de análise de tempo ............................................ 94

Quadro 8 - Evidências e descobertas relacionadas à unidade de análise de fatores internos ............... 95

Quadro 9 - Recomendações relacionadas à unidade de análise de fatores internos ............................ 97

Quadro 10 - Evidências e descobertas relacionadas à unidade de análise de oportunidades.................98

Quadro 11 - Recomendações relacionadas à unidade de análise de oportunidades............................... 99

Quadro 12 - Evidências e descobertas relacionadas à unidade de análise de desafios ....................... 100

Quadro 13 - Recomendações relacionadas à unidade de análise de desafios ..................................... 102

Quadro 14 - Evidências e descobertas relacionadas à unidade de análise de ecossistema .................. 103

Quadro 15 - Recomendações relacionadas à unidade de análise de ecossistema ................................ 104

Quadro 16 - Evidências e descobertas relacionadas à unidade de análise de estrutura organizacional

Quadro 17 - Recomendações relacionadas à unidade de análise de estrutura organizacional............ 108

Quadro 18 - Evidências e descobertas relacionadas à unidade de análise de cultura .......................... 109

Quadro 19 - Recomendações relacionadas à unidade de análise de cultura ....................................... 110

Quadro 20 - Evidências e descobertas relacionadas à unidade de análise de gestão e composição de equipe.

Quadro 21 - Recomendações relacionadas à unidade de análise de gestão e composição de equipe. 113

Quadro 22 - Evidências e descobertas relacionadas à unidade de análise de mentoria ....................... 114

Quadro 23 - Recomendações relacionadas à unidade de análise de mentoria .................................... 115

Quadro 24 - Evidências e descobertas relacionadas à unidade de análise de outros métodos............ 116

Quadro 25 - Recomendações relacionadas à unidade de análise de outros métodos.......................... 118

Quadro 26 - Evidências e descobertas relacionadas à unidade de análise de startup enxuta............... 118

Quadro 27 - Recomendações relacionadas à unidade de análise de startup enxuta............................ 120

Quadro 28 - Evidências e descobertas relacionadas à unidade de análise de métricas....................... 121

Quadro 29 - Recomendações relacionadas à unidade de análise de métricas..................................... 122 


\section{LISTA DE ILUSTRAÇÕES}

Ilustração 1 - Espinha de peixe para definição da questão de pesquisa

Ilustração 2 - Desenvolvimento do plano de marketing no processo de desenvolvimento de produtos 19

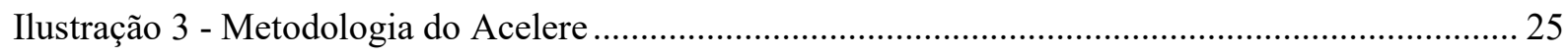

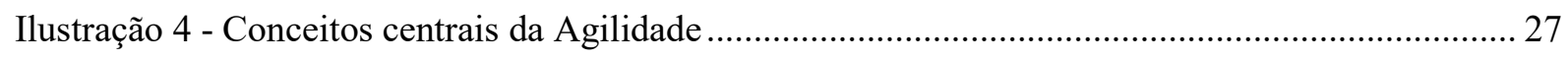

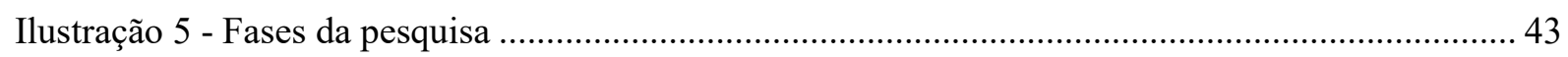

Ilustração 6 - Ciclo de crescimento da construção de teoria aplicada ................................................... 48 


\subsection{Antecedentes}

Esta dissertação visa a estudar sobre o tempo no lançamento de novos produtos por organizações de grande porte. Tendo por base a experiência profissional da autora no lançamento de produtos neste tipo de instituição, e tendo sido verificado por meio de pesquisa com dados secundários a relevância do tempo nesta atividade de entrada no mercado - em instituições de pequeno e grande porte -, o objetivo desta dissertação é oferecer recomendações que possam ser seguidas pelas corporações de modo a atender os requisitos de agilidade necessários à inovação.

Ainda que se possa verificar a relevância do tempo na inovação em diversos contextos, optouse neste estudo pela análise do lançamento de produtos de informação. Esse recorte demonstra que o enfoque será no momento da entrada do produto no mercado (embora por vezes o desenvolvimento aconteça simultaneamente à entrada no mercado e o desenvolvimento de características adicionais seja realizado também após o lançamento).

A opção por produtos de informação se deve às particularidades e desafios desta indústria. Esses produtos são aqueles cujo valor está em seu conteúdo (ainda que seu formato e mídia também sejam características relevantes para diferenciar entre suas versões) - como notícias, livros, aulas e consultorias, entre outros. Os recentes avanços tecnológicos favoreceram a redução de custos de armazenamento e distribuição de dados, impulsionando o crescimento dos produtos de informação e também demandando o estudo específico de suas características para permitir que esse crescimento seja sustentável. 


\subsection{Problema de Pesquisa}

\subsubsection{Relato}

Essa dissertação se baseia em uma experiência da autora, relatada neste capítulo; porém, visa à identificação de problemas comuns a instituições diversas. O relato técnico descreve um caso único cujo contexto será generalizado por meio de dados secundários, apresentando a sua relevância em diversas situações e instituições. $\mathrm{O}$ caso estudado é o lançamento de um novo produto de consultoria - classificado como produto de informação - no mercado latinoamericano após seu lançamento na Europa.

Parte do portfólio de uma multinacional com mais de 90 anos no mercado, com ativos avaliados em mais de 120 bilhões de euros no final de 2016 e presente em mais de 20 países, o produto havia sido desenvolvido e estava em operação nascente na Europa. O desafio na América Latina era adequá-lo à demanda local, atendendo aos requisitos técnicos e regulatórios e ao mercado consumidor de cada país.

O produto de consultoria em questão inovou por reduzir custos e melhorar os resultados quando comparado a produtos anteriores, utilizando ferramentas de Big Data que tornam as análises mais precisas e estudos estatísticos de maior qualidade quando comparados ao que existia anteriormente.

Para a sua entrada no mercado, foram necessárias adaptações ao público-alvo (como adequação à demanda e à disponibilidade de caixa dos clientes potenciais), à operação da organização (como recursos internos e infraestrutura técnica) e ao mercado no qual estava entrando (como fatores políticos, econômicos e sociais). A proposta de valor do produto já havia sido desenvolvida e o objetivo era mantê-la na América Latina, embora seus componentes pudessem ser adaptados se necessário.

Esta operação de lançamento envolveu múltiplas atividades e dezenas de áreas internas à organização, tais como Atendimento ao Cliente, Financeiro, Viabilidade Técnica, Compras, Jurídico, Marketing, Vendas, entre outras. Para executar estas tarefas, foi selecionada uma 
equipe de produtos para coordenar a implantação e a interface com todas as áreas de modo a garantir que todos os requisitos fossem atendidos.

O lançamento cumpriu seu objetivo em termos de escopo (isto é, foi entregue o que estava definido para ser entregue); contudo, uma maior agilidade na condução desse processo poderia ter permitido aos clientes usufruir dos novos serviços antecipadamente e à organização menor tempo para atingir o ponto de equilíbrio financeiro. Uma vez que a instituição foi a primeira a lançar o produto nos países onde atuava, o tempo mais curto do lançamento não teria afetado o seu pioneirismo - embora esse fator também seja relevante na inovação.

Para identificar os principais fatores que impactaram o tempo do lançamento do novo produto, detalham-se algumas situações envolvendo esse lançamento a seguir.

Havia um fluxo único para o lançamento de novos produtos e melhorias incrementais, que envolviam aprovações por mais de 20 departamentos. Cada departamento definia seu modo de gestão, e com frequência as áreas de apoio não possuíam uma pessoa dedicada à inovação. Havia um prazo para cada área aprovar ou questionar especificidades do projeto - algo positivo sob a perspectiva da agilidade -, mas o fluxo das aprovações deveria ser reiniciado se houvesse algum questionamento que exigisse detalhamento. Visto que o fluxo era único para todos os produtos e eles eram de naturezas distintas, exigia-se ao responsável pela aprovação aprender as características relacionadas a cada produto - algo que requeria tempo e especialização.

Observou-se também que quando eram necessárias as áreas de suporte, havia competição entre os diversos produtos do portfólio. Nesses casos, os produtos maduros eram geralmente priorizados pelo fato de que seu resultado era imediato e apresentava maior impacto. Não havia regras claras para a fila de priorização de demandas.

Outro desafio interno à empresa e associado à competição interna entre novos produtos e produtos tradicionais se referia ao treinamento e ao incentivo da força de vendas. Requerendose maior esforço para aprender as funcionalidades de cada produto e já existindo demanda pelos produtos atuais, a força de vendas tendia a favorecer a venda dos produtos tradicionais pela facilidade de sua comercialização (em comparação à inovação). Ao mesmo tempo, incentivos melhores para a venda da inovação aumentavam o custo operacional do novo produto - cuja 
previsão de vendas e de faturamento ainda era incerta. Essa incerteza também dificultava a identificação de custos fixos e variáveis, bem como a definição dos canais de comercialização do novo produto.

Quanto ao ambiente externo, algumas características locais não aproveitavam o esforço já realizado internacionalmente - como os requisitos legais. O produto também estava sujeito a alterações regulatórias ao longo do processo de lançamento. Ademais, concorrentes com produtos substitutos entraram no mercado e reduziram a vantagem competitiva relacionada à exclusividade.

Alguns clientes potenciais também foram resistentes à inovação ou avessos ao risco. Inicialmente, o produto era desconhecido e não possuía casos de sucesso locais, e eventualmente havia percepção de risco ou indisposição para mudança de fornecedor ou de produto por parte dos clientes. Ademais, clientes corporativos geralmente já possuíam orçamentos anuais específicos para suas aquisições e não eram capazes de alterá-lo.

Diversos dos desafios observados não são exclusivos a produtos de informação; no entanto, há aspectos específicos a eles. Visto que os dados armazenados podem ser utilizados para múltiplos estudos a um custo proporcionalmente menor que estoques de outras matérias-primas, e que os custos variáveis se restringem às atividades de venda e de análise de dados, grande parte do custo desses produtos está no investimento inicial (anterior a testes com o mercado) mas esse investimento é relativamente flexível. Também, o valor da informação como produto só é reconhecido quando consumido, e o valor decai uma vez que é conhecido por todo o mercado.

Verificou-se que a corporação reconheceu o potencial de receita a longo prazo do novo produto; contudo, a sua lucratividade real era determinante para que ele se mantivesse no portfólio. Portanto, uma vez que os resultados financeiros são essenciais, o tempo - assim como os demais recursos investidos, sejam eles humanos, físicos, e o próprio custo de oportunidade de investir em outros projetos de lucratividade imediata ou de menor risco - era um fator crítico no lançamento do produto. A própria característica de inovação está associada ao pioneirismo. 


\subsubsection{Identificação do tema e do problema de pesquisa}

O relato demonstra alguns desafios da entrada de novos produtos no mercado devido à rapidez de mudanças e à complexidade de previsão dos fatores que impactam a comercialização desse produto - fatores que geram impacto sobre a eficiência e o retorno sobre o capital investido. Nas empresas, inovação e eficiência por vezes indicam caminhos opostos. Ainda que haja oportunidade de aumento de eficiência decorrente da adoção de processos inovadores, em geral a inovação apresenta maior risco que os produtos tradicionais, menor potencial de economias de escala, e exige investimentos a longo prazo. Estes fatores tendem a acarretar em menor eficiência no curto prazo do que as operações atuais da empresa. Essa dissertação reflete sobre os diversos fatores que se inter-relacionam com o tempo da entrada no mercado de novos produtos de informação sob a ótica de uma corporação e a subsequente criação de recomendações para a redução desse tempo. Embora nem sempre a opção deve ser por acelerar o lançamento, o presente estudo enfoca na agilidade do lançamento comercial, atendendo à persectiva de eficiência apresentada no relato da experiência da autora.

Apresentando o relato no modelo espinha de peixe, a Ilustração 1 reflete as causas-raiz do problema da eficiência do lançamento e a questão de pesquisa a ser estudada:

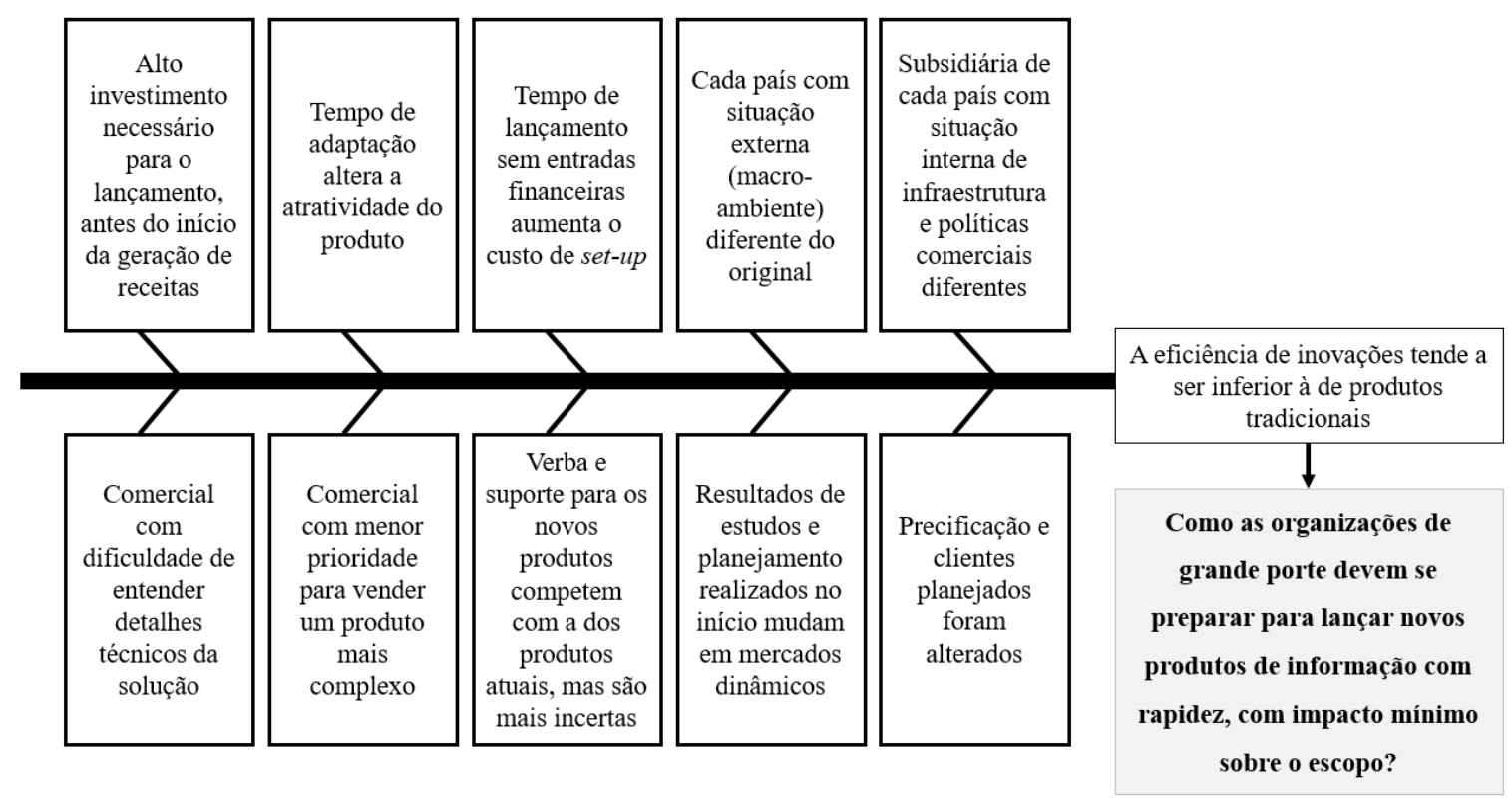

Ilustração 1 - Espinha de peixe para definição da questão de pesquisa 
A pergunta que este estudo responde é: como as organizações de grande porte devem se preparar para lançar novos produtos de informação com rapidez e eficiência - isto é, com impacto mínimo sobre o escopo?

\subsection{Objetivos da pesquisa}

O principal objetivo dessa pesquisa é elaborar recomendações para agilizar o lançamento de novos produtos de informação em corporações - entendendo-se estas organizações como aquelas de grande porte nascidas antes da Era Digital.

De modo a atingir tal objetivo, definiram-se como objetivos secundários deste estudo:

a) elencar os principais fatores internos e externos à organização que geram impacto sobre o tempo de lançamento de novos produtos de informação e como eles se interrelacionam;

b) identificar métodos e modelos de gestão focados na aceleração do lançamento comercial em startups e aceleradoras com aqueles existentes em corporações;

c) comparar o lançamento de produtos de informação em corporações e startups de modo a verificar semelhanças e diferenças entre elas.

\subsection{Organização da Dissertação}

Essa dissertação é composta por cinco capítulos, seguida pelas Referências e Apêndice.

O Capítulo Um trata do tema de estudo, relato técnico, pergunta de pesquisa e objetivos do trabalho. 
O Capítulo Dois é composto pelo Referencial Teórico. O capítulo inicia-se apresentando conceitos de tempo na inovação - e os trade-offs entre tempo, custo e escopo, uma vez que a decisão a favor de um dos aspectos tende a afetar o desempenho dos demais. Em seguida, trata de modelos de aceleração da inovação utilizados por corporações e métodos aplicados em programas de aceleração de startups.

O Capítulo Três define os métodos de investigação e coleta de dados utilizados na dissertação. Neste capítulo também se definem as unidades de análise do estudo.

O Capítulo Quatro analisa os dados obtidos por meio das entrevistas com gestores de grandes empresas, gestores das aceleradoras e empreendedores e compara suas opiniões.

O Capítulo Cinco destaca as evidências e descobertas da pesquisa em relação a cada unidade de análise, e recomendando ações que favoreçam a agilidade do lançamento de produtos de informação em empresas de grande porte, com base nos resultados obtidos ao longo do trabalho.

O Capítulo Seis conclui essa dissertação apontando limitações e oportunidades para estudos futuros.

Por fim, são apresentados as Referências Bibliográficas e o Apêndice. 


\section{REFERENCIAL TEÓRICO}

\subsection{O lançamento de novos produtos}

A ênfase dessa dissertação no tempo de lançamento de novos produtos visa à reflexão acerca da perspectiva comercial da entrada de novos produtos no mercado. Ressalta-se, porém, que lançamento e desenvolvimento podem ocorrer de modo quase simultâneo ou de maneira cíclica. Efetivamente, o desenvolvimento de produtos será referenciado com frequência - embora o objetivo do estudo seja discutir o tempo durante a entrada e o crescimento inicial do produto no mercado.

A importância do tema do lançamento de produtos se deve ao fato de que essa é frequentemente a fase de maior custo no desenvolvimento de novos produtos (BENEDETTO, 1999), e também a fase mais arriscada e menos bem-gerenciada neste processo (CALANTONE; MONTOYAWEISS, 1993). O plano de lançamento envolve decisões táticas (como os canais de comunicação e distribuição) e estratégicas (como o grau de inovação, a decisão por mercados de massa ou nicho e a opção por liderar ou seguir a concorrência). Essas decisões são apresentadas na Ilustração 2 em cada fase do desenvolvimento do novo produto, como sugerida por Guiltinan (1999):

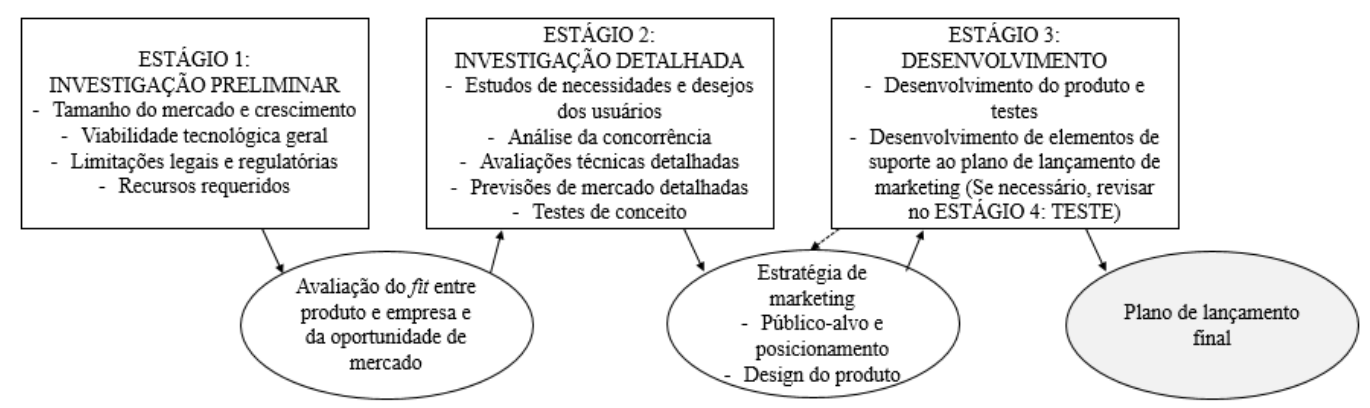

Ilustração 2 - Desenvolvimento do plano de marketing no processo de desenvolvimento de produtos FONTE: Adaptado de GUILTINAN, 1999, p. 511 
Guiltinan (1999) reconhece os distintos objetivos do plano de marketing de acordo com o grau de inovação do produto: produtos disruptivos exigem a criação de um novo mercado e, portanto, precisam sobretudo obter aceitação e difusão, produtos incrementais almejam à substituição de um produto anterior e seu foco é em migrar a demanda existente, e novas adições a um portfólio existente focam na experimentação por parte dos clientes e visam à recompra.

Grande parte do desafio do lançamento se deve à resistência a novas ideias e produtos, uma vez que elas desestabilizam o equilíbrio anterior (CHAKRAVORTI, 2004). A desestabilização pode ser entendida como a mudança das escolhas por parte dos clientes. A resistência à adoção é mais comum quando os clientes estão interconectados, como em mercados corporativos, principalmente em indústrias tradicionais. Nestes ambientes, é comum que os potenciais clientes esperem que algum de seus competidores adote a inovação para que os outros o sigam - evitando assim assumir o maior risco (CHAKRAVORTI, 2004). Por outro lado, a adoção será facilitada quanto melhor o desempenho do produto em relação à opção anterior (isto é, sua vantagem competitiva), quanto menor a complexidade de utilização, quanto mais os clientes puderem experimentar e reduzir a incerteza relacionada à adoção e quanto mais tangíveis forem os benefícios observados do novo produto (GUILTINAN, 1999).

Uma última consideração relacionada ao lançamento de novos produtos em empresas de grande porte destaca uma diferença significativa em relação às empresas de pequeno porte: em geral, o primeiro grupo tende a possuir um portfólio mais diversificado de produtos que o segundo. Portanto, empresas de grande porte possuem maior flexibilidade para equilibrar o risco e o retorno do portfólio enquanto startups possuem maior flexibilidade em alterar processos internos para que eles se adéquem ao novo produto.

\subsubsection{A importância do tempo no lançamento de novos produtos}

O tempo da entrada de novos produtos no mercado é mencionado por diversos autores como crucial à inovação, gerando valor à marca e ganhos financeiros. Chryssochoidis e Wong (1998) ressaltam que um período longo até o lançamento deixa a empresa suscetível a concorrentes 
mais rápidos, e que tempos curtos alavancam vantagens competitivas sob a perspectiva de domínio de tecnologias proprietárias, maior lucratividade, mais vendas, atingimento mais acelerado do ponto de equilíbrio e fortalecimento da imagem como marca pioneira. Além disso, o primeiro produto (a inovação) é aquele que define o conceito de produto em termos de funcionalidades, características e utilização pelos clientes; portanto, os consumidores avaliarão todos os produtos futuros a partir do primeiro.

Gupta e Wilemon (1990), por sua vez, entendem que o desenvolvimento contínuo de novas tecnologias torna os produtos atuais obsoletos rapidamente e que a frequente mudança de demandas por parte dos clientes reduz o ciclo de vida dos produtos - assim como o fato de que a maior competição nacional e internacional exige um processo de lançamento mais ágil. Os autores também destacam a liderança como determinante à agilidade. $\mathrm{O}$ tempo de entrada no mercado é também uma competência crítica para o sucesso de novos produtos e uma necessidade econômica (LYNN et al., 1999), bem como um pré-requisito para a aquisição de vantagem competitiva em um ambiente globalizado com desenvolvimento tecnológico acelerado e em mercados maduros que dependem de inovações para crescerem (CHIU et al., 2006).

A agilidade da entrada no mercado é determinante quando os ciclos de vida do produto ou o período até o pico de vendas são curtos, se as margens financeiras estão se reduzindo rapidamente, quando os competidores possuem um produto de baixa performance relativa (BAYUS, 1997) e o tamanho do mercado potencial é pequeno (COHEN et al., 1996). No entanto, os custos da aceleração e de desenvolvimento (que por sua vez também criam barreiras de entrada no mercado) reduzem a necessidade de acelerar o tempo do lançamento (BAYUS, 1997), assim como a existência de um produto a ser substituído (que dará lugar à inovação) com altas margens e baixa competição (COHEN et al., 1996).

Por outro lado, quando os níveis de venda esperados são altos, o alto faturamento pode pagar pelos custos elevados do desenvolvimento mais ágil - embora o risco dessa estratégia também seja maior. Uma alternativa para lidar com os elevados custos da aceleração é usar técnicas de marketing para aumentar a velocidade das vendas e reduzir o tempo para retorno do investimento (COHEN et al., 1996). Já quando o novo produto enfrenta concorrência forte, o lançamento rápido pode evitar perda de participação de mercado, embora também exista a 
pressão para a entrada de um produto de qualidade comparado aos competidores. Destaca-se, entretanto, que a opção recorrente de tempo sobre escopo acarreta em uma proliferação de produtos de baixa performance, com ciclos de vida curtos e baixo potencial de ganhos (BAYUS, 1997).

Ressalta-se que a decisão ideal do tempo para o lançamento de um produto pode ser a de adiamento caso o mercado não esteja preparado para recebê-lo (DACKO et al., 2015). Embora o adiamento do lançamento de novos produtos seja frequentemente associado a algo negativo, ele poderá ser positivo se gerar uma expectativa positiva em relação ao lançamento (BOUZAS; MIRANDA, 2009), assim como no caso de produtos sazonais - quando o prazo deve ser otimizado de acordo com a demanda do mercado (RADAS; SHUGAN, 1998). Ainda entre esses autores, admite-se que os atrasos tendem a ser intrinsecamente insatisfatórios para a maioria dos consumidores - sendo necessário também distinguir atraso e adiamento.

Destacam-se também as possíveis consequências negativas decorrentes do desenvolvimento acelerado de produtos. Crawford (1992) menciona a possível ênfase excessiva em inovação incremental em detrimento de inovações disruptivas (devido ao menor investimento de tempo demandado pelas inovações incrementais) e o maior potencial de erros ao longo do processo.

Compreendendo que há momentos em que o lançamento do produto deve ser adiado - de acordo com o grau de preparo dos consumidores, o desenvolvimento de produtos e serviços complementares, entre outros - e também que a decisão de adiar o lançamento é de natureza distinta daquela de agilizar o lançamento (uma vez que o adiamento visa ao amadurecimento do mercado e a aceleração visa à eficiência de processos internos) -, essa dissertação se centra nas ações de aceleração. Isto é, este estudo visa à identificação de métodos para agilizar o lançamento quando já foram identificados precedentes que levam à necessidade de aceleração. 


\subsubsection{Aspectos relacionados ao tempo de lançamento}

O tempo é um dos recursos que precisam ser geridos no lançamento de um produto, de modo inter-relacionado com outros aspectos. O maior tempo para o lançamento está associado a um maior uso de recursos (pessoas, infraestrutura, entre outros) - que por sua vez acarretam em maior custo. Também, o investimento em inovação geralmente é de retorno em longo prazo. Havendo diversos projetos competindo pelos mesmos investimentos, este aspecto passa a ser crítico, visto que a inovação tende a gerar um retorno a maior prazo e risco na comparação com os produtos existentes (COOPER et al., 2001).

A necessidade da decisão inter-relacionada entre tempo e custo também é vista em técnicas de aceleração como a engenharia paralela - que propõe equipes diferentes no desenvolvimento de um mesmo produto de modo simultâneo (SMITH; EPPINGER, 1998), mas incorrem em maior custo de desenvolvimento. Também, a estratégia de portfólio de produtos em corporações é balanceada para obter retorno financeiro positivo com os produtos em seus diversos estágios de vida (ELBERT, 2006) - uma vez que um portfólio mais amplo facilita o equilíbrio do risco e do retorno dos diferentes produtos.

Quantificando o impacto financeiro no maior tempo de lançamento de produtos, Hendricks e Singhal (1997) identificaram que empresas menos diversificadas e em setores mais competitivos são aquelas que sofrem maior impacto financeiro no atraso - ainda que o atraso tenda a causar perdas também para as demais empresas.

Por fim, destaca-se a existência dos custos incorridos pelos clientes. Os custos de troca (switching costs) se referem aos custos de experimentação e troca de fornecedor. Burnham et al. (2003) definem como tipos de custo de troca aqueles de: processo (avaliação e aprendizado sobre o novo produto), financeiros (perdas monetárias associadas a descontos e contratos de fidelidade com o fornecedor anterior) e de relacionamento (familiaridade com o produtor anterior e relacionamento com a marca). 


\subsection{Modelos de aceleração do lançamento de novos produtos e inovação}

Demonstrada a relevância do tempo na inovação, diversos autores recomendam ações para o lançamento ágil. Stalk (1988) propôs a produção flexível como capaz de combinar produção a custos baixos e maior variedade de produtos. A flexibilidade permite que em tempos favoráveis à economia, a indústria seja capaz de aumentar a variedade (ainda que a custos mais altos, porque as receitas são suficientes para custear a produção), e que em tempos de crise econômica, a produção seja menos diversificada e focada em ganhos de escala. Stalk (1988) trata da gestão de produtos em geral, embora sua proposta seja bem adequada a novos produtos de informação: flexibilidade por meio da produção de lotes menores, tomada de decisão descentralizada, equipes multifuncionais e inovações incrementais e constantes. Complementase às recomendações o fato de que já em 1988, Stalk afirmava que o tempo passaria a ser a nova fonte de vantagem competitiva para as empresas.

Reconhecendo a importância do tempo decorrido entre o investimento inicial em um produto e o início de suas receitas, Calantone e Benedetto (2011) apontam o lançamento enxuto (lean launch), com baixo comprometimento de recursos e estoques, lento aumento de capacidade de produção e integração ao longo da cadeia. Os autores defendem adiar a finalização do formato do produto para o último momento possível, para reduzir a incerteza, o risco operacional e os custos, bem como aumentar a flexibilidade operacional.

A inovação incremental é outra sugestão para reduzir o esforço para entrar com um novo produto no mercado (SMITH; REINERTSEN, 1997). A consequência negativa dessa proposta se evidencia na baixa oportunidade de ganhos substanciais, obtendo apenas melhorias marginais.

Para acelerar o lançamento, Corso et al. (2001) recomendam: o uso de equipes de trabalho simultâneas, o design flexível que permita à empresa reagir rapidamente às mudanças, a gestão de projetos explorando as sinergias entre eles, o aprendizado organizacional com criação e transferência dinâmica de conhecimento, a estrutura organizacional composta por gatekeepers que conectam a empresa com o ambiente externo e o envolvimento desde o início com clientes 
e fornecedores. Polijaniuk e Strinsjö (2014) ressaltam a importância da autonomia das equipes, e que algumas equipes consideradas autônomas pelo fato de serem responsáveis pelo planejamento de seu trabalho também são forçadas a seguir políticas internas que restringem sua autonomia na alocação de recursos e tomada de decisão, bem como sua agilidade. A comunicação, a multifuncionalidade e a experiência anterior da equipe também são apresentadas como fatores de sucesso que promovem a eficiência em equipes de inovação por Polijaniuk e Strinsjö (2014). Ademais, a inovação aberta permite que especialistas externos possam contribuir sem que a empresa precise desenvolver internamente todas as capacidades exigidas para o lançamento - incorrendo em impacto direto sobre o seu tempo.

Na aceleração de projetos, Kotter (2012) sugere a utilização de um modelo de gestão com dois sistemas operacionais: um responsável pelas atividades atuais e rotineiras e outro que se concentre em oportunidades e demandas futuras. Para acelerar o ciclo de inovação, o autor recomenda ações de cunho cultural (criar senso de urgência e valorizar a mudança), processual (remover barreiras dos processos) e em gestão (compor equipes de colaboradores voluntários e valorizar o aprendizado). A Ilustração 3 apresenta os aceleradores para a mudança propostos por Kotter (2012):

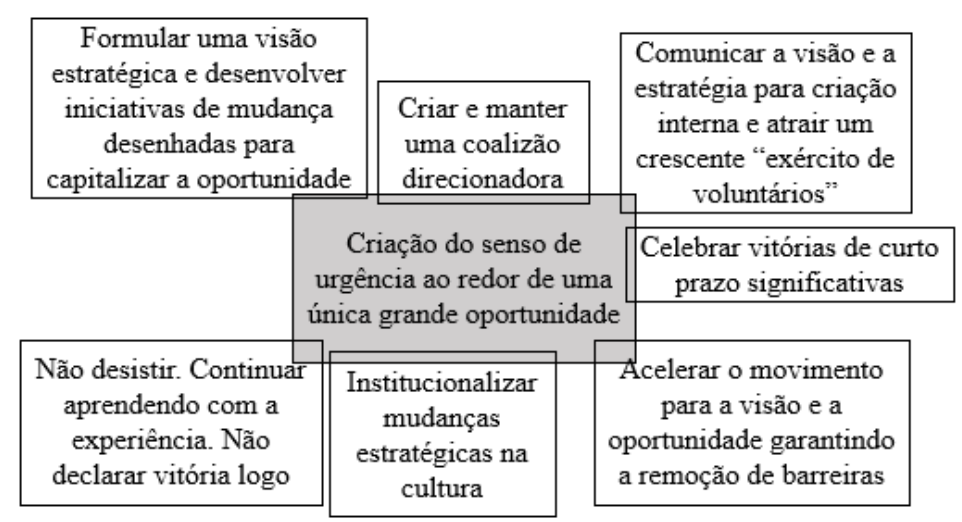

Ilustração 3 - Metodologia do Acelere

FONTE: Adaptado de KOTTER, 2012

O modelo de Kotter (2012) se assemelha à proposta de March (1991) de combinação da exploração com a característica de exploration (risco, experimentação e descoberta) e exploitation (refinamento e a eficiência na execução). A combinação entre ambas permite o 
desenvolvimento de novos produtos e o aumento do retorno financeiro dos produtos já comercializados, assim como favorecem a eficiência (MARCH, 1991). Volberda (1997) efetivamente recomenda a separação horizontal ou vertical da empresa - em que alguns departamentos estejam envolvidos na exploration (como P\&D) e outros na exploitation (como Marketing) -, ou dividindo a exploração em estágios, de modo que após um estágio de exploration venha um estágio de exploitation.

A flexibilidade organizacional - presente em diversos modelos - é estudada por Gjerding (1999), que propõe alguns componentes internos que a incentivam, conforme o Quadro 1.

Quadro 1 - Componentes internos da flexibilidade organizacional

\begin{tabular}{|l|l|}
\hline Frente de atuação & Ações \\
\hline Estrutura & $\begin{array}{l}\text { Equipes multifuncionais } \\
\text { Círculos de qualidade }\end{array}$ \\
\hline Processos & $\begin{array}{l}\text { Rotação entre funções } \\
\text { Integração de funções } \\
\text { Contínuo treinamento } \\
\text { Atividades educacionais customizadas para a empresa } \\
\text { Planejamento educacional de longo prazo }\end{array}$ \\
\hline Cultura & $\begin{array}{l}\text { Delegação de responsabilidade } \\
\text { Planejamento pessoal das atividades a serem executadas } \\
\text { Autoavaliação pelos funcionários em relação ao seu trabalho }\end{array}$ \\
\hline
\end{tabular}

FONTE: Adaptado de GJERDING, 1999, p. 5

Também o aprendizado - que aparece no modelo de Kotter (2012) e é compreendido por Stata (1989) como potencialmente a única vantagem competitiva sustentável corporativa, principalmente em setores intensivos em conhecimento e na inovação - é valorizado também por outros autores. O aprendizado organizacional deve ser um objetivo estratégico à organização que queira acelerar seu ciclo de inovação (MEYER; PURSER, 1993). Equipes que aprendem rapidamente e constantemente também são capazes de inovar mais rápido e com mais sucesso (LYNN et al., 1999). Senge (1990) define como as organizações que aprendem (learning organizations) aquelas que valorizam o aprendizado prático e constante, a integração dos sistemas internos e a comunicação interdepartamental e intradepartamental.

Em relação à necessidade de aprendizado, coloca-se também a baixa probabilidade de a empresa possuir internamente todos os recursos necessários para inovação, de modo que as 
redes podem auxiliá-la significativamente (CORSO et al., 2001). Isto é, parcerias aceleram o processo de aprendizado interno que seria necessário na sua ausência. Un et al. (2010) afirmam que as parcerias externas são a fonte predominante de inovação de produtos, por seu conhecimento especializado - opinião reiterada por Benedetto (1999). Ressalta-se, porém, que a integração com múltiplos stakeholders acarreta no desafio de lidar com interesses conflitantes de cada parte.

É imprescindível ao tratar da aceleração do lançamento de produtos mencionar a existência e o crescimento das metodologias ágeis (Agile methodology). Originadas na indústria de softwares - setor no qual o tempo é crítico devido à rapidez do avanço tecnológico -, a metodologia valoriza a agilidade e a flexibilidade para responder a mudanças nos ambientes técnicos e de negócios durante o projeto de modo eficaz e eficiente (HENDERSON-SELLERS; SEROUR, 2005, LEE; XIA, 2010). Frequentemente refere-se à metodologia ágil como um movimento, que surgiu frente à necessidade de acelerar os métodos tradicionais de gestão, dividindo o trabalho em ciclos curtos, iterativos e incrementais. A proposta é de que os ciclos curtos permitam uma retroalimentação constante, adaptando o produto durante a fase de produção (DYBA ${ }^{\circ}$; DINGSØYR, 2008).

São centrais à Produção Ágil: a capacidade de reconfiguração (flexibilidade), a valorização do conhecimento, a informatização das atividades e a gestão das competências centrais da organização (YUSUF et al., 1999) - conceitos que se repetem no decorrer dessa dissertação sob diversas óticas. As características são apresentadas na Ilustração 4.

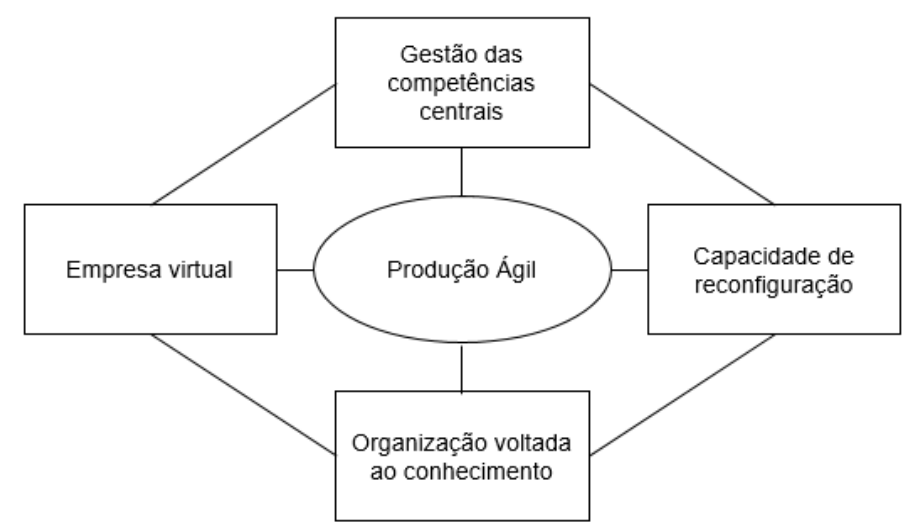

Ilustração 4 - Conceitos centrais da Agilidade

FONTE: YUSUF et al., 1999, p. 38 
Alinhada a este conceito, a gestão enxuta será explorada com mais profundidade em seguida. O modelo da Startup Enxuta é um dos mais amplamente usados na aceleração de projetos de inovação e diversas ramificações e adaptações da metodologia estão surgindo e fortalecendose.

\subsubsection{Startup Enxuta}

Na pesquisa por referências práticas de aceleração de projetos de inovação, a teoria mais amplamente mencionada é a Startup Enxuta, apresentada em obra de Ries em 2011. A metodologia enxuta ganhou projeção internacional no campo da Administração com o Sistema Toyota de Produção, que propõe criar sistemas de produção mais ágeis e eficientes com a eliminação de desperdício (TOYOTA, 2017). Os quatro princípios do Sistema Toyota de Produção são o cliente, a valorização da equipe, o foco no ambiente de trabalho e a melhoria contínua (kaizen) - baseado em uma cultura de resolução de problemas em todos os níveis organizacionais (HAINES, 2014).

Ries (2011) propôs o ciclo da startup enxuta a partir dos princípios do pensamento enxuto (LEAN ENTERPRISE INSTITUTE, 2017). O enfoque da startup enxuta está em testar o produto com os adotantes iniciais, iterações constantes, práticas ágeis como Scrum e ciclos curtos de desenvolvimento de produtos (os chamados sprints). A metodologia startup enxuta engloba, além dos princípios explícitos - como a experimentação, a aceitação de imperfeições e o ciclo de interação com os clientes -, princípios implícitos como a aceitação de risco e de falha ou insucesso do produto, a colaboração e uma hierarquia mais horizontal (HAINES, 2014).

As principais críticas a esse modelo são: a dificuldade de se criar produtos mínimos viáveis para pilotos em diversas indústrias, como automotiva e a química (OSTROWER, 2014), o risco de enfatizar excessivamente o mínimo (WALTON, 2015), a dificuldade de encontrar clientes dispostos a dispender recursos para testar protótipos (FINNERNAN, 2013), o possível excesso 
de alterações com base no feedback dos clientes (LADD, 2016), e a dificuldade de criar métricas de acompanhamento ou premissas para validação no início do processo (HAINES, 2014).

Por ser a metodologia-base de estudo e exploração de dados, especificam-se os princípios do método startup enxuta, estabelecidos por Ries (2011) como:

a) Empreendedores estão em todos os lugares. Startups são instituições que criam novos produtos em condições de extrema incerteza - de qualquer porte e em qualquer indústria;

b) Empreendedorismo é gestão. A startup é a instituição (não o produto). Portanto, todas as empresas que dependem da inovação deveriam aplicar a gestão empreendedora;

c) Validar o aprendizado. O aprendizado em criar negócios sustentáveis deve ser validado com experimentos que permitam testar os elementos de negócio;

d) Construir, medir e aprender. A atividade da startup é transformar ideias em produtos, medir como os clientes respondem às ideias e decidir (ou 'aprender') se estas ideias devem ser pilotadas, alteradas ou eliminadas. Todos os processos devem visar a acelerar este ciclo de retroalimentação;

e) Controle da inovação. É imprescindível medir o progresso, criar indicadores de evolução (milestones) e priorizar o trabalho para tornar mais eficiente a gestão dos produtos de inovação.

Ries (2011) afirma que muitas startups falham por falta de um bom plano de negócios, de uma estratégia sólida ou de uma pesquisa de mercado eficaz - bem como pela visão de que a gestão não é necessária e de que 'basta executar'. Devido a problemas de gestão ao longo da experiência dos empreendedores, por vezes eles apresentam resistência ou aversão a processos de mensuração e planejamento na inovação; entretanto, embora possam ser adaptados, os processos são imprescindíveis.

Embora a experiência inicial da metodologia da startup enxuta tenha sido aplicada em negócios nascentes (BOUND; MILLER, 2011; COHEN, 2013), a metodologia vem sendo cada vez mais usada também em empresas de grande porte. De fato, um dos princípios colocados por Ries (2011) é de que a startup enxuta pode ser aplicada em diversos tipos de organizações. General Electric, Telefônica, 3M, American Express e Experian já utilizaram a metodologia 
(KIRSNER, 2016; BALIK, 2016; SATELL, 2016). Executivos de multinacionais valorizam na metodologia a tomada de decisão com base em dados (em detrimento de intuição), a agilidade, e a melhor qualidade de feedback de clientes - assim como a flexibilidade, a criação de uma cultura mais empreendedora e a aplicação mais eficiente dos investimentos (KIRSNER, 2016). Alguns desafios percebidos pelos executivos de corporações, no entanto, são o risco de levar ao mercado produtos ainda não totalmente prontos, a dificuldade de criar um produto mínimo viável em algumas indústrias e a pouca flexibilidade da organização atual para alterar seu modelo de atuação. A menor hierarquização, a decisão descentralizada e tópicos regulatórios também foram mencionados como riscos por executivos de multinacionais na pesquisa de Kirsner (2016).

\subsection{Aceleração de startups}

Simultaneamente ao desafio de acelerar o tempo de lançamento de novos produtos em grandes empresas, verifica-se um fenômeno equivalente ocorrendo em paralelo em startups. Com a fundação da Y Combinator em 2005, surge o conceito de aceleradoras de startups (BOUND; MILLER, 2011) como instituições compostas por empreendedores experientes mentorando empreendimentos nascentes com o objetivo de aumentar o seu potencial de sucesso e direcionados à comercialização das inovações (O’CONNELL, 2011).

As aceleradoras, segundo Haines (2014), funcionam como um sistema social, provendo infraestrutura e know-how para a criação de startups e aportando valor sobre os aspectos: econômico (investimento), social (rede de fundadores, mentores e clientes) e cultural (valores e princípios propagados pela metodologia de cada programa). Para isso, as aceleradoras identificam os principais obstáculos no lançamento de produtos e auxiliam as startups a superálos. Aparecem como obstáculos comuns: a identificação do público-alvo, a dificuldade de acesso ao mercado e a falta de experiência dos fundadores em marketing e vendas (HOFFMAN; KELLEY, 2012). 
Tipicamente, os programas de aceleração possuem duração limitada - em geral três a seis meses - e proveem capital, espaço e oportunidades de networking e mentoria às startups, direcionando estas atividades ao desenvolvimento comercial do novo produto. Os programas finalizam com o demo day - uma apresentação da startup a potenciais investidores (COHEN, 2013).

As startups obtêm de programas de aceleração, principalmente: financiamento da ideia, acesso a mentores experientes, oportunidade de conexão com potenciais clientes e investidores, aprendizado, suporte de outros empreendedores, auxílio na construção e desenvolvimento da ideia, experiência prática, apoio na validação do produto (BOUND; MILLER, 2011), acesso a profissionais especializados (como advogados e contadores), infraestrutura e um ambiente para compartilhamento e teste das ideias de negócios (HOFFMAN; KELLEY, 2012).

Sob a ótica das startups aceleradas, os fatores de decisão para a escolha de uma aceleradora são: a conexão com fontes de investimento, a marca da aceleradora - cujo nome estará nas divulgações futuras da startup, gerando credibilidade às futuras negociações com clientes e investidores -, o suporte administrativo e o suporte ao produto (CHRISTIANSEN, 2009). A mentoria, a pressão por resultados e a disciplina colocadas sobre os projetos, bem como a própria aprovação no processo de seleção valoriza a reputação da startup para fins de financiamento, vendas e recrutamento de funcionários; (BOUND; MILLER, 2011). A aceleração agiliza o crescimento ou a consumação da iniciativa, sendo que a consumação de uma ideia cujo potencial de faturamento foi entendido como baixo é positiva pois evita o desperdício de recursos neste projeto (COHEN; HOCHBERG, 2014).

A aceleradora possui fins lucrativos e seu modelo de negócios valoriza produtos escaláveis de rápido crescimento para obtenção de retorno financeiro em prazos menores. Frequentemente ela se torna proprietária de cerca de 5 a $8 \%$ da startup acelerada e não há interesse da aceleradora em controlá-la (HOFFMAN; KELLEY, 2012; DEMPWOLF et al., 2014).

Examinando as atividades das aceleradoras, a autora dessa dissertação categorizou-as em três componentes básicos do programa de aceleração: Ambiente, Pessoas e Gestão. É de suma importância destacar que a classificação foi proposta pela autora a partir da análise dos processos das aceleradoras identificados na pesquisa bibliográfica e que há intersecção de tópicos entre unidades distintas pelo fato de que essas atividades são interdependentes e 
ocorrem em paralelo. Ou seja, o objetivo dessa classificação é unicamente o de organização dessa pesquisa em unidades de estudo.

\subsubsection{Ambiente}

O primeiro componente do programa de aceleração - Ambiente - consiste na criação de um ecossistema que favoreça e incentive a inovação, envolvendo elementos internos e externos à organização.

\subsubsection{Seleção}

A seleção de startups pelos programas de aceleração é aberta e a competição é acirrada, um dos fatores que favorecerá a credibilidade da startup no futuro. O processo de seleção pode durar até três meses e é visto como uma etapa crucial pelas aceleradoras (COHEN; HOCHBERG, 2014).

Os fatores de seleção variam, sendo alguns programas específicos a um único setor ou estágio do ciclo de vida da startup. Geralmente a seleção se baseia na viabilidade do conceito de negócio, no potencial de escala e na entrada em nichos de mercado pouco explorados. Em alguns momentos, interferem critérios como o interesse pessoal dos gestores da aceleradora na ideia da startup. A capacidade da aceleradora em agregar valor à startup, o perfil dos fundadores (comportamento, habilidade técnica e experiência na indústria em que atuam), a solução de um problema real de um modo eficaz e um protótipo funcionando são outros fatores de decisão (HOFFMAN; KELLEY, 2012). Também se valoriza a composição da equipe em detrimento do plano de negócios em si, uma vez que a ideia de negócios inicial tende a alterar-se radicalmente ao longo do programa (LEVY, 2011; BARREHAG et al., 2012), sendo raro que 
empreendedores individuais sejam aceitos, devido ao volume de trabalho demandado pelo programa bem como pelas sinergias da diversidade da equipe (BARREHAG et al., 2012).

\subsubsection{Infraestrutura e suporte administrativo}

As aceleradoras oferecem serviços de corretagem (como os demo days), serviços técnicos (como a gestão de recursos humanos e a assistência contábil e jurídica), aportes financeiros e infraestrutura física (DEMPWOLF et al., 2014; COHEN; HOCHBERG, 2014).

Também proveem serviços como a conexão com investidores, facilitam a abertura do capital e apoiam indiretamente por conceder credibilidade à startup quando estas buscarem clientes ou investidores (DEMPWOLF et al., 2014).

\subsubsection{Investimentos e redes de parceiros}

As redes de parceiros são frequentemente citadas pelas aceleradoras como o grande diferencial de seus programas (HOFFMAN; KELLEY, 2012; HAINES, 2014). Os dias de demonstração (demo days) estão também presentes em diversos programas e são voltados a investidores que podem financiar e alavancar os resultados das startups.

Algumas aceleradoras proveem aportes financeiros, ainda que isso não ocorra em todos os programas. O valor dos aportes varia, podendo configurar-se como investimentos diretos na organização, permitir a realização de protótipos ou apenas garantir aos fundadores deixar outras atividades e concentrar-se unicamente no projeto da startup. Os modelos de investimento e aporte podem ser ações ordinárias, notas conversíveis ou empréstimos facilitados (CALEY; KULA, 2013). 
Os empreendedores frequentemente têm dificuldade de identificar o valor dos serviços prestados pela aceleradora - que vão além do aporte financeiro direto da aceleradora (CALEY; KULA, 2013). Além disso, o suporte vai além do período em que a startup permanece na aceleradora, havendo acompanhamento e treinamentos após este período com os alumni.

\subsubsection{Pessoas}

A Cultura é o segundo componente-chave do programa de aceleração. Ela é responsável por direcionar os esforços dos empreendedores e o modo como são executadas as atividades das startups.

\subsubsection{Mentoria}

A mentoria é um aspecto comum a diversos programas de aceleração (BARREHAG et al., 2012). Além do próprio aprendizado, a mentoria provê networking e frequentemente é vista como uma das principais razões pelas quais os empreendedores buscam aceleradoras (COHEN; HOCHBERG, 2014) e como a atividade principal das aceleradoras (BARREHAG et al., 2012). A maneira como ela ocorre varia significativamente: há programas com até 75 mentores diferentes no primeiro mês, e outros com um único mentor por startup, ou ainda de acordo com a necessidade da startup em cada fase (COHEN; HOCHBERG, 2014).

É comum o modelo de mentores voluntários, seja por razões altruísticas ou networking (COHEN; HOCHBERG, 2014). Os mentores podem ser ad-hoc ou comprometidos a médio prazo. Algumas aceleradoras estruturam a mentoria por pares, uma vez que as startups estão passando pelos mesmos desafios de gestão simultaneamente (BOUND; MILLER, 2011). Para Cohen (2011), o valor da mentoria é o constante feedback sobre as ideias da startup. 
O 'Manifesto para Mentores' criado pela aceleradora Techstars facilita o entendimento das tarefas e posturas esperadas para os mentores - como a necessidade de comunicação bidirecional, de objetividade, e do foco em fatos e em ações pragmáticas (COHEN, 2011).

\subsubsection{Suporte dos pares}

O suporte entre pares pode ser entendido como uma consequência dos fatos de que as startups passam por desafios similares ao longo do programa e de que a comunicação entre elas gerar sinergias e aprendizado (BARREHAG et al., 2012). Essa simultaneidade na entrada no programa e a imersão exigida aos empreendedores contribui para fortalecer o relacionamento e a identidade dos fundadores no mesmo processo (COHEN; HOCHBERG, 2014). Uma vez que as aceleradoras frequentemente mantêm contato com alumni de programas anteriores, há também aprendizado e troca com startups aceleradas anteriormente.

\subsubsection{Treinamentos}

O programa educacional das aceleradoras é extensivo e inclui pontos práticos e teóricos em diversos temas, como empreendedorismo, economia, marketing, negociação e contabilidade ministradas por diretores do programa ou convidados (COHEN; HOCHBERG, 2014). São compostos por treinamentos especializados, workshops e palestras. 


\subsubsection{Gestão}

O terceiro e último componente dos programas de aceleração conforme identificado na criação de unidades de análise é a Gestão. Esse componente compreende os métodos de gestão de novos produtos e de suporte a vendas.

\subsubsection{Metodologia}

A aceleração combina a perspectiva técnica e a comercial, envolvendo tópicos como a proposta de valor, o modelo de negócios, entre outros (DEMPWOLF et al., 2014). Os métodos sugeridos pelas aceleradoras são adaptados de acordo com as startups de cada cohort (NESTA, 2014).

Referências comuns são a startup enxuta e o desenvolvimento dos consumidores, baseadas respectivamente nas obras de Eric Ries e Steven Blank. As metodologias utilizadas enfatizam a adaptação ao mercado e a escala do negócio (COHEN; HOCHBERG, 2014).

\subsubsection{Métricas}

As aceleradoras geralmente trabalham com métricas e colocam objetivos para as startups aceleradas. Aceleradoras avaliam seu próprio resultado com base em métricas de investimento e de crescimento das startups aceleradas. É fundamental que as startups e aceleradoras não se restrinjam às métricas financeiras e de curto prazo para avaliação do sucesso do empreendimento em sua fase inicial, sendo algumas das métricas sugeridas: o volume de novos clientes, a retenção e a fidelidade, a indicação entre clientes e o pagamento pelo serviço - caso o produto utilize o modelo freemium (ESPINAL, 2013).

Outras métricas sugeridas por Marsdd (2017) para novos produtos são: a evolução do valor do pipeline ao longo do tempo, a estabilidade das vendas por região e vendedor, as tendências de 
vendas associadas a eventos ou sazonalidade, a caracterização das vendas por indústria ou segmento e a conversão de vendas por região e vendedor.

Croll e Yoskovitz (2013) recomendam métricas claras, comparativas e que geram ação (isto é, não apenas para acompanhamento). Combinar métricas quantitativas e qualitativas, descritivas e acionáveis, exploratórias e rotineiras, que observam o passado e predizem o futuro, de correlação e causa devem ser estabelecidas de acordo com os objetivos de cada startup. $\mathrm{O}$ Quadro 2 apresenta algumas das métricas propostas pelos autores.

Quadro 2 - Métricas relevantes por componente do canvas

\begin{tabular}{|l|l|}
\hline \multicolumn{1}{|c|}{ Quadro Canvas } & \multicolumn{1}{c|}{ Métricas relevantes } \\
\hline Problema & $\begin{array}{l}\text { Clientes em potencial que possuem o problema; leads conscientes que possuem o } \\
\text { problema }\end{array}$ \\
\hline Solução & $\begin{array}{l}\text { Leads que testaram o MVP, engajamento, churn, funcionalidades do produto mais ou } \\
\text { menos usadas, clientes que se disponibilizam a pagar pela solução }\end{array}$ \\
\hline Proposta de valor & $\begin{array}{l}\text { Feedback dos usuários, análise de sentimentos, comentários de usuários (qualitativos), } \\
\text { questionário, análise competitiva }\end{array}$ \\
\hline Segmento de clientes & Facilidade de encontrar prospects, funil de clientes \\
\hline Canais & $\begin{array}{l}\text { Clientes e leads por canal, coeficiente viral, índice net promoter score, taxa de abertura, } \\
\text { margem das afiliadas, click-through rate, page rank }\end{array}$ \\
\hline $\begin{array}{l}\text { Vantagem } \\
\text { competitiva }\end{array}$ & $\begin{array}{l}\text { Compreensão da proposta de valor, patentes, valor da marca, barreiras de entrada, } \\
\text { exclusividade, quantidade de novos entrantes }\end{array}$ \\
\hline Fontes de receita & Valor do cliente, conversão, receita por usuário, itens por usuário \\
\hline Fontes de custos & Custos: fixos, de aquisição de clientes, do serviço do cliente adicional, de suporte \\
\hline
\end{tabular}

FONTE: Adaptado de CROLL; YOSKOVITZ, 2013, p.49

\subsubsection{Críticas aos programas de aceleração}

Uma crítica às aceleradoras levantada por Bound e Miller (2011) se refere ao fato de a maioria dos programas restringir-se a alguns setores econômicos, principalmente digitais. Outra crítica é de que há pouca pesquisa formal que indique que esses programas de fato aceleram o atingimento das principais metas da startup - como o tempo para adquirir investimento ou clientes (HALLEN et al., 2016; SMITH; HANNIGAN, 2015). Konczal (2012) nota que os estudos realizados sobre a eficácia desses programas demonstram problemas estatísticos, como amostras muito pequenas, dados imprecisos e resultados mal dimensionados devido a outliers. 
Uma terceira perspectiva sobre o tema é a incerteza se o sucesso das startups em programas de aceleração se deve ao programa em si ou à seleção inicial (NESTA 2014).

Bradford (2014) critica a excessiva ênfase em resultados de curto prazo e os interesses divergentes entre as startups e as aceleradoras. Haines (2014) aponta que embora as aceleradoras afirmem que criam produtos disruptivos, a metodologia de iterações constantes e feedback dos clientes favorece as inovações evolutivas. Outra crítica é a de que à medida que o número de startups aceleradas por um mesmo grupo de investidores aumenta, o valor investido em cada uma tende a diminuir, reduzindo a probabilidade de obtenção de um investimento mais significativo e de maior valor (NESTA, 2014).

\subsection{Destaques na gestão do lançamento de novos produtos}

Apresentados os modelos de aceleração de projetos e a composição de aceleradoras de startups, identificam-se diversos conceitos comuns. Os três componentes da aceleração identificados neste capítulo - Ambiente, Pessoas e Gestão - visam à identificação dos aspectos mais relevantes na gestão do lançamento de novos produtos. Estas três áreas de atuação servirão como base para todos os capítulos dessa dissertação, sendo complementares e interdependentes.

Conceitos presentes e explícitos na maioria dos modelos são a interação constante com clientes e parceiros, a utilização de equipes multidisciplinares e com maior autonomia, o enfoque no aprendizado e no desenvolvimento contínuo, a flexibilidade para mudanças e a comunicação multidirecional. Esses conceitos - em conjunto com as propostas dos entrevistados - servirão para a criação de recomendações para a aceleração do lançamento de produtos de informação em grandes empresas.

Pontua-se na conclusão deste Referencial Teórico a forte influência do PMBoK na criação de categorias e unidades de análise dessa dissertação. Optou-se por não utilizar o guia como base teórica, embora sejam utilizadas suas áreas de conhecimento (nem sempre de modo formal) 
para direcionar a análise multidisciplinar do lançamento. Uma ressalva a ser realizada é a de que o lançamento de um produto é de fato frequentemente considerado um projeto; contudo, uma das reflexões desta dissertação é orientada a avaliar se o lançamento deveria assim ser considerado. O conceito de projeto colocado pelo PMBoK (2012) é o de empreendimento temporário com o objetivo de criar um produto ou serviço único, enquanto a autora propõe que o lançamento seja visto como uma atividade contínua. 


\section{MÉTODO DE PESQUISA}

\subsection{Caracterização geral do método de pesquisa e coleta de dados}

A proposta desta dissertação é partir de um problema de pesquisa empírico que descreve uma situação organizacional real no relato técnico, estudando-o com o rigor científico acadêmico e priorizando o conhecimento prescritivo e a recomendação de soluções práticas, conforme indicação de Biancolino et al. (2012).

Esta dissertação associa a experiência da autora, entrevistas com profissionais que atuam no lançamento de produtos e referencial teórico para sugerir recomendações para o lançamento de novos produtos de informação em empresas de grande porte.

\subsection{Tipologia de pesquisa}

O tipo de pesquisa adotado para a compreensão do tema aceleração do lançamento de novos produtos no mercado é de caráter qualitativo e exploratório. Vista como mais flexível que a quantitativa, a pesquisa qualitativa é orientada ao processo e destaca o contexto da situação. Por essa razão, são particularmente úteis para explorar relações, enquanto os métodos quantitativos são mais adequados para testar hipóteses (CASSELL; GUILLIAN, 1994).

A pergunta de pesquisa da presente dissertação foi criada a partir da experiência da autora e consequente identificação do problema de pesquisa, relatados no Capítulo Um. Entretanto, com o objetivo de tornar as recomendações desta dissertação aplicáveis a outras organizações, 
buscou-se a identificação de situações similares em outras empresas por meio de pesquisa bibliográfica e entrevistas com profissionais de outras organizações - de modo a identificar os desafios semelhantes que poderiam ser generalizados. O objetivo primário do estudo (as recomendações para acelerar o lançamento de produtos de informação em grandes empresas) será atendido a partir de técnicas de convergência e divergência da teoria e da prática. Os objetivos secundários são explorados por meio das entrevistas em campo com profissionais que trabalham com o lançamento de novos produtos em diferentes organizações, de referencial teórico sobre o tema e artigos profissionais que discorrem sobre a temática de modo empírico.

Um aspecto final a ser destacado é que a autora deste trabalho está envolvida na situação exposta no relato técnico. Por este motivo, para manter a rigidez científica e evitar uma perspectiva subjetiva, optou-se por favorecer na análise de dados a literatura e as entrevistas com outros profissionais. O perfil dos entrevistados foi diversificado de modo que as conclusões não se restringissem à situação do relato, mas aplicável também a outras organizações.

\subsection{Estrutura da Pesquisa e Métodos de Coleta e Análise de Dados}

Foram definidas três fases para a estrutura desta dissertação: a definição do tema de trabalho, a coleta de dados primários e secundários para responder à pergunta proposta e as recomendações para a solução do problema apresentado.

A Ilustração 5 apresenta as três fases: o Capítulo Um - composto pela identificação e apresentação do problema de pesquisa -; os Capítulos Dois, Três e Quatro - compostos pela análise de dados primários e secundários e definição de técnicas de coleta e análise de dados , e o Capítulo Cinco - que apresenta as recomendações resultantes das fases anteriores. É então apresentado o Capítulo Seis com as conclusões, seguido pelas Referências e Apêndice. Cada etapa da pesquisa é apresentada com seu objetivo e técnica para atingi-lo. 


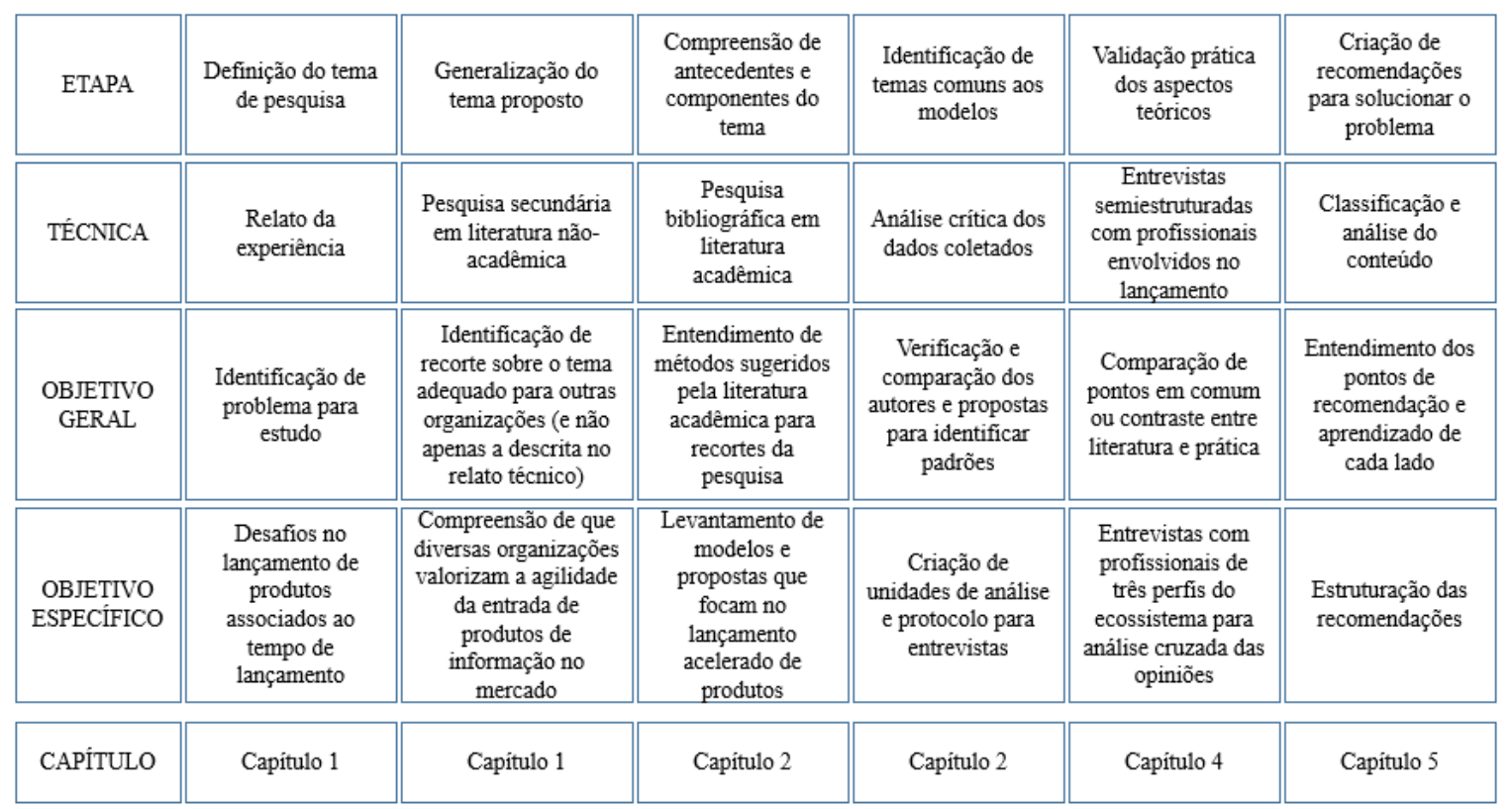

\section{Ilustração 5 - Fases da pesquisa}

A definição das técnicas para atingir cada objetivo valorizou a análise do contexto estudado sob mais de uma perspectiva. Essa opção pela triangulação se deve ao fato de que a composição de técnicas que se complementem permite compensar as desvantagens de um método único pelas vantagens de outros métodos (JICK, 1979). Efetivamente, Guillham (2000) afirma que um indício confiável de que a situação tenha sido analisada corretamente ocorre se diferentes métodos convergem a uma mesma conclusão.

A Ilustração 5 apresenta as fases dessa pesquisa em ordem cronológica. Desse modo, com base em uma reflexão crítica no Relato da Experiência da autora - que considera o contexto do lançamento de um produto de informação em uma organização de grande porte (conforme descrito no capítulo inicial) -, buscou-se compreender se o contexto relatado era comum a outras organizações. A experiência narrada ocorreu anteriormente ao início desta dissertação, de maneira que não foi possível aplicar técnicas comuns a estudos de caso únicos, como observação em campo ou a coleta de documentos (evidências) para análise (YIN, 2010).

Devido a essa limitação, mas também buscando um tema de pesquisa que pudesse gerar recomendações a outras organizações (e não apenas à empresa estudada), as causas apresentadas na espinha de peixe para a definição da questão de estudo formaram a base para uma primeira pesquisa por dados secundários em literatura de caráter não-acadêmico (como 
artigos de revistas especializadas em negócios) para identificar a ocorrência das situações descritas na espinha em outras organizações. Observando-se a existência de problemas comuns ao relato da autora e a diversos lançamentos de produtos de informação, iniciou-se a pesquisa bibliográfica acerca dos problemas descritos na espinha de peixe e as soluções para eles propostas sob a perspectiva acadêmica, principalmente em artigos científicos, monografias e livros. Buscou-se entender também o modo como diversos autores tratam a inovação sob a ótica do tempo, as fases do lançamento de produtos e os modelos de agilidade em empresas abordando múltiplas perspectivas.

Para o referencial bibliográfico relacionado a atividades e características das aceleradoras, foram utilizadas fontes diversas, como websites, blogs de fundadores de startups aceleradas e gestores de aceleradoras e documentos de instituições de fomento ao empreendedorismo e à inovação - devido ao limitado número de obras de cunho acadêmico disponíveis descrevendo os programas de aceleração (tanto no Brasil como no exterior).

Após coletados os dados secundários, iniciou-se a análise de conteúdo - que visava à identificação de pontos de destaque no tema estudado e que seria novamente aplicada com os dados primários. Essa análise serviu como base para a criação de códigos e unidades de estudo. Visando à interpretação de dados qualitativos objetivamente, a análise de conteúdo consiste no estudo das comunicações registradas, transformando dados em um padrão claro (BABBIE, 2001), e sua essência é a identificação das informações que geram valor ao estudo (GILLHAM, 2000).

As unidades de análise definidas após as fases de conceptualização, redução e elaboração de categorias propostas por Corbin e Strauss (2007) são apresentadas no Quadro 3 - de modo que o Componente é a área de estudo macro, que são subdivididos em temas (Famílias) e detalhados nas unidades de maior detalhe (Código): 
Quadro 3 - Componentes subdivididos em famílias e códigos de para análise de dados

\begin{tabular}{|c|c|c|}
\hline Componente & Família & Código \\
\hline \multirow{5}{*}{ Ambiente } & \multirow{2}{*}{$\begin{array}{lr}\text { Antecedentes } & \mathrm{e} \\
\text { consequências } & \text { do } \\
\text { lançamento de novos } \\
\text { produtos }\end{array}$} & O tempo e a agilidade no lançamento de novo produtos \\
\hline & & Fatores internos relacionados à agilidade \\
\hline & \multirow{3}{*}{ Stakeholders externos } & Desafios relacionados à agilidade \\
\hline & & Oportunidades relacionadas à agilidade \\
\hline & & Ecossistema da inovação, parcerias e clientes \\
\hline \multirow{4}{*}{ Pessoas } & \multirow{2}{*}{ Estrutura de pessoas } & Estrutura organizacional \\
\hline & & Gestão e composição das equipes \\
\hline & \multirow{2}{*}{ Equipe } & Cultura e Competências \\
\hline & & Mentoria \\
\hline \multirow{5}{*}{ Gestão } & \multirow{2}{*}{ Aceleração } & Fases e atividades da aceleração \\
\hline & & Limitações da aceleração \\
\hline & \multirow{2}{*}{ Metodologia de aceleração } & Metodologias diversas \\
\hline & & Startup enxuta para aceleração \\
\hline & Métricas & Métricas na entrada no mercado \\
\hline
\end{tabular}

A criação de categorias é um processo interpretativo por parte do pesquisador e utiliza rótulos comuns à linguagem dos participantes, sendo possível hierarquizar mais de um nível de categoria (ELLIOT; TIMULAK, 2005). Já a codificação visa à criação de sentido a partir dos dados e à construção de padrões significativos dos fatos, sendo preliminar à análise (JORGENSON, 1989).

Definidas as unidades de análise, desenhou-se o protocolo para coleta dos dados primários de acordo com cada objetivo a ser atingido com as entrevistas. O protocolo (disponível no Apêndice A) apresenta o objetivo geral de cada entrevista e é subdividido em objetivos específicos para a coleta de dados. Foi também na criação do protocolo que foram planejados os três perfis de profissionais para entrevista, com visões complementares sobre o tema de estudo.

As entrevistas semiestruturadas foram usadas para coleta de dados primários por equilibrarem os benefícios dos questionários estruturados com entrevistas em profundidade não-estruturadas. Uma das suas vantagens é o fato de ela permitir ao pesquisador reconhecer tópicos novos não identificados na pesquisa bibliográfica, aumentar a confiança dos dados ao tratar do mesmo tema com diversos entrevistados, e por ser capaz de manter um objetivo mais específico que as entrevistas não estruturadas (FYLAN, 2005). 
Para explorar diferentes perspectivas, a amostra dos entrevistados combinou profissionais com experiências em diversas funções e atuando em diversos tipos de organização. Todos os entrevistados trabalhavam no momento da pesquisa com o lançamento de produtos - em grandes empresas, startups ou aceleradoras (algumas vezes combinando mais de um perfil). Os três públicos foram selecionados porque enquanto profissionais corporativos se enquadravam diretamente na questão de pesquisa, os empreendedores contribuiriam com uma ótica crítica e complementar, e as aceleradoras ofereceriam uma visão externa e integradora dos públicos anteriores.

Visando à obtenção de uma amostra diversificada e devido a limitações de recursos, foi necessário realizar entrevistas por três meios distintos (presencial, telefone e conferência por Skype). Optou-se por entrevistas presenciais sempre que possível; contudo, verificou-se alta qualidade de dados coletados em todos os meios - seja em termos da profundidade das respostas, exemplos e insights trazidos pelos entrevistados. Todas as entrevistas foram gravadas e transcritas pela autora. As respostas transcritas foram então classificadas novamente em matrizes de acordo com as unidades de análise e o perfil dos entrevistados.

Para análise dos dados obtidos nas entrevistas, os textos foram transformados em matrizes que foram qualitativamente e quantitativamente estudadas conforme proposta de Kohlbacher (2006). O conteúdo transcrito foi classificado de acordo com a sua relação com as unidades de estudo definidas e os perfis dos entrevistados, transposto em matrizes para facilitar a análise e a comparação das respostas. Para analisar não só o conteúdo manifesto do material, mas também seu conteúdo latente, foram seguidas as orientações de Kohlbacher (2006):

- a separação entre os fatores do emissor (experiências e opiniões), a situação da produção do conteúdo, o contexto sociocultural e o material em si;

- a análise sistemática do material, transformando-o em unidades de análise;

- a categorização de todas as descobertas;

- a adaptação dos procedimentos do método ao contexto e ao tópico de pesquisa; e

- a orientação pelas teorias existentes associadas à temática estudada.

$\mathrm{Na}$ análise do conteúdo, pontua-se algumas atividades adotadas, após verificada a sua viabilidade em diferentes metodologias. Houve situações, por exemplo, em que a mesma entidade foi alocada em mais de um código de análise - algo aceitável de acordo com 
FOLKESTAD (2008), ainda que o autor sugira que não faça sentido repetir muitas vezes a categorização. Um processo interativo, a categorização do conteúdo deve permitir a análise de casos cruzados para aumentar o potencial de generalização e aprofundar o entendimento e a explicação de um fenômeno (MILES; HUBERMAN, 1994). As matrizes foram então analisadas de modo a destacar opiniões e percepções convergentes e divergentes entre os entrevistados, de modo a ressaltar essas comparações no capítulo de Análise de Dados. Palavras, frases, padrões de comportamento, modos de pensamento e eventos que se repetem se destacaram neste processo, conforme proposto por Ryan e Bernard (2003).

As recomendações finais do estudo tomam por base dados coletados na fase de pesquisa primária e secundária, combinando a opinião de entrevistados com bibliografia acadêmica e não-acadêmica.

\subsection{Construção de modelo}

Sendo o objetivo primário dessa dissertação oferecer recomendações para a gestão do lançamento de novos produtos de informação, utilizou-se o ciclo de Lynham et al. (2002). Com um método geral de construção de teoria em disciplinas aplicadas, que pode ir no sentido da pesquisa dedutiva para indutiva (teoria à prática) ou inversamente, os autores propõem o ciclo apresentado na Ilustração 6: 


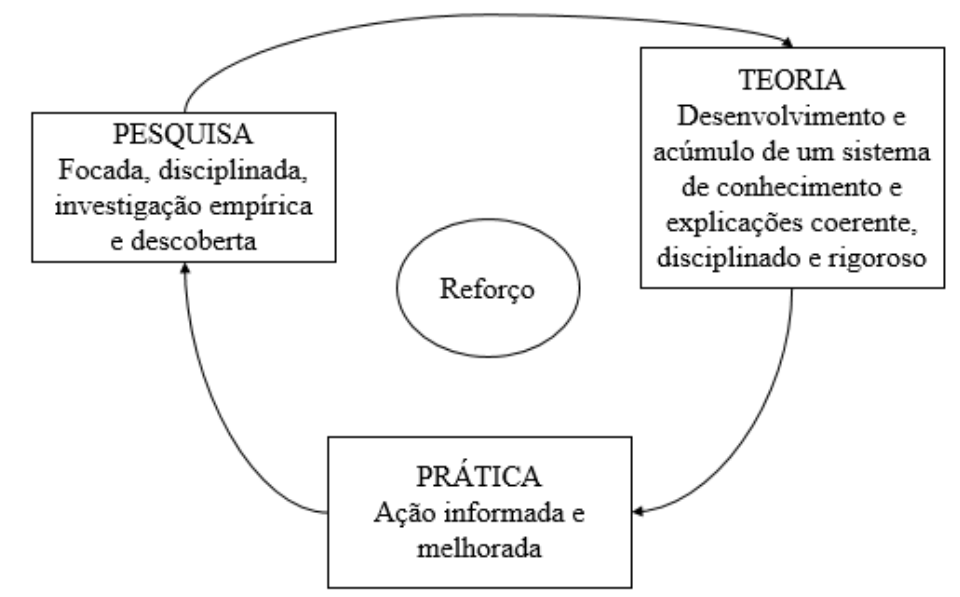

Ilustração 6 - Ciclo de crescimento da construção de teoria aplicada

FONTE: Adaptado de LYNHAM, 2002, p.229

Também, no decorrer da pesquisa, valorizaram-se alguns critérios para validar as recomendações. Com base na sugestão de Lincoln e Guba (1985), diferentes técnicas e métodos foram adotados para aumentar a qualidade das recomendações, conforme apresentados no Quadro 4: 
Quadro 4 - Critérios e técnicas para garantir confiabilidade na pesquisa qualitativa

\begin{tabular}{|l|l|}
\hline Critério & Método para atender o critério \\
\hline $\begin{array}{l}\text { Validade interna } \\
\text { (Credibilidade) }\end{array}$ & $\begin{array}{l}\text { - Triangulação por meio de entrevistados diversos em um mesmo contexto, evitando } \\
\text { sobrevalorizar uma única ótica } \\
\text { - Análise de casos contrários: críticas de empreendedores e aceleradoras à inovação } \\
\text { em grandes empresas }\end{array}$ \\
\hline $\begin{array}{l}\text { Validade externa } \\
\text { (Transferabilidade) }\end{array}$ & $\begin{array}{l}\text { - Entrevistados em mais de uma empresa do setor para avaliar opiniões divergentes } \\
\text { - Entrevistados em diferentes países (ainda que haja uma tendência forte no Brasil) } \\
\text { para evitar que o contexto nacional (governo, política, economia, etc.) interferisse } \\
\text { excessivamente nas respostas }\end{array}$ \\
\hline $\begin{array}{l}\text { Confiabilidade } \\
\text { (Dependência) }\end{array}$ & $\begin{array}{l}\text { - Proteção da confidencialidade dos entrevistados } \\
\text { - Amostra diversificada dentro do contexto analisado } \\
\text { - Codificação interativa (comparação entre possíveis códigos para análise) }\end{array}$ \\
\hline $\begin{array}{l}\text { Objetividade } \\
\text { (Integridade) }\end{array}$ & $\begin{array}{l}\text { - Análise de conteúdo } \\
\text { - Delimitação de unidades de análise } \\
\text { - Gravação e transcrição das entrevistas para análise criteriosa } \\
\text { - Metodologia de análise }\end{array}$ \\
\hline
\end{tabular}

FONTE: Adaptado de SHAH; CORLEY, 2006, p. 1830

\subsection{Limitações metodológicas}

Uma preocupação da autora ao partir do relato de sua experiência foi o de entender os aspectos comuns estudados em outras situações e organizações. Com o objetivo de generalizar as descobertas e evitar o viés subjetivo, foram analisadas as percepções de diferentes atores no ecossistema de inovação. Embora os entrevistados sejam diversificados em termos de experiência e origem, a amostra não é aleatória ou representativa de toda a população. Malhotra (2012) afirma que uma das características da pesquisa exploratória é a análise qualitativa de dados obtidos de uma amostra pequena não-representativa da população. Desse modo, compreende-se que exista a oportunidade de análise quantitativa da pergunta de pesquisa desta dissertação em uma amostra representativa de organizações, mas que essa limitação amostral seja uma característica da metodologia adotada. 
Outra limitação trata o viés da experiência da própria autora na pesquisa. Para contorná-la, buscou-se separar o relato da experiência da autora no capítulo introdutório dos exemplos divulgados em artigos apresentados no Referencial Teórico e das entrevistas com outros profissionais no capítulo de Análise de Dados. 


\section{ANÁLISE DE DADOS}

Seguindo o protocolo apresentado no Apêndice A, foram entrevistados 16 profissionais que trabalham com o lançamento de novos produtos em startups, corporações e aceleradoras. $\mathrm{O}$ protocolo e a nomenclatura dos entrevistados diferenciam estes três perfis. Utiliza-se o termo "Corp" para entrevistados que trabalham em corporações, o termo "Acel” para entrevistados que trabalham em aceleradoras e o termo "Empr" para os entrevistados atuando como empreendedores. A autora planejava utilizar apenas essa nomenclatura para manter o anonimato dos entrevistados. No entanto, o entrevistado EntEmpr6 solicitou que o seu nome fosse divulgado, uma vez que recomendou técnicas com as quais trabalha. Reconhecida a propriedade intelectual do entrevistado, expõe-se sua identidade: Pedro Donati. Ao longo da análise, suas opiniões são associadas à nomenclatura unificada para manter o padrão textual.

A amostra abrange diversos setores de atuação, tempo de experiência profissional, função relacionada ao lançamento do produto e tipo de instituição. Ademais, durante as entrevistas, foi verificado que diversos entrevistados já atuaram em perfis diferentes de sua classificação atual. Para explorar essa característica, a autora mesclou algumas perguntas referentes a mais de um perfil. Compreende-se que esse acaso valorizou a pesquisa, por permitir uma abordagem mais profunda de comparações e recomendações.

\subsection{Entrevistados}

O Quadro 5 apresenta a nomenclatura utilizada nesse capítulo para identificar os entrevistados e a organização à qual estão associados, bem como um breve histórico da sua experiência profissional, a data da entrevista e o meio utilizado para realizá-la. 
Quadro 5 - Caracterização dos entrevistados

\begin{tabular}{|c|c|c|c|}
\hline Entrevistado & Organização & Breve histórico & Data e Meio \\
\hline EntCorp1 & $\begin{array}{l}\text { Corporação A } \\
\text { Unidade Brasil }\end{array}$ & $\begin{array}{l}\text { Gerente de Vendas com dois anos de experiência em } \\
\text { startup e um em multinacional de grande porte, com novos } \\
\text { produtos de informação }\end{array}$ & $\begin{array}{l}13 \text { dez. } 2016 \\
\text { Presencial }\end{array}$ \\
\hline EntCorp2 & $\begin{array}{l}\text { Corporação A } \\
\text { Unidade } \\
\text { Espanha }\end{array}$ & $\begin{array}{l}\text { Gerente de Marketing com quatro anos de experiência na } \\
\text { Inglaterra e Espanha em empresa de grande porte com } \\
\text { produtos de informação }\end{array}$ & $\begin{array}{l}18 \text { dez. } 2016 \\
\text { Presencial (em } \\
\text { inglês) }\end{array}$ \\
\hline EntCorp3 & $\begin{array}{l}\text { Corporação A } \\
\text { Unidade } \\
\text { América Latina }\end{array}$ & $\begin{array}{l}\text { Gerente de Produtos em multinacional com } 16 \text { anos de } \\
\text { experiência, sendo quatro anos em Inovação }\end{array}$ & $\begin{array}{l}21 \text { dez. } 2016 \\
\text { Presencial }\end{array}$ \\
\hline EntCorp4 & $\begin{array}{l}\text { Corporação } \quad \text { B } \\
\text { (brasileira) }\end{array}$ & $\begin{array}{l}\text { Coordenadora de desenvolvimento de novos produtos de } \\
\text { informação há três anos em empresa brasileira de grande } \\
\text { porte }\end{array}$ & $\begin{array}{l}25 \text { jan. } 2017 \\
\text { Skype }\end{array}$ \\
\hline EntCorp5 & $\begin{array}{l}\text { Corporação A, } \\
\text { América Latina }\end{array}$ & $\begin{array}{l}\text { Diretor de Unidade de novo produto de informação há } \\
\text { quatro anos, com experiência anterior (há cerca de } 20 \\
\text { anos) no lançamento de produto de informação B2B } \\
\text { disruptivo na Europa }\end{array}$ & $\begin{array}{l}10 \text { fev. } 2016 \\
\text { Presencial }\end{array}$ \\
\hline EntAcel1 & $\begin{array}{l}\text { Aceleradora A } \\
\text { Brasil }\end{array}$ & $\begin{array}{l}\text { Gerente de Comunicação em aceleradora há três anos, } \\
\text { com experiência em aceleradoras, parques tecnológicos e } \\
\text { corporações }\end{array}$ & $\begin{array}{l}05 \text { jan. } 2017 \\
\text { Presencial }\end{array}$ \\
\hline EntAcel2 & $\begin{array}{l}\text { Aceleradora A } \\
\text { Reino Unido }\end{array}$ & $\begin{array}{l}\text { Gerente de Parcerias em aceleradora no Reino Unido há } \\
\text { um ano; experiência anterior de dois anos com estratégia } \\
\text { de novos produtos na América Latina e Reino Unido }\end{array}$ & $\begin{array}{l}09 \text { jan. } 2017 \\
\text { Telefone }\end{array}$ \\
\hline EntAcel3 & $\begin{array}{l}\text { Aceleradora A } \\
\text { Brasil }\end{array}$ & $\begin{array}{l}\text { Gerente de Aceleração, com três anos de experiência em } \\
\text { startups e aceleradoras }\end{array}$ & $\begin{array}{l}10 \text { jan. } 2017 \\
\text { Telefone }\end{array}$ \\
\hline EntAcel4 & Aceleradora B & $\begin{array}{l}\text { Fundador de aceleradora há seis anos, experiência de } 15 \\
\text { anos na área de inovação em aceleradoras }\end{array}$ & $\begin{array}{l}21 \text { jan. } 2017 \\
\text { Skype }\end{array}$ \\
\hline EntAcel5 & Aceleradora C & $\begin{array}{l}\text { Gestor de aceleradora há três anos, com experiência } \\
\text { anterior em grande empresa }\end{array}$ & $\begin{array}{l}23 \text { jan. } 2017 \\
\text { Telefone }\end{array}$ \\
\hline EntEmpr1 & $\begin{array}{l}\text { Empreendimen- } \\
\text { to não acelerado }\end{array}$ & $\begin{array}{l}\text { Cofundador de startup de plataforma tecnológica há cinco } \\
\text { anos }\end{array}$ & $\begin{array}{l}09 \text { jan. } 2017 \\
\text { Telefone }\end{array}$ \\
\hline EntEmpr2 & $\begin{array}{l}\text { Empreendimen- } \\
\text { to mentorado e } \\
\text { acelerado }\end{array}$ & $\begin{array}{l}\text { Cofundador de startup de hardware há um ano, } \\
\text { experiência anterior como consultor em grande empresa }\end{array}$ & $\begin{array}{l}10 \text { jan. } 2017 \\
\text { Skype }\end{array}$ \\
\hline EntEmpr3 & $\begin{array}{l}\text { Empreendimen- } \\
\text { to acelerado }\end{array}$ & $\begin{array}{l}\text { Cofundador de startup acelerada há três anos (produto de } \\
\text { tecnologia), experiência anterior em consultoria }\end{array}$ & $\begin{array}{l}12 \text { jan. } 2017 \\
\text { Presencial }\end{array}$ \\
\hline EntEmpr4 & $\begin{array}{l}\text { Empreendimen- } \\
\text { to acelerado }\end{array}$ & $\begin{array}{l}\text { Cofundadora de startup acelerada (produto de } \\
\text { informação) há três anos, experiência anterior em empresa } \\
\text { de grande porte }\end{array}$ & $\begin{array}{l}20 \text { jan. } 2017 \\
\text { Presencial }\end{array}$ \\
\hline EntEmpr5 & $\begin{array}{l}\text { Empreendimen- } \\
\text { to não acelerado }\end{array}$ & $\begin{array}{l}\text { Empreendedor há três anos, com } 25 \text { anos de experiência } \\
\text { incluindo Diretoria de Marketing e Vendas em } \\
\text { multinacional de grande porte }\end{array}$ & $\begin{array}{l}24 \text { jan. } 2017 \\
\text { Presencial }\end{array}$ \\
\hline EntEmpr6 & $\begin{array}{l}\text { Empreendimen- } \\
\text { to em inovação }\end{array}$ & $\begin{array}{l}\text { Empreendedor com } 18 \text { anos de experiência em startups, } \\
\text { grandes empresas e atual empreendimento que auxilia } \\
\text { grandes empresas a inovar }\end{array}$ & $\begin{array}{l}02 \text { fev. } 2017 \\
\text { Skype }\end{array}$ \\
\hline
\end{tabular}




\subsection{Impressões iniciais sobre as entrevistas}

Os protocolos das entrevistas (ver Apêndice A) variam de acordo com o perfil do entrevistado, e eventualmente as perguntas foram interpretadas de modo moderadamente diferentes. Buscouse aproveitar essas diversas interpretações para construir uma perspectiva mais completa sobre o tema.

O roteiro do protocolo foi adaptado em todas as entrevistas, principalmente quando possível explorar um tópico sobre o qual o entrevistado possuía mais experiência. A entrevista foi adaptada de acordo com o valor que cada entrevistado poderia aportar à pesquisa, enfatizando a sua experiência.

Todas as entrevistas foram gravadas e transcritas pela autora. Trechos dessas entrevistas foram utilizados para evidenciar as opiniões colocadas por cada entrevistado em relação a cada unidade de análise.

\subsection{Ambiente}

O tópico de Ambiente é dividido em temas internos e externos à organização referentes ao lançamento de produtos de informação. O tema engloba pontos positivos e negativos associados ao ambiente no qual a organização está inserida. 


\subsubsection{Antecedentes e consequências do lançamento de novos produtos}

A primeira unidade de análise do componente Ambiente são os antecedentes e consequências do lançamento de produtos. Essa unidade analisa principalmente o ambiente interno à organização e os fatores internos que influenciam o lançamento de um novo produto, bem como a relevância do tempo neste contexto.

\subsubsection{O tempo e a agilidade no lançamento de novos produtos}

Ao estudar como o tempo influencia a decisão e o planejamento do lançamento de novos produtos, buscou-se compreender o seu impacto na inovação e em quais situações ele é relevante. Há duas vertentes mais destacadas entre os entrevistados: o valor associado a ser o primeiro (posicionamento, inovação) e a inter-relação deste com os demais fatores de influência no lançamento de produtos (como o custo e o escopo, por exemplo).

A partir da análise dos dados coletados, entendeu-se que a agilidade é importante, mas que o contexto influencia o grau de importância. A agilidade é principalmente associada a dois fatores: os ganhos associados a chegar mais rápido ao mercado e a eficiência dos recursos aplicados. Isto é, ser mais rápido pode ajudar a organização a chegar antes da concorrência e obter monopólio ao menos por um período - posicionando-se como inovadora e aumentando a capacidade de obtenção de margens financeiras mais elevadas (EntEmpr1, EntEmpr4, EntEmpr5, EntCorp5). Ser mais rápido também aumenta a eficiência dos recursos aplicados ou seja, o tempo mais longo para o início das vendas aumenta o tempo necessário para atingir o ponto de equilíbrio financeiro e requer investimento em recursos que ainda não estão gerando retorno (EntAcel1, EntAcel5, EntAce14). Ressalta-se, contudo, que essa relação não necessariamente existirá, caso um tempo maior de lançamento esteja atrelado ao crescimento acelerado do produto devido a sazonalidade ou expectativa do mercado, por exemplo. Ademais, uma vez que geralmente há risco envolvido quando se trabalha com inovação, quanto maior o tempo para se validar a proposta de produto e a sua viabilidade, maior o investimento dedicado 
a um projeto sobre o qual ainda não se obteve retorno - e maior terá que ser o retorno futuro para manter a viabilidade financeira.

Outro aspecto do tempo é relacionado à tomada de decisão. Isto é, o tempo é um dos fatores inerentes a qualquer decisão e deve ser trabalhado de modo a adequar-se aos demais requisitos do negócio. EntEmpr5, por exemplo, sugere que o profissional deva tomar decisões rápidas com o máximo de informações que possuir no momento, e também reconhece a importância do tempo adequado - uma vez que o mercado precisar estar preparado para receber o novo produto.

Para EntEmpr5, os profissionais devem buscar a agilidade sempre que possível e avaliar "[...] as relações de dependência, de complementaridade, de amadurecimento de mercado" e o teste com possíveis clientes para identificar o tempo correto. A opinião é reiterada por EntEmpr6, que afirma que a agilidade não é necessariamente fazer mais rápido: “[...] é escolher melhor que partes construir e quando". Entendendo que haja recursos limitados - inclusive de tempo EntCorp3 considera que a priorização das atividades deva ser proporcional ao faturamento do produto no portfólio de uma grande empresa. Evidencia-se, no entanto, a dificuldade de um novo produto crescer se o faturamento é sempre priorizado, uma vez que essa inovação ainda está na fase de lançamento. De fato, possivelmente devido à tradição de priorizar-se faturamento atual em detrimento de potencial futuro, muitas inovações são malsucedidas.

Alguns entrevistados (EntEmpr5, EntEmpr6) avaliam que estudar o contexto é fundamental para tomar a decisão relacionada ao tempo, enquanto outros (EntEmpr1, EntEmpr4, EntCorp4) acreditam que a agilidade se transforma em vantagem competitiva frente à concorrência. EntEmpr1 nota que "[...] dificilmente sua ideia vai ser única" - isto é, embora inovadora ela provavelmente será local -, enquanto EntCorp4 lembra que "[...] se você está pensando em inovação, provavelmente todos os seus concorrentes estão pensando coisas similares" e que “[...] em um ou dois anos, o seu concorrente com certeza vai chegar e desenvolver a mesma coisa que você desenvolveu. Mas você ganhou um, dois anos". Por fim, EntAcell corrobora estes pontos afirmando que "[...] é superimportante [para] todas as empresas - as pequenas, as médias e as grandes - estarem atentas às tendências do mercado [...]. Mas no caso da startup, ela precisa correr, porque se uma grande vier, ela consegue abocanhar”. A entrevistada também ressalta que o tempo deve ser combinado com outros fatores de decisão. Finalmente, abordouse o diferencial por ser o primeiro - um aspecto relacionado a criar o conceito do produto no 
mercado ou à perda de oportunidade de entrada de novos competidores em monopólios. Como afirma EntEmpr5, “[e]m negócios de inovação [...] ser o primeiro faz muita diferença", uma vez que se "chegar depois de um concorrente, [...] tem que mostrar que o seu é melhor. A sua referência é o cara que já está lá. Ele já tomou espaço na cabeça dos clientes [...]”. EntCorp5 corrobora que ser o primeiro pode não ser uma vantagem pois "é muito mais oneroso em dinheiro, em investigação. Então às vezes ser o segundo é melhor [...] se eu tiver capacidade de replicar rapidamente" - ainda que também entenda as diversas situações possíveis relacionadas ao pioneirismo, afirmando que para alguns produtos, "ser o market leader vai dar um edge durante um período temporal significativo" e ainda que em alguns mercados "se eu não for o primeiro, não faz mais sentido chegar".

Principalmente em aceleradoras destacou-se a importância da agilidade das startups como seu diferencial em relação a grandes empresas (EntAcel3), e que o próprio papel da aceleradora é incentivar o crescimento acelerado das startups (EntAcel1). A rapidez também aparece como um dos aspectos da eficiência, visto que um tempo maior decorrido até o lançamento do produto acarreta em custos mais altos para a organização. A limitação de recursos em si exige velocidade, conforme colocado por EntAcel5 e EntEmpr4:

A startup é uma organização que está fazendo um projeto inovador, cheio de incertezas e em geral com poucos recursos, com pouco dinheiro e com um time reduzido. Por isso ela precisa ser muito eficiente. Ela precisa fazer muito com pouco e ela precisa ser rápida, senão não tem como ela ser competitiva. Se ela demorar, ela vai perder o fator inovação para alguém que possa colocar mais dinheiro, mais recursos para fazer mais rápido que ela. (EntAcel5)

Startup é um reloginho. Sabe aquela ampola de areia? Que virou. Corre, porque a areia vai acabar. E a areia é o dinheiro. Então, por exemplo, a gente entrou aqui [na aceleradora], recebeu aporte, temos vendido para outras empresas. Só que: como eu continuo isso com o que eu preciso investir em pessoas, tecnologia, para fazer a empresa crescer? [...]. Então é uma corrida contra o tempo, contra os seus concorrentes, contra processos internos, e para você conciliar tudo isso, é muito diferente da grande, porque na grande você tem mais recurso. (EntEmpr4)

Finaliza-se a análise deste componente com a ponderação de EntCorp5, que compara as vantagens e desvantagens do pioneirismo em relação à concorrência, resumindo que:

Dependendo da inovação, ser o primeiro não é uma vantagem. Ser o primeiro significa que é muito mais oneroso em dinheiro, em investigação. Então, às vezes, ser o segundo é melhor; [...] se são inovações que têm ciclos um pouco mais largos, é melhor ser o segundo porque se eu tiver capacidade de replicar rapidamente, $[. .$.$] tenho um custo de investigação um pouquinho$ mais baixo, de investimento de CAPEX e consigo replicar e ter o mesmo benefício [...]. E o contrário também. Não é? Tem produtos que ser o market leader vai dar um edge durante um 
período temporal significativo. Então isso pode ser algo positivo. E o outro é não fazer sentido substitutivo. Isto é, se eu não for o primeiro, não faz mais sentido chegar. Se vai ter que concorrer de forma comoditizada, tem que baixar o preço; se for baixar o preço, não vai rentabilizar a inovação. (EntCorp5)

\subsubsection{Fatores internos à organização}

O tópico que se ressalta como aquele em que há maiores diferenças entre corporações e startups é o dos fatores internos à organização que impulsionam ou dificultam o lançamento de produtos.

Os processos estruturados foram mencionados por diversos entrevistados como centrais no lançamento, podendo atuar tanto como um fator positivo quanto como um fator negativo nas grandes empresas. Os processos avaliados como positivos tendem a ser aqueles que permitem o crescimento (escala) dos produtos a partir dos ativos existentes (como a base de clientes, recursos internos, relacionamento forte com toda a cadeia de valor) e em eficiência (EntAcel4, EntAcel1, EntAcel5, EntAcel2). EntAce14, de fato, afirma que após a validação do produto no mercado, os processos bem definidos e em larga escala das grandes empresas são adequados, mas em geral devem ser evitados até que haja essa validação.

O aspecto negativo dos processos é associado geralmente ao excesso de aprovações e falta de autonomia da equipe que acarretam diretamente em custo, tempo e eficiência do lançamento (EntAce14, EntAce15, EntEmpr6, EntEmpr5, EntAcel1). EntEmpr4 observa que grandes empresas podem demorar até três anos para entregar um novo produto - prazo que hoje já não é competitivo. Frisa-se que os processos são criados para atender a outras necessidades da empresa, como aqueles relacionados a governança e controle, e por isso a sua centralidade na governança organizacional. Por outro lado, exemplos de como a burocracia afeta negativamente as grandes empresas são apontados por EntAcel4 e EntAcel5:

Então, em vez de aprovar um modelo, diretor que vai falar com não sei quem, para fazer uma RFP para contratar um estudo de mercado, para fazer uma reunião de kickoff, briefing, sei-láo-quê, marcar reunião, e esse processo todo que vai demorar seis meses, o empreendedor faz uma landing page, joga no ar, vai ter o mesmo resultado ou um resultado muito melhor, em uma semana gastando cem reais, sabe? (EntAcel4) 
Esses processos [corporativos] são horrorosos para inovação. Se eu seguir os mesmos princípios, vou gastar cem vezes mais, vai demorar dez vezes mais e a taxa de sucesso vai ser dez vezes menor e eu mato a possibilidade de sucesso [...]. Então, se eu penso com a cabeça de startup, eu vou ter uma eficiência no meu processo de inovação mil vezes maior. [...] eu não preciso de cinco camadas de decisão para aprovar uma decisão, eu vou de hoje para amanhã da maneira mais simples possível e eficiente, posso mudar até encaixar (EntAcel4)

Se você tem que seguir o business plan de qualquer maneira, cegamente, você acaba ficando preso a hipóteses que muitas vezes não se confirmaram. E isso custa muito dinheiro, e muito tempo para as corporações. Muitos projetos vão ser considerados malsucedidos não porque o propósito dele era ruim, ou porque o projeto do produto era ruim em si, mas porque seriam necessárias mudanças de rota durante o processo de inovação que não puderam ser feitas porque a pessoa estava preocupada em cumprir a meta e cumprir o business plan. (EntAcel5).

EntAcel1 corrobora essas opiniões ao afirmar que o principal aprendizado que as grandes empresas poderiam ter com as startups são a agilidade e o contato inicial com os clientes, bem como a ser menos dependente de processos e estruturas formais. Por outro lado, a entrevistada sustenta que as startups precisam incorporar mais processos em suas atividades para organizarse. EntAcel1 sugere, por exemplo, às startups começar suas operações já como pessoa jurídica e com uma organização societária, principalmente pela facilidade de se obter investimento depois e pela complexidade de se organizar processos organizacionais quando há objetivos futuros que demandem atenção.

Uma opinião que se sobressai entre os diversos entrevistados é a de que excessivas camadas de aprovação, orçamentos pouco flexíveis e roteiros muito definidos são comuns em grandes empresas, apesar de encarecerem e dificultarem a inovação (EntAcel5, EntAcel4, EntEmpr4). Entacel4 lembra que: "Inovação e eficiência tem problemas de convivência; [...] para ter uma eficiência operacional você precisa de processos mais rígidos e esses processos mais rígidos matam todo o processo de inovação".

Por outro lado, grandes empresas também possuem vantagens significativas. EntAcel2 acredita que a força das grandes empresas é a disponibilidade de recursos - que lhes permite prototipar muito mais que as startups - e uma visão mais estratégica. Para EntAcel3, a agilidade é imprescindível às startups na competição com corporações principalmente pelo fato de as últimas possuírem mais recursos. EntAcel4, no entanto, acredita que recursos são desperdiçados devido à excessiva necessidade de aprovações e tomada de decisão centralizada, opinando que a startup "[...] consegue validar as coisas de uma forma muito mais simples, eficiente e barata" (EntAcel4). Credibilidade, força da marca (EntEmpr5, EntAcel5), e o conhecimento de gestão, 
estratégia e estruturação dos negócios (EntAcel2, EntAcel3, EntAcel1, EntAcel5, EntEmpr1) foram outros diferenciais das empresas de grande porte apontados por entrevistados.

A base de clientes que as grandes empresas detêm é mencionada por EntAcel4, EntEmpr5 e EntEmpr3 como um recurso valioso, combinado com a capacidade de distribuição e acesso a este público (EntCorp5). EntEmpr4 concorda, opinando que o bom relacionamento que a corporação consegue manter com os clientes é fundamental para superar o chamado 'vale da morte' (período em que muitos produtos saem do mercado por não conseguirem crescer). EntAcel5 reforça, argumentando que as grandes empresas “[...] têm um relacionamento muito bom com toda a cadeia de valor [...], estão acostumadas a fazer negócios em grande volume”.

Também houve dois entrevistados que recomendaram adequar cada modelo de gestão ao ciclo de vida da startup e contexto do mercado. EntAcel5 acredita que a eficiência e a agilidade da startup na inovação são mais adequados a esse momento inicial, e EntAcel4 recomenda que após as validações e no momento em que é necessário ao produto crescer, “[...] dá para plugar no mundo das grandes empresas para escalar". EntCorp5, por sua vez, afirma que "[...] o mais complicado tem a ver em como colocar esse novo produto no portfólio mental do vendedor", lembrando que o foco sobre cada produto único é menor em grandes empresas com um portfólio diversificado do que em startups com um único produto.

A vertente de portfólio de produtos foi levantada também por EntCorp3 - que acredita que há excessivos lançamentos com potencial baixo de receitas ou sem planejamento adequado. Para a entrevistada, os recursos poderiam ser melhor geridos se houvesse uma prova de conceito em conjunto com o cliente antes da implantação. Outra dimensão trazida por EntAcel4 se refere ao incentivo à inovação. $\mathrm{O}$ entrevistado afirma que as metas para os executivos em corporações são de curto prazo e trabalhar com inovação não o é, e de que por isso há menor interesse no desenvolvimento comercial desses produtos.

A percepção de que grandes empresas precisam aprender com as pequenas a ser mais ágeis e flexíveis foi apontada por EntAcel2, EntAcel3 e EntAcel5. EntAcel5 diz ser imprescindível ter a capacidade de mudar o planejamento sempre que necessário (e por vezes, trabalhar sem um planejamento). EntEmpr4, que trabalhou anteriormente na área de Inovação de uma multinacional, considera que não é possível tardar para entrar no mercado se a corporação 
quiser se manter competitiva. A entrevistada afirma que por mais que a startup não tenha recursos, ela tem flexibilidade e não tem medo de arriscar - dois aspectos raros em corporações em sua opinião, corroborada por EntAcel2. A necessidade de otimizar recursos e de não ter medo de errar também são citadas como imprescindíveis por EntAcel5 e EntCorp2 a grandes empresas que queiram inovar.

\subsubsection{Stakeholders externos}

A unidade de stakeholders externos estuda as influências externas à organização no lançamento de produtos. Composta por clientes, fornecedores e parceiros, essa unidade discorre acerca do ecossistema de inovação.

\subsubsection{Oportunidades}

Destaca-se entre as oportunidades o valor do conceito do 'novo' e da 'novidade' - aspectos que atraem o interesse dos clientes. Os entrevistados discutem oportunidades para a empresa (menor concorrência, melhor posicionamento) e para o cliente (obtenção de benefícios com a aquisição do produto).

A vantagem mais citada relacionada à inovação sob a perspectiva da organização foi a inexistência de concorrência e consequente menor competição baseada em preço, como aponta EntCorp1: “[...] quando você vende inovação é muito mais difícil ter um produto similar ao seu no mercado, logo você consegue uma diferenciação mais fácil". Por outro lado, o mercado ainda imaturo pode ser um aspecto negativo à medida que ele reduz a probabilidade de o cliente em potencial identificar a necessidade de adquirir o produto e possuir um orçamento designado à sua aquisição (EntCorp2). 
Também foi mencionado que as corporações já reconheceram: a necessidade de inovar para manter sua competitividade (EntEmpr4, EntEmpr5, EntAcel2), o interesse dos clientes por inovação (EntEmpr4, EntEmpr5), a curiosidade dos clientes em conhecer os novos produtos ainda que essa curiosidade nem sempre se traduza em vendas (EntEmpr2) - e a oferta de um benefício adicional para o cliente obtido na aquisição do produto inovador (EntCorp4).

\subsubsection{Desafios}

No estudo dos desafios relacionados ao lançamento de produtos, coletou-se uma grande diversidade de opiniões e percepções. Por este motivo, a autora divide as respostas em três categorias: (a) identificação e acesso ao mercado-alvo, (b) previsões de vendas e atividades decorrentes dessa previsão (isto é, aspectos decorrentes da incerteza advinda com a inovação), e (c) fatores macroeconômicos sobre os quais a empresa exerce baixo ou nenhum controle.

A primeira categoria, de acesso ao mercado, é subdividida em duas: criar a proposta de valor do negócio e identificar a quais clientes ela atende. O objetivo da proposta de valor é solucionar um problema para o qual existe um mercado pagante. Esse desafio foi levantado mais frequentemente entre os entrevistados ligados às startups (EntAcel4, EntAcel5, EntEmpr6, EntEmpr2, EntAcel3, EntAcel1) mas também colocado sob a forma de “[...] identificar as ideias financeiramente válidas” (EntCorp3) e “[...] provar que essa inovação funciona para os fins a que se destina e com o valor que se propõe" (EntCorp5) por entrevistados de multinacionais.

Entendendo-se a proposta de valor como: “[...] dos benefícios que meu produto oferece, quais são aqueles que o cliente está percebendo com mais valor" (EntAce14), EntEmpr6 entende que é comum em grandes empresas desenhar o produto com base na opinião de executivos e ver a que mercado ele serve apenas no lançamento (em detrimento de verificá-lo anteriormente). Para potencializar o sucesso do novo produto, o entrevistado sugere identificar não só o problema, mas também o potencial de aquisição por parte dos clientes - isto porque mesmo necessidades identificadas pelos consumidores podem não ser suficientes para que eles adquiram o produto. 
A imprevisibilidade da reação do público é um desafio mencionado por EntAcel5, EntCorp4, EntEmpr3 e EntCorp3, sendo a validação prévia com o público-alvo entendida como a maneira ideal de ajustar a proposta ao mercado. Sob a ótica de acesso aos clientes, EntAcell nota a dificuldade de novos empreendimentos de chegar ao comprador no segmento B2B, mesmo após identificar esse comprador.

EntEmpr2 acredita que a identificação do primeiro cliente - o entusiasta da solução que vai testar o protótipo e aceitar que o produto ainda não está completo - é o principal desafio no lançamento. A resistência por parte dos clientes é levantada por EntCorp3, e a necessidade de ajuste da solução às necessidades do consumidor é vista como essencial por EntEmpr5. Entretanto, para ajustar a solução, o vendedor precisa “[...] gastar tempo com o cliente [...], um risco para quem está vendendo" (EntEmpr5) porque há a possibilidade de a venda potencial não ser efetivada. A evangelização do cliente - entendida como a conquista de clientes que passam a interessar-se ao nível de se tornarem defensores do produto - é recomendada por EntEmpr4.

Outra vertente relacionada aos clientes é a dificuldade de superar o equilíbrio estático; isto é, alterar um hábito de compra ou de uso que o cliente já possui - colocada por EntCorp4 como “[...] uma questão de comportamento do consumidor" e por EntEmpr4 como "[...] mexe na zona de conforto". Também, são comuns clientes que “[...] nem entendem o que você está falando, [...] o risco de eu não estar falando com a pessoa certa” (EntEmpr4).

A segunda subcategoria dos desafios se relaciona à assertividade das previsões comerciais e operacionais. Sem histórico de sucesso (EntEmpr2) ou referências para a venda (EntEmpr5), um novo produto depende da credibilidade e histórico dos sócios ou da corporação (EntEmpr5). Outro fator trazido por EntCorp5 é a complexidade de relacionamento entre diversos componentes do processo:

Então toda essa cadeia fim-a-fim tem vários pontos - e obviamente quando você começa, você tem que criar hipóteses para todos eles. Depois você começa a desenhar as hipóteses que você acha que são as mais prováveis, mas nem sempre as multi-relações se comprovam como esperado. Às vezes as análises univariadas das componentes funcionam bastante bem mas têm correlações que não são fáceis de perceber. (EntCorp5)

A dificuldade de previsão de vendas gera também incertezas que dificultam o planejamento de investimentos, estrutura de custos e precificação dos produtos (EntCorp1, EntCorp3, EntEmpr1). Demonstrar os benefícios do produto é fundamental para o cliente reconhecer o seu 
valor (EntEmpr1) e é uma atividade que deve ser realizada envolvendo treinamentos internos e externos à empresa, com colaboradores e clientes (EntAcel2, EntCorp2).

Ao desafio de previsão de vendas por parte da empresa está associado o risco percebido pelo cliente em relação ao novo produto. EntEmpr4 exemplifica:

[...] se você compra uma Oracle, uma SAP e não der certo, o produto é horrível. A culpa é de quem? Da Oracle ou da SAP. Por quê? É a referência no mercado. Agora, se você não comprar a Oracle e comprar a [startup]. Se não der certo, aí a culpa é de quem? De quem comprou. (EntEmpr4)

Para reduzir o risco, EntEmpr4 afirma que corporações burocratizam o processo de compras exigindo diversos documentos. Essas exigências acarretam em um ciclo de vendas mais longo, um problema principalmente para novos produtos com restrição de caixa a médio prazo. Soluções para reduzir a percepção de risco por parte do cliente apontadas por EntEmpr6 e EntAcel3 são interagir constantemente com o mercado iterando o produto por meio de protótipos e melhorias em parcerias com clientes potenciais.

A terceira categoria de desafios consiste no macroambiente. Alguns dos tópicos levantados foram política externa, apoio à inovação, regulamentação, sistema educacional e economia.

EntCorp2 nota que assuntos políticos - mencionando o terrorismo, a imigração e a crise dos refugiados - interferem diretamente na inovação a curto e médio prazo, assim como a crise econômica. Entretanto, a entrevistada entende que o governo possui um papel de longo prazo no incentivo à inovação, por exemplo incentivando cursos técnicos no planejamento do sistema educacional. Já EntCorp3 traz a regulamentação como um desafio, sendo que "[...] quanto mais diferente esse novo produto, mais resistência desses órgãos [reguladores] em aprovar esses produtos". A entrevistada considera que há risco e desincentivo também nos setores nãoregulamentados pelo governo, e poucas leis que incentivam o empreendedor a criar ou inovar.

As políticas de fomento ao empreendedorismo são entendidas por EntCorp2 como cruciais para a inovação, posto que é comum que os empreendedores sejam de um único perfil e em geral de classe média-alta, de modo que possam arcar com os custos e riscos de um novo empreendimento. Assim, se o governo provê fundos específicos à inovação, esse é um estímulo direto ao empreendedorismo inovador. As políticas governamentais são indubitavelmente essenciais no estímulo ao empreendedorismo. Contudo, levanta-se a importância de uma 
compreensão cuidadosa do tema pelos profundos impactos que elas podem gerar e diferenciando-se as características e necessidades o empreendedorismo inovador do denominado "empreendedorismo por necessidade".

Outros desafios identificados pelos entrevistados são o fato de as leis não conseguirem acompanhar o ritmo de desenvolvimento das inovações (EntCorp3), a necessidade de integração da cadeia de valor (EntCorp5) - levantando-se as diferenças de capacidades e interesses ao longo dessa cadeia -, o financiamento a longo prazo e alto risco (EntEmpr2), e o contínuo acompanhamento dos avanços tecnológicos (EntEmpr1).

Resumindo os desafios apontados pelos demais entrevistados, EntEmpr6 exemplifica o processo de inovação evolutiva em uma empresa de grande porte e as complexidades ao longo de cada etapa do processo:

Quando uma empresa grande hoje decide fazer uma coisa [...], começa dizendo o que o diretor acha que tem que ser feito, dispara a discussão para um analista que vai desenhar e justificar aquilo, aquilo vai entrar em uma fila de priorização, que vai entrar numa discussão de valuation, [...], que vai gerar prioridade, passar para a fila de tecnologia - que agora quer entender direito o escopo, e vai ter uma gigantesca discussão do escopo completo -, com tudo que tem que ser feito [...]. A empresa já mudou desde então porque já foram seis meses de projeto [...] para colocar aquele negócio estável e funcionando até estar no ar. Agora vamos para o próximo projeto. E ninguém fica mexendo e evoluindo aquilo que foi colocado no ar [...]. O digital é muito mutável. Se você não está o tempo todo evoluindo e adaptando, você perde awareness, você perde relevância, você perde negócio.

Uma das constatações das entrevistas foi que mais entrevistados de grandes empresas mencionaram o macroambiente em geral - como EntCorp2, EntCorp5 e EntCorp3 -, enquanto mais entrevistados envolvidos com pequenas empresas mencionaram o acesso ao mercado como principais desafios - como EntEmpr5, EntEmpr4, EntEmpr2 e EntAcel1. Um desafio que foi relatado exclusivamente por entrevistados de grandes empresas foi a dificuldade de treinar a equipe de vendas com novos produtos continuamente (EntCorp2) - em consequência do portfólio mais diversificado. Por outro lado, a complexidade da precificação (EntEmpr1, EntCorp1 e EntCorp2) e o entendimento do mercado consumidor (EntEmpr2, EntCorp2, EntCorp3, EntCorp1, EntCorp4, EntEmpr5, EntEmpr6, EntAcel3) são desafios comuns a ambos os portes de empresas. 


\subsubsection{Ecossistema: Fornecedores, Pares e Clientes}

Observa-se o surgimento de um ecossistema - ou uma rede - que une startups, empreendedores, aceleradoras, estudantes e grandes empresas interessadas em inovação e em fomentar esse ecossistema. Essa unidade aborda como diferentes portes de organização trabalham com a inovação. O relacionamento entre diferentes atores do ecossistema de inovação é mencionado - e recomendado - por diversos entrevistados (EntAcel1, EntEmpr2, EntAcel4, EntAcel5, EntEmpr5, EntCorp4), sendo que tal relacionamento pode ocorrer de distintas formas.

EntEmpr2 acredita que parcerias entre startups e corporações podem ser mutuamente benéficas se a corporação contribuir com acesso a mercado e suporte (logística, serviços especializados, entre outros) bem como investindo na própria startup - enquanto obtém retorno financeiro sobre os produtos da empresa nascente. Efetivamente, o momento do crescimento de vendas é aquele mencionado também por EntEmpr4 e EntAcel4 como o ideal para as corporações auxiliarem as startups, tracionando os clientes e organizando os processos comerciais. Corroborando as opiniões anteriores, EntAcel3 acredita que no médio prazo a maioria das corporações desenvolverá aceleradoras que fomentem negócios em sua indústria de atuação.

EntAcell aborda o exemplo de atividades além da aceleração promovidas por grandes empresas que estimulam as parcerias com as pequenas. É o exemplo da Tecnisa, que cria eventos mensais para que as startups do setor (em seu sentido expandido - que possam atuar de modo conjunto e como fornecedoras da corporação) possam apresentar seus negócios (como forma de estimular parcerias entre ambas). A entrevistada também mencionou que empresas como a Telefônica e o Bradesco criaram operações específicas para trabalhar com startups, após reconhecer que inovação não é só Pesquisa e Desenvolvimento e que a inovação aberta pode trazer-lhes benefícios.

Já EntEmpr5 aborda a aquisição de startups por grandes empresas, afirmando que estas aquisições podem dizimar a startup se não houver um trabalho de adaptação. Isto é, empresas tradicionais não acostumadas com a cultura de startup "[...] às vezes acabam comprando essa inovação e matando. Quando traz para dentro, as pessoas não se adaptam com a cultura, processos, formas de trabalhar, formas de pensamento" (EntEmpr5). Assim, diversos produtos 
são descontinuados, de modo que nem a startup consiga crescer nem a corporação possa criar valor com a inovação. Essa opinião é reiterada por EntCorp4, que defende parcerias entre empresas de pequeno e grande porte (mas desincentiva as aquisições) - apontando, porém, a confidencialidade necessária a alguns projetos como o principal desafio da inovação aberta.

Outra vertente trazida por EntCorp5 salienta a necessidade de todos os elementos da cadeia de valor trabalharem em conjunto para que a inovação seja bem-sucedida. Afirmando que a atuação de cada um dos componentes da cadeia de modo separado pode não ser equivalente à atuação conjunta, o entrevistado exemplifica que uma capacidade muito superior de entrega de determinada característica não possui valor se os demais elementos não satisfazem o mínimo necessário para a venda. A perspectiva é interessante por evidenciar a centralidade da integração de toda a cadeia de valor.

Outra dimensão do ecossistema de inovação é o espaço físico das aceleradoras, que oferece infraestrutura aos empreendedores e atrai diversos atores deste ecossistema. EntAcell destaca a importância das parcerias e das trocas que acontecem nesse ambiente - e que embora nenhuma startup seja obrigada a manter-se no espaço da aceleradora, exista uma perda decorrida dessa menor interação entre os pares. A relevância da interação é entendida como tão elevada que ainda que a startup não mantenha seu escritório na aceleradora, ela deva visitar presencialmente a aceleradora todas as semanas durante o processo de aceleração (EntAcel1). Os empreendedores acelerados EntEmpr3 e EntEmpr4 de fato confirmaram que conhecer outras startups e partilhar experiências na aceleradora foram fundamentais para o seu aprendizado. Uma segunda perspectiva colocada por EntAcel1 é a multiplicação do conhecimento quando os empreendedores acelerados vão ao mercado "[...] dando treinamento, dando mentoria, participando de palestras contando sua história; então elas [as startups] conseguem levar para o mercado muitas coisas que elas aprendem aqui”. Ou seja, a troca não é apenas dentro da aceleradora, sendo que esse aprendizado é frequentemente propagado para outras instituições. EntAcel4 reitera que o valor do processo de aceleração “[...] depende diretamente da qualidade dessa rede de colaboração". 


\subsection{Pessoas}

O componente Pessoas aborda o planejamento e estruturação da equipe, assim como aspectos relacionados a conhecimentos, comportamentos e atitudes dos profissionais e equipes envolvidos no lançamento de produtos.

\subsubsection{Estrutura de pessoas}

A estrutura de pessoas foi dividida na macroestrutura (isto é, a estrutura organizacional formal e a divisão de papéis e responsabilidades na empresa) e na microestrutura (entendida como a gestão e a composição de equipes, a definição de modelos de trabalho e a cultura empresarial).

\subsubsection{Estrutura organizacional}

A estrutura da organização é central ao negócio, uma vez que envolve a interação de todas as áreas da organização. Sendo um fator interno à organização, a principal vantagem de planejar a estrutura de modo a estimular a inovação é depender exclusivamente dos gestores - que devem adequá-la de modo a maximizar os resultados do negócio. Por refletir as interações organizacionais, tópicos de Ambiente e Gestão aparecem nesta unidade.

A principal descoberta realizada no âmbito de estrutura é a necessidade de flexibilidade. Imprescindível à inovação como um todo, a flexibilidade deve estar refletida na estruturação das equipes de modo a permitir mudanças nas funções e papéis dos colaboradores (EntAcel5, EntEmpr1) - algo que EntEmpr1 afirma ser pouco comum em grandes empresas. 
EntAcel4, por outro lado, aponta que a alta rotatividade de pessoas, constantes mudanças de papéis e responsabilidades e pouco incentivo formal (como metas e remuneração variável) à inovação por parte da alta direção dificultam o desenvolvimento e o lançamento de produtos. Sua perspectiva é interessante à medida que enquanto EntAcel5 e EntEmpr1 valorizam a flexibilidade de mudança, EntAcel4 acredita que a mudança constante dificulta a gestão. Os pontos de vista não são contraditórios uma vez que o argumento de EntAcel4 aborda a necessidade de comprometimento da equipe a longo prazo (e não a inexistência de possibilidade de adequação de estrutura). Esse aspecto é interessante por levantar a reflexão para o grau ideal de mudança, bem como o planejamento de como estimular essa mudança da maneira adequada - seja sob a forma de job rotations, parcerias externas, ou outras configurações.

EntAcel5 considera que a flexibilidade é essencial porque muitos projetos de inovação "[...] vão ser considerados malsucedidos não porque o propósito dele era ruim [...], mas porque seriam necessárias mudanças de rota durante o processo de inovação que não puderam ser feitas porque a pessoa estava preocupada em cumprir a meta e cumprir o business plan". Desse modo, o entrevistado orienta as corporações a incentivarem a autonomia para que a equipe possa tomar decisões rapidamente e de modo independente.

Outra perspectiva trazida por EntAcel4 é de que se a área de Inovação de uma grande empresa trabalha como as demais áreas, essa área não precisaria existir. O entrevistado sugere que a área de Inovação valorize a experimentação, que as falhas sejam associadas a algo positivo e que o risco seja incentivado (proposta também colocada por EntCorp4). Ademais, os incentivos precisam estar adequados aos resultados esperados, exigindo metas de longo prazo (EntAcel4).

Um ponto da cultura organizacional que se associa com a estrutura está relacionado ao papel da área de Recursos Humanos em estimular a cultura empreendedora em corporações (EntCorp2). Apesar de frequentemente visto com um papel prioritariamente burocrático, EntCorp2 coloca que o departamento de RH possui um papel estratégico na criação da cultura empreendedora - devendo propor ações que estimulem a curiosidade, acelerem o aprendizado e incentivem a melhoria contínua.

EntEmpr6 ressalta que empresas maiores deveriam replicar não apenas a cultura - mas também a estrutura - das startups em times de inovação. O entrevistado, de fato, atualmente empreende 
em um negócio que descreve como uma construtora de corporate ventures - o modelo que acredita ser ideal para grandes empresas trabalharem com inovação. Definindo a estrutura ideal para inovação como "[...] times multidisciplinares trabalhando numa cultura mais de resultado, mais de métricas de sucesso, de colaboração. Todo mundo estruturado para o mesmo objetivo" (modelo designado como startups internas ou 'garagens' pelo entrevistado), EntEmpr6 acredita que esse modelo enfatiza a mudança de gestão - uma vez que são necessárias mudanças desde as relações contratuais até ao incentivo à mentalidade de melhoria contínua. Para o entrevistado, a mudança estrutural é necessária pois a maioria das empresas de grande porte hoje tornaramse bem-sucedidas em um momento em que era necessário obter escala, mas não flexibilidade no entanto, atualmente ambas escala e flexibilidade são essenciais.

Por fim, retomando a discussão acerca de processos já tratada sob o tópico de fatores internos, coloca-se que por serem intrínsecos à organização, os processos organizacionais podem ser otimizados para alavancar a inovação. A recomendação é que os processos sejam mais simples e exijam menos camadas de aprovação (EntAcel1, EntAcel4).

\subsubsection{Cultura}

Após entendidas as necessidades de estrutura, identificam-se a cultura e a mentalidade que estimulam a inovação. Como colocado por EntAcel2, a inovação "[...] precisa de pessoas que são eager, que querem fazer, que estão dispostas a explorar as coisas, que tenham essa mentalidade. Em startup ou alguma coisa inovadora, você precisa de uma mente muito aberta ao novo".

Detalhando a cultura adequada à inovação, EntEmpr6 reconhece que há diferenças entre criar uma nova cultura e alterar uma cultura existente, mas afirma ser imprescindível a ambas equipes autônomas e a cultura do empoderamento associada à governança. $\mathrm{O}$ entrevistado, que cita Spotify, Netflix, Google, Amazon, Facebook como exemplos fortes da cultura de empoderamento, pondera que "são empresas que nasceram agora. Elas não tiveram o jeito 
antigo de ser para mudar depois. Então é diferente a trajetória de quando você está criando do zero e de quando você está transformando do que você era para um novo estágio" (EntEmpr6).

Outra vertente da cultura que aparece com frequência é a cultura do risco. EntCorp4 acredita que "[...] o aprendizado vem do risco", "[...] o risco faz parte do negócio" e "[...] é muito importante você errar". A entrevistada acredita que o risco tende a ser evitado pela maioria das corporações, embora seja inevitável à inovação. Portanto, ela propõe utilizar o MVP, uma vez que ele permite que a empresa teste o mercado e corra um risco controlado, por envolver consequências menores. Também em relação ao erro, EntAcel1 considera que “[...] a maioria [dos empreendedores] erra muitas vezes. Então, a gente [aceleradora] está aqui para fazer com que elas errem menos e acertem mais, mas elas vão errar assim como a gente também vai errar" e que "A recomendação que a gente dá é aprender com isso". EntCorp5 reforça que "[...] o insucesso em inovação não é uma coisa má [...], falhar em determinada hipótese, em determinado experimento não é uma coisa má contanto que ela seja rápida e pragmática nessa percepção" - corroborando a relevância do aprendizado na inovação. Para reduzir o risco, EntCorp1 e EntCorp2 recomendam ir ao mercado testar o produto, posto que o profissional responsável pelo lançamento está fortemente envolvido com o produto, e tende a possuir uma visão enviesada acerca de seu empreendimento.

Por fim, ressalta-se que o aprendizado está profundamente associado à cultura da inovação. As aceleradoras reconhecem o seu papel no aprendizado formal (como treinamentos e workshops) e informal (como o ambiente de aprendizado e a troca com outros empreendedores). EntAcel1 descreve o ambiente de constante aprendizado como "[...] uma das coisas mais incríveis de estar numa aceleradora”, e que ocorrem: “[...] o aprendizado de treinamento, o aprendizado pessoal, o aprendizado da troca" (entre as startups). A entrevistada nota que a própria infraestrutura permite à aceleradora estimular uma cultura de incentivo à inovação em seu espaço físico. 


\subsubsection{Perfil da equipe}

O tópico de perfil da equipe é estudado de modo a auxiliar o planejamento e desenvolvimento das equipes responsáveis pelo lançamento de produtos.

\subsubsection{Gestão e composição das equipes}

A gestão e a composição das equipes são inter-relacionadas com a estrutura organizacional. Isto é, as equipes precisam ser compostas de modo a atender as necessidades da organização.

A relevância da composição das equipes é colocada por EntAcel5 ao afirmar que "[...] startups são times muito enxutos com recursos bastante limitados, o que faz com que cada pessoa desse time seja muito importante e que tenha que desempenhar muitas funções diferentes". Muitas vezes são "[...] equipes de três, quatro, cinco pessoas que têm que cuidar desde questões contábeis, financeiras e burocráticas de se abrir uma empresa até questões relacionadas a marketing, vendas, design, usabilidade, otimização para várias plataformas, desenvolver em diversas plataformas" (EntAcel5), demandando multifuncionalidade e aprendizado constante. Nas palavras do entrevistado, "[...] numa startup há funções em que o empreendedor vai ser especialista, mas em várias outras ele não vai ser e estará fazendo aquilo pela primeira vez; então ele vai ter que aprender muito nesse processo para conseguir fazer bem" (EntAcel5).

Além da multiplicidade de atividades a ser executada por cada membro da equipe, a natureza de tais atividades muda significativamente ao longo do tempo. Em um período curto, uma equipe de quatro fundadores pode se tornar uma equipe de cinquenta pessoas, exigindo competências totalmente diferentes das iniciais (EntAcel3). Essa característica faz com que o aprendizado contínuo seja um fator imprescindível às equipes. EntEmpr3 efetivamente lembra que "[...] quando você está fazendo um negócio novo, o ciclo de aprendizado é quase infinito. Você está sempre fazendo coisa nova" - opinião reiterada por EntCorp5 ao afirmar que falhar em partes do processo do lançamento não é negativo - mas natural, sendo fundamental aprender 
com o erro e utilizá-lo para retroalimentar o ciclo. EntAcel4 também observa a necessidade de incentivo por meio de líderes engajados e metas associadas ao lançamento.

Essas alterações de papéis e responsabilidades evidenciam a necessidade da diversidade dos times (EntCorp2). EntCorp2 sustenta que as companhias de tecnologia mais bem-sucedidas são as de força de trabalho mais internacionais, visto que são pessoas que já trabalharam em diferentes empresas, estiveram em diversos mercados, e entendem como os produtos são aceitos ou rejeitados em outros países. Essa experiência, de acordo com a entrevistada, ajuda a acelerar o lançamento da inovação. EntEmpr3 também aponta a importância da diversidade na formação de equipe, afirmando que "Pessoas é importantíssimo. A gente precisa de gente diferente da gente, e a gente tem uma tendência a buscar pessoas mais parecidas, porque a gente conhece mais o perfil, mas é ruim". De acordo com o entrevistado, os conflitos também surgem mais frequentemente em times mais diversos, sendo essa diferença importante porque: "[...] quanto mais gente diferente, com cabeça diferente, experiência diferente, repertório diferente, facilita muito você ver o mundo de outro jeito. Você aprende muito com essas pessoas" (EntEmpr3).

A relevância da diversidade demonstra que a composição da equipe se inicia tão cedo quanto o planejamento do produto. EntAcel4 coloca que "[...] o processo começa antes da aceleradora, começa na seleção", e que um dos desafios das aceleradoras é tornarem-se atrativas para as startups, posto que "[...] quem acelera de fato é o empreendedor" (EntAcel4). A partir desse entendimento, a aceleradora pela qual o entrevistado é responsável atualmente busca identificar os fatores críticos de sucesso entre os empreendedores e quais são as características necessárias a serem avaliadas na seleção. EntAcel4 comenta que o sucesso das aceleradoras depende do sucesso das startups aceleradas, e que o modelo de seleção desses empreendimentos é muitas vezes similar ao processo de funil de inovação nas grandes empresas.

Afirmando que as capacidades do negócio não se restringem às capacidades da equipe, EntEmpr5 sustenta ser fundamental ao empreendedor identificar as competências necessárias ao negócio, lembrando que dificilmente o próprio empreendedor será capaz de atendê-las todas ele próprio. Portanto, é necessário “[...] desenvolver e buscar suprir o que falta” (EntEmpr5) por meio de funcionários, treinamentos, sócios ou capital - sendo três os capitais necessários a um empreendimento bem-sucedido: o financeiro, o intelectual e o social (este último entendido como os relacionamentos, as indicações, os contatos, as instituições de apoio e os parceiros). 
Embora concorde que cada integrante da equipe atue com múltiplas atividades, EntEmpr6 entende que haja papéis básicos necessários ao time de empreendedores. Em sua opinião, são necessários: o visionário “[...] que consegue transmitir o propósito. Consegue mobilizar e cativar as pessoas por construir algo grande", o executor "[...] que faz acontecer", o designer “[...] para traduzir a necessidade do cliente em características" e o engenheiro capaz de "[...] alavancar a emerging technology" (EntEmpr6).

Os fatores relacionados às pessoas são mais amplos, porém, que a necessidade de uma equipe diversa e motivada. Na aceleradora em que EntAcel4 trabalha, os empreendedores participam de "[...] um processo de team building [...]: psicólogos e coaches que trabalham com cada time, para identificar perfis de liderança, pontos fortes e pontos de desenvolvimento de cada membro da equipe". Também, diversas empresas ainda não estão constituídas e a aceleradora as apoia neste processo, para que ele seja realizado corretamente (EntAcel4, EntAcel1, EntAcel3).

Às equipes, essa combinação de competências técnicas e comportamentais advêm de aprendizado prático e teórico. Para EntCorp2, são cruciais treinamentos teóricos, bem como experiência prática (como contato com o cliente, por exemplo). A entrevistada aponta que o aprendizado independente é essencial na inovação. Uma vez que a tecnologia avança rapidamente, os profissionais muitas vezes não aprenderam na faculdade tudo o que precisam hoje para realizar suas atividades cotidianas. Por essa razão, a área de Recursos Humanos é colocada pela entrevistada como central na criação de uma cultura que estimule a curiosidade e o aprendizado das equipes - incentivando que elas busquem cursos online para realizar nas horas vagas, que haja mentoria como um processo de troca de conhecimento dos dois lados, que os diversos tipos de aprendizado sejam valorizados, e que haja uma competição positiva em que as pessoas percebam que as outras estão investindo na sua formação e busquem investir também elas próprias em sua própria educação.

A experiência profissional é um diferencial por EntCorp4, que a descreve como a "expertise de pessoas que estão há muito tempo no negócio, a experiência, o cabelo branco”. Para EntEmpr2, é relevante aprender como lidar com as falhas, reconhecer erros, receber ofeedback dos clientes de modo a construir a partir das críticas, e trabalhar a diversidade com a equipe de sócios - que possuem percepções e opiniões diferentes acerca dos diversos desafios do negócio. O crescimento pessoal é também colocado como essencial por EntEmpr3, quando afirma que “[...] 
muita gente fala em acelerar o crescimento do negócio; o crescimento é um reflexo do seu crescimento pessoal. E da sua equipe". Por outro lado, EntEmpr3 também afirma que é necessário "[...] sempre ser muito pé no chão [...]; se você cresce muito rápido - mais do que você tem capacidade de absorver cultura - você acaba perdendo a sua cultura e isso é péssimo para a empresa".

Quanto ao perfil necessário à equipe de novos produtos, foram mencionados: a dedicação que eles colocam em seus empreendimentos (EntAcel2), a visão de tecnologia combinada com mercado (EntEmpr1), a proatividade (EntEmpr3), a curiosidade para explorar a novidade (EntAcel2), o engajamento (EntAcel5), a dedicação (EntAcel5) e a motivação certa (EntAcel2, EntEmpr5), como um propósito de vida ou uma missão (EntEmpr5). Outros comportamentos mencionados foram: foco no problema em detrimento do produto (EntAcel3, EntEmpr6), a “[...] capacidade de entender o que funciona e o que não funciona rápido" (EntAcel3) e "[...] ser bom em executar sem ter muito planejamento. Ou então até ter planejamento, mas conseguir abrir mão de muitas partes do planejamento para poder chegar onde quer chegar" (EntAcel3).

\subsubsection{Mentoria}

A mentoria é colocada como uma das fases fundamentais da aceleração no Referencial Teórico. Essa atividade possui múltiplos formatos, conforme descreve EntAcel5:

\footnotetext{
O processo de mentoria pode ser desde uma mentoria individual em que a gente vai pegar um mentor especialista em um tema e vai ajudar uma startup que tem algum problema [...] naquela área de atuação que o mentor é especialista; ou a gente pode trazer muitos mentores com perfil bem especialista, alguém que conhece muito aquele mercado, passou por aquele problema anteriormente; ou a gente pode fazer algumas mentorias coletivas - seja na forma de apresentação com espaço para diálogo com empreendedores, seja na forma de workshop, talvez um treinamento para esses empreendedores.
}

De fato, o ponto comum aos diversos programas de mentoria é o de auxiliar as tarefas do empreendedor com um olhar externo (EntAcel2, EntAcel1, EntAcel5, EntEmpr2, EntAcel3).

EntAcell afirma que inicialmente o programa de mentoria na aceleradora em que trabalha era com voluntários. No entanto, ao reconhecer o valor da mentoria para os empreendedores, a 
atividade passou a ser formalizada e hoje paga-se aos mentores e palestrantes que auxiliam as startups. As startups também podem solicitar temas de seu interesse para a mentoria. Já EntAcel3 afirma que o programa de aceleração com o qual trabalha oferece um plano estruturado de mentoria, dividido em temas que ajudam a startup a crescer de maneira sustentável. Esse programa recebe investimento específico, com mentores vindos do mercado, pagos pela mentoria, e em um relacionamento um-a-um que acompanham os empreendedores por até uma semana - e não apenas palestras. EntEmpr2 (mentorado por um programa corporativo) relatou também poder escolher especialistas da corporação para apoio - havendo um equilíbrio entre temas técnicos e comerciais.

Outro modelo de mentoria é descrito por EntAcel2, acerca da aceleradora em que atua: composto por cerca de cinco mentores voluntários que trabalham como gerentes seniores de outras empresas e estão interessados em estar mais próximos às startups. Já o programa de coach é paralelo e focado em habilidades específicas (como vendas e pitch). Além disso, a equipe da própria aceleradora acompanha as startups no dia-a-dia.

\subsection{Gestão}

O terceiro e último componente a ser estudado é a Gestão - entendida como os métodos, as técnicas e os modelos de negócios adequados para o lançamento ágil de produtos. Este componente está dividido entre os métodos dos programas de aceleração - com enfoque à metodologia da startup enxuta - e outros aspectos relacionados à gestão do produto notadamente, as métricas de acompanhamento da evolução do produto. 


\subsubsection{Programas de aceleração}

O primeiro tópico de análise em gestão é a aceleração - entendida como o programa oferecido pelas aceleradoras às startups. O objetivo deste tópico é descrever as atividades desses programas e analisar criticamente seus pontos positivos e negativos. Ressalta-se também que este tópico possui um caráter exploratório que servirá como base para todas as demais unidades de análise, visto que os programas das aceleradoras abrangem desde a busca por oportunidades comerciais até o treinamento metodológico. Esse tópico não estará presente no capítulo de Recomendações como um dos subcapítulos, mas servirá como base a todos os demais tópicos.

\subsubsection{Fases e atividades da aceleração}

Os programas de aceleração serão analisados de modo a identificar o modo como as aceleradoras agregam valor ao lançamento de novos produtos - para futura comparação de oportunidades de aprendizado por parte de grandes empresas.

O objetivo da aceleradora é a própria aceleração da entrada de um produto no mercado ou a aceleração do crescimento após as primeiras vendas (EntAcel1, EntAcel3). É interessante mencionar, entretanto, que muitos entrevistados citam como objetivos da aceleradora: treinar, financiar o desenvolvimento da ideia e gerar parcerias com outros empreendedores ou investidores (EntAcel4, EntAcel5, EntEmpr3) - sem mencionar aspectos relacionados ao tempo. É evidente que tais atividades aceleram a entrada do produto no mercado à medida que o empreendedor aprende ou obtém recursos; porém, é interessante que diversos entrevistados não mencionem a agilidade em si como objetivo - demonstrando como o tempo é inerente embora por vezes não de modo explícito - à gestão dos novos produtos.

As atividades para agilizar o processo de lançamento relacionam-se ao apoio ao negócio - desde a validação do produto até a estruturação administrativa -, a formação de redes e parcerias entre diferentes atores do ecossistema de inovação, a melhora da reputação da startup (por vezes mencionada como o 'selo' da aceleradora - que permite às startups facilidades frente a clientes 
e investidores), e a aceleração do aprendizado (EntAcel1, EntAcel3, EntAcel5, EntAcel4, EntEmpr4, EntEmpr3, EntAcel2).

A agilidade é relacionada à transferência de aprendizado da aceleradora aos empreendedores. Isto é, a aceleradora auxilia provendo know-how do mercado e relacionados à gestão de negócios de modo que os empreendedores possam otimizar o seu tempo com atividades relacionadas ao produto em detrimento de aspectos jurídicos, contábeis, entre outros, bem como desfrutar da experiência e do conhecimento da aceleradora no mercado de atuação (EntAcel1, EntEmpr3, EntAce15, EntAcel4, EntAcel3, EntEmpr5, EntAcel2). A necessidade de auxílio decorre do fato de que os empreendedores acelerados muitas vezes são jovens e por vezes é seu primeiro contato com o mercado corporativo (EntAcel3, EntAcel2, EntAcel5, EntEmpr6). Ademais, os empreendedores precisam atuar em diversas funções - inclusive aquelas em que eles possuem pouco conhecimento (EntAce15, EntEmpr3, EntEmpr2), havendo a necessidade de buscar apoio externo com frequência, inclusive entre os empreendedores mais experientes (EntEmpr5, EntAcel1). Para EntEmpr6, o modelo de aceleradora é particularmente útil por estimular a gestão e a profissionalização da startup.

EntAcel5 descreve a função da aceleradora como "[...] entender muito profundamente dos processos que levam ao desenvolvimento acelerado da inovação" aplicando ferramentas de gestão de inovação de modo a "[...] acelerar o processo de validação de cliente, e de desenvolvimento de produto", além de "[...] todo esse suporte metodológico para que eles [empreendedores] sejam mais consistentes nessa fase de lançamento". Frisa-se que "[...] às vezes esse acelerar, pode ser minimizar" (EntAce14). A aceleradora é também um intermediário em diversos pontos do processo " [...] ajudando a startup a conceber, a formatar, a validar esse produto no mercado antes do lançamento" (EntAcel5), concedendo assertividade no processo de aceleração pela experiência que ela possui (EntAcel4, EntEmpr2) e capacitando as startups por meio de dois ativos principais: treinamentos e contatos (EntAcel2). Efetivamente, as redes e os mentores nas aceleradoras permitem às startups " [...] pular alguns passos, pular alguns erros e acelerar na verdade o seu processo de aprendizado e validação” (EntAcel3).

A validação da ideia e do produto como o processo de "[...] explorar o mercado, ver como o mercado funciona e reage, fazer um produto duas ou três vezes para tentar vender para esse mercado e descobrir uma linha de ingresso" (EntAcel3) também aparecem como papel das 
aceleradoras. A credibilidade concedida pela aceleradora é mencionada inclusive sob o formato de credenciais na comunicação com clientes ou na busca por investidores (EntEmpr4, EntEmpr2, EntAcel1, EntAce14, EntAcel3), bem como o direcionamento a resultados (EntEmpr2, EntAcel1, EntAcel4, EntEmpr3) - detalhado no tópico de Métricas.

Outra função da aceleradora é criar redes e fomentar parcerias - aspecto já explorados no tópico de Stakeholders. A facilidade do contato com outros empreendedores e parceiros para a troca de experiências é um fator destacado por EntEmpr2, EntEmpr3, EntAcel5 e EntAcel4. EntAcel4 afirma que as redes são o aspecto mais importante na aceleração, por ser "[...] um período muito curto que você consegue fazer um número enorme de conexões - que vão ser muito úteis durante os próximos passos" e que todo o processo "[...] depende diretamente da qualidade dessa rede de colaboração”.

$\mathrm{O}$ aspecto de educação também é primordial. Os treinamentos são incentivados pelas aceleradoras - e embora não sejam obrigatórios, a maioria das startups tende a aproveitá-los sempre que possível (EntAcel1). Também, a aceleradora frequentemente acompanha as startups aceleradas em programas passados, e empreendedores de programas anteriores continuam a ser convidados para treinamentos (EntAcel1).

Em relação ao apoio financeiro, EntAcel3 afirma que o investimento monetário na startup não é o diferencial para as startups buscarem as aceleradoras, mas sim o smart money (como denomina todos os benefícios advindos com o processo). Por outro lado, ao menos um empreendedor (EntEmpr3) citou o acesso ao capital - como aporte da aceleradora ou como investimento de venture capital (que, por sua vez, pode estar incluído no conceito de smart money descrito por EntAcel3) - como um dos motivos pelos quais decidiram ser acelerados. Efetivamente, EntAcel2 considera que frequentemente o grande desafio no lançamento de novos produtos é o fluxo de caixa.

Empreendedores buscando apenas investimento podem procurar outras alternativas: EntEmpr1 afirma ter optado por investidor-anjo pois o empreendimento precisava apenas de aporte de capital, e as aceleradoras exigiam um tipo de envolvimento mais próximo e em maior prazo algo que não era de seu interesse. Ainda assim, a aceleradora auxilia o acesso ao capital de diversas maneiras: o próprio aporte realizado pela aceleradora, a credibilidade que ela concede 
à startup quando esta busca investidores externos e por meio dos chamados demo days - ou dias de demonstração -, em que as startups apresentam o seu produto para investidores em potencial. EntAcel 2 considera que o acesso ao capital é o aspecto que a aceleradora mais consegue aportar aos empreendedores, enquanto EntAcel3 considera que a aceleradora é de grande valor no apoio ao planejamento financeiro, à criação do business plan e ao acesso ao capital.

Outros fatores que motivaram os empreendedores entrevistados a participar de programas de aceleração são os recursos da multinacional à qual a aceleradora está associada, como a base de clientes (EntEmpr3) e a experiência da aceleradora e dos mentores no mercado da startup (EntEmpr2). Também é significativo o auxílio em infraestrutura - que inclui o próprio espaço físico de trabalho e serviços de profissionais especializados como contadores e advogados (EntAcel5, EntAcel2, EntAcel3). EntAcel2 descreve o modelo de atuação da aceleradora em que trabalha como advogados e contadores disponíveis gratuitamente para as startups em troca do uso do escritório pelos profissionais - para quaisquer clientes seus (de modo que não precisem pagar pelo aluguel de seu próprio escritório) - um modelo particularmente adequado em cidades com alto valor de aluguel. Outra particularidade presente na aceleradora em questão é a presença de profissionais cuja responsabilidade é criar negócios entre as startups e a corporação à qual está associada (EntAcel2).

EntEmpr6 descreve outros modelos de instituições de aceleração - como um que implantou em uma instituição brasileira de grande porte cujo objetivo é o de conectar os participantes - sem a necessidade de equity, mas alugando o espaço do escritório a startups pré-selecionadas. Para o entrevistado, exigir equity criaria uma seleção adversa, posto que o objetivo era criar um espaço que favorecesse as conexões (entre startups, profissionais, mentores, investidores e empresas). Também entre os modelos tradicionais de aceleradoras, estas podem ter diferentes objetivos: há aquelas direcionadas ao teste de um novo conceito tecnológico e outras voltadas a auxiliar o crescimento de um produto já existente (EntAcel3).

Também, coloca-se que o programa de aceleração vai se adaptando ao longo do tempo (EntAcel3, EntAcel4, EntAcel2), com validações contínuas visto que as aceleradoras também podem ser consideradas startups por serem um modelo relativamente recente e em construção (EntAcel3, EntAcel4). Ademais, as atividades são adaptadas a cada startup, posto que cada uma está em uma fase diferente e requer suporte em distintas tarefas (EntAcel2). 


\subsubsection{Limitações dos processos de aceleração}

De modo a fortalecer a compreensão do papel das aceleradoras, buscou-se identificar também suas limitações. Isto é, contrapor diferentes visões para identificar oportunidades de melhorias. A limitação não é necessariamente algo negativo, mas possivelmente algo fora do escopo de trabalho da aceleradora.

Quando EntAcel4 afirma que "[...] a capacidade de ajuda à startup é diretamente proporcional à capacidade de entrega do empreendedor. Entrega e também abertura", o entrevistado resume a limitação mais frequentemente associada às aceleradoras: a incapacidade de oferecer algo além do suporte - não atuando diretamente no negócio (EntEmpr4, EntAcel5, EntEmpr3, EntAcel2 e EntAcel1).

Outras limitações são relacionadas à dificuldade de suporte pela aceleradora em situações como a necessidade de intensa dedicação da equipe frente ao esforço exigido pelo novo empreendimento (EntAcel2), a tomada de decisão final após sucessivos conselhos (EntAcel3) e a resolução dos problemas do dia-a-dia da startup (EntAcel5).

Há também exemplos de ações específicas sobre as quais as aceleradoras possuem menor impacto. EntEmpr4 sustenta que um dos pontos que as aceleradoras não conseguem auxiliar eficazmente é o crescimento de vendas, enquanto EntAcel3 diz que em estágios mais avançados, a própria aceleradora pode não ter experiência para auxiliar o empreendedor em alguma situação específica. EntAcel2 reitera que cerca de $80 \%$ das startups não consegue sobreviver e que essa é uma taxa normal e esperada. Portanto, ainda que haja apoio, este não é garantia de sucesso.

Deve-se esclarecer inicialmente que há diferenças significativas entre os programas de aceleração. EntEmpr2 descreve um momento em sua experiência quando sua startup foi aprovada em um processo de aceleração, e que ele e os demais fundadores optaram por não ser acelerados. EntEmpr2 avaliou que a participação era demasiadamente alta, e com acordo de 
não-diluição. Ou seja, se os empreendedores buscassem investimento de outras instituições no futuro, apenas a parte deles próprios seria impactada, de modo que eles perderiam mais participação que a aceleradora.

Além disso, a aceleradora avaliada por EntEmpr2 "[...] não teve nenhuma saída relevante das empresas que ela acelerou. Então ela não demostrou criar tanto valor assim". A pesquisa bibliográfica indicou a necessidade de investimentos a longo prazo - de modo a ser complexo estimar seu valor em seus primeiros anos de atuação. Contudo, também levantou a dúvida quanto à efetividade da aceleradora - se o programa de aceleração é realmente útil ou se uma boa seleção é a razão do sucesso das startups. De fato, EntAcel3 lembra que "“[...] a aceleradora por definição, ela não é um modelo financeiro que fecha a conta [...]. A maioria das aceleradoras que abriu, tanto no Brasil quanto no mundo, fechou". Segundo o entrevistado, elas fecharam “[...] porque é difícil levantar o capital que você precisa para rodar o programa de aceleração, porque tem o capital de investimento mais o capital operacional", uma vez que o investimento envolve alto risco e longo tempo para o retorno. $\mathrm{O}$ entrevistado menciona que os primeiros resultados tendem a ocorrer de cinco a sete anos após o investimento, principalmente entre as startups em estágio inicial. Por isso, “[...] a maioria das aceleradoras morre” (EntAcel3).

Por outro lado, EntAcel3 identifica um novo modelo de atuação das aceleradoras: as aceleradoras corporativas, ou seja, aquelas que operam dentro de grandes empresas. Apresentando o exemplo da Techstars - que ajuda empresas a implementar programas de aceleração ou cria estes programas -, EntAcel3 entende que há uma tendência forte e crescente de aproximação entre grandes empresas e startups, e que "[...] até 2020, toda empresa vai ter sua área de novos negócios e inovação que vai ter aceleração".

EntEmpr2 também levanta a importância da experiência da aceleradora na indústria da startup e o formato do programa. Em seu exemplo, o desinteresse em um dos programas de aceleração no qual negociavam participação ocorreu devido ao fato de que os sócios precisavam desenvolver hardware e avaliaram que o programa de pouco mais de um mês era insuficiente para atingir este objetivo. 
Outro fator negativo às aceleradoras - e outros tipos de parcerias com grandes empresas - foram aspectos burocráticos e administrativos que envolvem processos rígidos, hierarquias e até mesmo conflitos de interesse que impactam a atuação da startup (EntEmpr2).

Por parte dos empreendedores não-acelerados, nem todos reconhecem o valor das aceleradoras, por entenderem que elas tratam de alguns problemas específicos que não necessariamente os seus empreendimentos possuem ou por entenderem que outras instituições podem atender melhor às suas necessidades (EntEmpr1, EntEmpr5).

\subsubsection{Metodologias de aceleração}

A análise das metodologias de aceleração foi dividida em: métodos e teorias gerais de gestão comercial e startup enxuta - estudada de modo separado devido à sua relevância, observada na coleta de dados primários e secundários.

\subsubsection{Modelos para aceleração de projetos e inovação}

Para não enviesar as entrevistas, a primeira pergunta relacionada à metodologia de aceleração foi de caráter genérico e exploratório, questionando aos entrevistados as técnicas e métodos utilizados na sua entrada no mercado. A metodologia de startup enxuta não havia sido mencionada em nenhum momento pela entrevistadora até o momento, ainda que alguns entrevistados já a houvessem citado especificamente (EntAce14, EntEmpr6, EntAcel3) - ou alguma de suas técnicas, como o MVP ou o ciclo de aprendizado (EntAcel4, EntEmpr4, EntCorp4).

O auxílio metodológico foi mencionado pelas aceleradoras como parte essencial de sua função (EntAcel5, EntAcel1, EntAcel3, EntAcel4). Então, a questão buscava elencar teorias, técnicas, 
conceitos e literatura utilizados por aceleradoras e empreendedores para lidar com os desafios ao longo do ciclo de crescimento de vendas do novo produto.

Em relação à criação da proposta de valor, os conceitos mais mencionados foram o entendimento de dores do cliente, as atividades a serem realizadas (jobs to be done) e o desenvolvimento dos consumidores (customer development) - propostos por Osterwalder e Blank (EntAcel4, EntAcel3, EntEmpr2, EntAce15). Outro conceito levantado foi o de customer success (EntEmpr3), que reforça a visão de entender o objetivo final do cliente para uma venda bem-sucedida. Para identificar e criar essas propostas de valor, técnicas como design thinking, pesquisa etnográfica e personas foram mencionadas (EntAcel4).

Em relação ao modelo de trabalho, foram mencionadas obras e teorias relacionadas principalmente à tomada de decisão e mentalidade do empreendedor. O effectuation de Sarasvathy (trazido por EntEmpr2) aborda a importância de efetuar o trabalho com o melhor que se possui no momento, ao invés de esperar as melhores condições possíveis para atuação. Já o Selecionismo - conforme proposto por Fletche (EntEmpr1) - enfatiza o uso de alternativas distintas de modo simultâneo inicialmente, para que a seleção de uma das alternativas seja realizada mais adiante - devido à dificuldade de executar um planejamento preciso desde o início em situações de extrema incerteza. The hard things about hard things de Horowitz (EntEmpr4) trata das dificuldades que acontecem durante o processo de empreender e como não há respostas prontas ao longo desse processo. Em visão do negócio, a obra Organizações Exponenciais de Ismail foi citada por EntEmpr4 como a maneira que os empreendedores devem avaliar os novos produtos (a entrevistada exemplifica como uma das melhores recomendações da obra em sua opinião a relevância de negócios disruptivos, que 'destruam' o produto anteriormente no mercado).

Mais voltados ao período de crescimento do negócio, após o lançamento, EntEmpr3 mencionou a obra Traction de Weinberg - que discute sobre a estratégia da aproximação com o cliente (comunicação, mensagem, canais, entre outros) e o desenvolvimento do produto associado à solução dos problemas dos clientes. Predictable Revenues de Ross e Tyler foi outra obra citada por EntEmpr3 e apresenta uma perspectiva de aproximação ao cliente ao longo de seu ciclo de vida (aquisição de consumidores, identificação dos clientes em potencial, acompanhamento do pipeline, estratégia de comunicação e escala). Por fim, o Inside Sales - mencionado novamente 
por EntEmpr3 - ressalta a relevância da utilização dos canais remotos (em geral, mais econômicos).

Ressalta-se que todas as obras e conceitos mencionados foram descritos de um modo sucinto visando acentuar o aspecto que o entrevistado tratou ao longo da entrevista. É relevante mencionar também que a maioria dos entrevistados cita diversas teorias e modelos - que são geralmente usados de modo combinado e dependendo do estágio do produto. Essa combinação de métodos é reforçada por EntAcel5, ao pontuar que a aceleradora em que trabalha criou uma nova metodologia para o programa de aceleração e "[...] para isso a gente usa vários métodos e várias metodologias existentes no mercado".

Sob a ótica do uso de métodos pelas aceleradoras, EntAcel3 afirma que as metodologias mudam de acordo com o tipo de aceleradora, de startup acelerada e de seu grau de desenvolvimento. $\mathrm{O}$ entrevistado diz que utiliza o conceito de OKR (objective key result, que pode ser entendido como o objetivo principal a ser atingido pela startup) para acompanhar as startups aceleradas, mas que os objetivos variam significativamente de acordo com o mercado e o estágio do empreendimento. EntAcel3 - que já mencionara que a aceleradora é em si uma startup (criando seu modelo de negócios) - reconhece que a aceleradora "[...] tenta um pouquinho de cada coisa, na verdade", lembrando a importância de testar, adaptar, construir e medir o resultado de cada ação.

O posicionamento de EntEmpr5 é o de que o mais adequado são as técnicas tradicionais de atendimento aos clientes, apesar de mencionar conceitos associados à literatura recente de gestão da inovação (como as dores dos clientes - ideia e nomenclatura utilizada por Osterwalder). Empatia, relações sustentáveis (no modelo "ganha-ganha") e boas propostas de valor são os fatores primordiais para a venda na opinião de EntEmpr5. O entrevistado reconhece o surgimento de soluções digitais para interação com o cliente, mas defende que o relacionamento de vendas tradicional é imprescindível. EntEmpr6 lembra que não basta aplicar um método para ter um produto bem-sucedido - opinião também colocada por EntCorp5 e EntEmpr5. Ademais, menciona que algumas empresas que afirmam utilizar determinadas metodologias a adaptam-na tanto a ponto de transformar seus conceitos básicos. Ao comentar sobre o Scrum, ele exemplifica: “[...] aquele product owner lá, ele não é nem product nem owner. Porque ele não está trabalhando em produto, ele está trabalhando em projeto, não tem 
ownership para tomar decisão" (EntEmpr6), uma vez que tudo já foi decidido antes da especificação.

Conclui-se esse tópico com as referências não de teorias, mas de organizações usadas como benchmarks. Essa abordagem é interessante pelo fato de que as organizações podem aplicar os mesmos métodos de modos distintos, combinando um conjunto de ações - que envolvem técnicas, cultura, infraestrutura, políticas internas, entre outros. Os exemplos citados pelos entrevistados foram a cultura de empoderamento (que pode ser interpretada como a cultura intraempreendedora) de Spotify, Netflix, Google, Amazon, Facebook (EntEmpr6), a "máquina de vendas" (entendida como o foco no cliente e em vendas) da Salesforce (EntEmpr3) e a gestão de produto e priorização de roadmap da User Voice (EntEmpr3). EntEmpr3 pontua que sempre busca benchmarks, visto que "Cada área, cada coisa que você vai fazer sempre tem alguém que já fez bem feito", complementando que essa é a filosofia da AMBEV: “[...] o que dá certo, copia. Não precisa ficar reinventado a roda".

\subsubsection{Startup enxuta}

A metodologia da startup enxuta é utilizada para diversas finalidades. Diversos entrevistados afirmaram utilizá-la para definir os requisitos (EntEmpr2), realizar testes (EntEmpr1, EntCorp2, EntEmpr3), reduzir custos (EntCorp1, EntCorp3), conhecer o cliente antes de maiores investimentos (EntAcel5, EntAce14, EntCorp1, EntCorp3), adequar o produto ao cliente (EntEmpr2, EntAce14), incentivar a cultura de teste e experimentação (EntEmpr4, EntEmpr3), e identificar o melhor modelo de negócios para o produto (EntAcel4, EntEmpr4) - sendo que o método pode ser adaptado a cada startup (EntEmpr3). Há também entrevistados que afirmaram que não reconheciam estar aplicando a metodologia porque não a conheciam, mas utilizavam alguns métodos propostos por ela, como prototipação (EntCorp4).

Avaliando a efetividade da metodologia de Startup Enxuta, EntEmpr2 avalia que reconheceu o erro em algumas premissas durante o piloto com o MVP (sendo, portanto, algo positivo - visto que a descoberta do erro foi feita após baixo investimento) e EntAcel5 destaca que há inclusive 
aprendizados não cobertos nas hipóteses - uma vez que alguns usuários se comportam de formas inesperadas (algo também avaliado de modo positivo pelo entrevistado devido à dificuldade do empreendedor em cobrir todas as hipóteses possíveis no planejamento).

Em relação ao produto mínimo viável, vários empreendedores relataram dificuldade inicial para defini-lo. EntEmpr3 reconhece que a primeira versão de seu MVP era robusta e que posteriormente ele adquiriu a mentalidade de definir qual premissa validar e qual indicador avalia cada premissa. Lembrando que "Na cabeça da empresa, o bom é inimigo do ótimo. $\mathrm{Na}$ startup, é o contrário: o ótimo é inimigo do bom", EntEmpr4 afirma que também desenvolveu um protótipo robusto inicialmente, mas que hoje, ela "[...] teria feito muito mais simples do que eu fiz para testar porque nesse um ano mudou tudo". EntCorp4 também relata a dificuldade de entender qual é o produto mínimo em tecnologia, apontando que frequentemente este já é quase o produto pronto. Dentre os empreendedores que informaram ter usado o MVP, EntEmpr2 foi o único que mencionou o foco na validação de hipóteses, mais do que no protótipo em si.

Uma última vantagem apontada em relação à startup enxuta, por EntEmpr4, foi a de manter disciplina, particularmente pelo fato de a empreendedora ter uma equipe remota (tecnologia no Rio de Janeiro e gestão em São Paulo), bem como a mentalidade de testar, medir e aprender.

Em relação à startup enxuta, Ries (2011) afirma que a metodologia é adequada em um ambiente de criação de produtos em condições de extrema incerteza. Ou seja, a startup é entendida em seu conceito mais amplo, inclusive em organizações de grande porte. De fato, todos os entrevistados de grandes empresas concordaram sobre a importância de utilizar métodos da startup enxuta. Para aplicá-la, EntCorp2 acredita que “[...] depende bastante dos líderes e de sua motivação em incentivá-1o ${ }^{1 \%}$, EntCorp1 afirma que se as grandes empresas não a utilizarem, elas “[...] não vão sobreviver. Até porque as startups têm uma vantagem de ser muito mais móveis, até mesmo por ser menores" e EntCorp3 finaliza dizendo que "[...] se encaixaria não só na construção de uma empresa ou de um novo produto", mas aplicável também "[...] no investimento, na parte financeira, em uma nova árvore de atendimento". Com efeito, o conceito

\footnotetext{
1 "It very much depends on the leaders and how willing they are to push through something like that."
} 
de ciclos que se retroalimentam e pilotos são aplicáveis a diversas mudanças - pequenas melhorias, inovações disruptivas e confirmação da eficácia de processos atuais.

Por outro lado, os entrevistados apontaram também barreiras relacionados à implantação do MVP. Foram mencionados: o risco à reputação (EntCorp2), a possível resistência do cliente em receber o fornecedor enquanto o produto não estiver acabado (EntCorp1), a cultura da empresa (EntCorp2) e o estágio da concorrência (EntCorp3). Destaca-se que concorrência e risco à reputação não foram citados por nenhum entrevistado de aceleradora ou empreendedor, demonstrando a maior relevância dessa preocupação em corporações.

Empreendedores sugeriram que para grandes empresas aplicarem a metodologia, há a necessidade de estruturar a empresa de modo que ela possa adaptar-se a mudanças (EntEmpr1) e compreender o conceito do MVP (EntAce14). Dentre os profissionais corporativos, as recomendações foram o recrutamento de gestores que já tenham trabalhado com o método anteriormente, a valorização dos recursos internos (isto é, não terceirizados) e o incentivo por parte dos líderes (EntCorp2).

\subsubsection{Métricas}

Todos os entrevistados foram favoráveis ao uso de métricas, indicando a necessidade de inicialmente valorizar as métricas relacionadas à satisfação do cliente. Foram abordados aspectos financeiros como o custo de aquisição de clientes e o retorno sobre o investimento, mas ambos entendidos como de menor relevância inicial quando comparados com a satisfação e o interesse por parte do cliente em adquirir o produto.

Outro âmbito discutido é a centralidade das métricas nos programas de aceleração. Todos os gestores de aceleradoras entrevistados informaram usar métricas e destacaram a sua dimensão dentro do programa. Uma vertente trazida por uma das aceleradoras foi o OKR (resultadosalvo), conceito que se distingue do mais conhecido KPI (indicadores de desempenho) pelo fato de evidenciar o resultado da ação em detrimento de um indicador de acompanhamento. 
As métricas possuem diversos formatos. EntAcel5 estabelece que as startups precisam de metas objetivas baseadas em métricas quantitativas para que os empreendedores possam acompanhar a evolução. Já EntAcel1 acredita que as métricas tendem a ser mais subjetivas inicialmente e que, na aceleradora em que trabalha, as metas são avaliadas a cada quatro meses em comitês quando são definidas novas metas. Esses comitês são o momento de novos aportes financeiros. O fato de a startup não bater a sua meta não a elimina do programa nem inviabiliza necessariamente um novo aporte, mas é o momento de uma análise crítica sobre a sua evolução.

Mais do que métricas específicas, EntAcell acredita que a principal finalidade da mensuração é instigar o foco em resultado. A entrevistada considera que a aceleração gera agilidade e eficiência por cobrar resultados das startups. EntEmpr3 concorda que a aceleradora estimula a cultura de experimentação e métrica; e EntAcel4 reforça que a eficiência da aceleração está na aplicação de método e na pressão colocada sobre os empreendedores. EntAcel5 afirma que embora as métricas mudem de acordo com o mercado, as startups devem sempre ser orientadas a elas e que o aprendizado da métrica é o principal aprendizado do empreendedorismo porque “[...] se você não mede, você não aprende nada. E além de medir, você ser questionador, fazer as perguntas certas, sempre se questionar", inclusive na fase de pós-venda (EntEmpr4).

Esclarecida a criticidade das métricas para o acompanhamento da evolução dos novos produtos, alguns entrevistados mencionam as métricas que consideram mais relevantes. Destacam-se: “[...] a satisfação do usuário com o produto" (EntEmpr2), “[...] entender a dor do cliente” (EntEmpr5), o modo como o produto resolve o problema do cliente (EntEmpr2, EntEmpr3 e EntAcel2), e o tempo de vida dos clientes (EntCorp2), a taxa de abandono (EntCorp2), a taxa de crescimento em variáveis como o faturamento e a quantidade de clientes ativos e pagantes (EntAcel3), o custo de aquisição (EntAcel4, EntEmpr3, EntAcel5), e o nível de adesão do produto pelo público-alvo - em quantidade de clientes ativos e na forma como o cliente utiliza o produto (EntEmpr1). Por fim, EntAcell sustenta que a fase do ciclo de vida das startups é a base para a criação das suas metas - sendo fundamentalmente diferentes as metas na etapa de ideação daquelas da fase de tração e crescimento; e EntCorp2 afirma ser imprescindível comparar as métricas do produto à concorrência, sendo possível utilizar métricas mais qualitativas (como a satisfação dos clientes) para inovações sem concorrentes diretos. 
Em relação aos clientes, EntAcel3 opina que “[...] o mais importante no começo e você saber se realmente as pessoas estão usando seu produto de fato. $\mathrm{O}$ crescimento sustentável" enquanto EntEmpr1 acredita que é essencial receber feedback dos clientes e ser responsivo - apesar de ser necessário equilíbrio na responsividade porque algumas alterações requerem um esforço demasiado para o retorno gerado. EntEmpr5 pontua a necessidade de "[...] equilibrar prospecção e venda", fidelizando os clientes atuais e também buscando novos clientes.

Por fim, coloca-se a opinião EntCorp3 - que levanta a necessidade de métricas e planejamento antes do lançamento do produto. A entrevistada ressalta que os cálculos antes do lançamento deveriam ser determinantes para quantificar o risco e justificar o esforço do desenvolvimento do novo produto. 


\section{RECOMENDAÇÕES}

O objetivo deste capítulo é retomar os principais aspectos levantados nas entrevistas e no referencial teórico para propor orientações às empresas de grande porte relacionadas à agilidade no lançamento de produtos de informação.

Observando a existência de modelos amplamente utilizados para acelerar o lançamento comercial de produtos em startups - bem como o surgimento de instituições que atuam com este foco específico, principalmente em produtos de informação -, a autora analisou o funcionamento dos programas de aceleração e avaliou como algumas de suas técnicas podem ser utilizadas por corporações.

Diversas recomendações propostas não se restringem a produtos de informação em grandes empresas, embora elas tenham sido criadas enfatizando esses produtos. Algumas das recomendações serão apresentadas em mais de um tópico. Optou-se por mantê-las para demonstrar a sua aderência a diferentes áreas de atuação definidas no Referencial Teórico (Componentes) para a agilidade do lançamento.

Este capítulo será subdividido nos Componentes: Ambiente, Pessoas e Gestão. Em cada uma dessas áreas, são apresentadas as evidências que levaram a descobertas associadas a cada unidade de análise. A comparação das descobertas e dos dados coletados gera as recomendações para otimizar as decisões do tempo do lançamento de produtos de informação em empresas de grande porte. 


\subsection{Ambiente}

As recomendações relacionadas ao Ambiente - compreendido como o entorno onde ocorre o lançamento dos produtos, seja ele interno ou externo à organização - são direcionadas a propiciar as condições internas ideais para agilizar o lançamento de produtos e para adequar-se às circunstâncias externas de modo a alavancar oportunidades e minimizar os obstáculos.

\subsubsection{Antecedentes e consequências do lançamento}

Dentro dos aspectos internos, são estudados o tempo em si e fatores internos à organização.

\subsubsection{O tempo e a agilidade no lançamento de produtos}

A relevância do tempo aparece de modo consistente na Análise de Dados. O tempo é inerente a todas as decisões da empresa, ainda que frequentemente de modo não explícito. $\mathrm{O}$ fato de o seu valor não estar explícito (isto é, o valor ganho com a agilidade ou a perda advinda de um atraso) ou quantificado é um dos motivos pelo qual o tempo eventualmente não é priorizado em relação a fatores mais explícitos, como o custo e o escopo. Porém, o tempo é um recurso cuja utilização impacta diretamente a eficiência do projeto, assim como impacta o custo, o escopo e o resultado deste projeto.

O tempo é a característica que define a inovação; isto é, o primeiro produto lançado - e conhecido do público - é aquele considerado inovador. Contudo, o tempo também pode ser um diferencial competitivo e é um dos fatores críticos de decisão no lançamento - a ser combinado 
com outros fatores internos ou externos à empresa. Desse modo, a organização toma decisões relacionadas ao tempo equilibrando a perspectiva externa (o tempo adequado, em que há demanda no mercado) e interna (a capacidade para lançar e a disponibilidade de recursos).

Quadro 6 - Evidências e descobertas relacionadas à unidade de análise de tempo

\begin{tabular}{|c|c|}
\hline Evidências & Descobertas \\
\hline 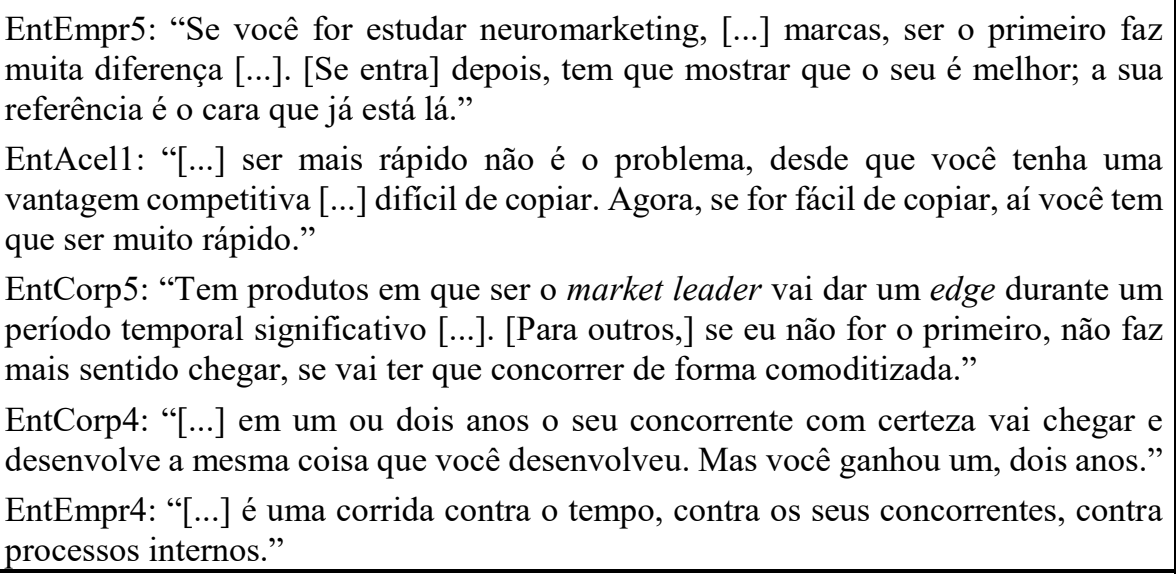 & $\begin{array}{l}\text { - Tempo define a } \\
\text { inovação. } \\
\text { - Tempo, custo e escopo } \\
\text { precisam ser geridos de } \\
\text { modo conjunto. } \\
\text { - Priorizar é tão } \\
\text { importante quanto } \\
\text { acelerar. }\end{array}$ \\
\hline $\begin{array}{l}\text { EntAcel3: "A única vantagem que a startup tem, efetivamente falando, em relação à } \\
\text { grande empresa é que ela é rápida [...] porque ela é pequena e enxuta." } \\
\text { EntAcel1: "[A startup] precisa correr, porque se uma grande vier, ela consegue } \\
\text { abocanhar." } \\
\text { EntAcel5: "A startup é uma organização que está fazendo um projeto inovador cheio } \\
\text { de incertezas e em geral com poucos recursos [...]. Por isso ela precisa ser muito } \\
\text { eficiente. Ela precisa fazer muito com pouco e ela precisa ser rápida." }\end{array}$ & $\begin{array}{l}\text { - Agilidade é vantagem } \\
\text { competitiva. }\end{array}$ \\
\hline $\begin{array}{l}\text { EntAcel1: “A ideia é que se ela [a startup] quebre, ela quebre logo, se ela tiver que } \\
\text { mudar a ideia, ela mude rápido, porque o mercado é muito voraz." } \\
\text { EntAcel4: "[...] acelerar a falha é bom porque você vai gastar menos dinheiro e } \\
\text { menos tempo para entender que aquele projeto não era viável." } \\
\text { EntCorp5: "[...] se são inovações que tem ciclos um pouco mais largos, é melhor ser } \\
\text { o segundo porque se eu tiver capacidade de replicar rapidamente, [...] tenho um custo } \\
\text { de investigação um pouquinho mais baixo, de investimento de CAPEX." } \\
\text { EntEmpr6: "O digital é muito mutável. Se você não está o tempo todo evoluindo e } \\
\text { adaptando, você perde awareness, você perde relevância, você perde negócio." }\end{array}$ & $\begin{array}{l}\text { - Tempo é recurso } \\
\text { (influencia a eficiência). }\end{array}$ \\
\hline $\begin{array}{l}\text { EntAcel2: “[Inovação] é a única forma de sobreviver, mas ao mesmo tempo é } \\
\text { impossível fazer revenue nos primeiros anos." } \\
\text { EntAcel4: “[...] a aceleradora também é uma investidora, é um modelo de super } \\
\text { longo prazo [...] e leva tempo para aquelas empresas serem grandes e bem-sucedidas, } \\
\text { se tudo der certo, e retornar esse capital investido." } \\
\text { EntCorp5: "[...] quem não muda vai ficando pelo caminho.” }\end{array}$ & $\begin{array}{l}\text { - É necessário reconhecer } \\
\text { que o investimento é a } \\
\text { longo prazo. }\end{array}$ \\
\hline $\begin{array}{l}\text { EntEmpr5: “O seu objetivo é maximizar a quantidade de informações disponíveis } \\
\text { para tomar decisão no tempo certo - que é o mais rápido possível." }\end{array}$ & $\begin{array}{l}\text { - Tempo é inerente a todas } \\
\text { as decisões. }\end{array}$ \\
\hline
\end{tabular}


A principal recomendação para lidar com o tempo em suas diferentes concepções é evidenciar esse fator na tomada de decisão. Uma vez que a tomada de decisão considera múltiplos fatores, é importante quantificar o ganho adicional (ou a perda financeira) relacionando-o com outras medidas (como a qualidade ou o escopo do projeto). Isto é, valorar cada unidade adicional de tempo de modo a explicitá-lo na tomada de decisão. É evidente que essa quantificação da perda ou do ganho pode levar à decisão de que em alguns momentos adiar seja melhor do que agilizar o lançamento. Esse cálculo de perdas e ganhos também favorece a decisão da priorização das características do produto, assim como o entendimento de quando simplificá-lo.

O tempo certamente pode ser calculado como o tempo decorrido em si por dias, semanas ou meses; a quantificação que se sugere é um cálculo que o compare com outros fatores. Por exemplo, o tempo na inovação está diretamente associado ao pioneirismo, ao período em que há demanda pelo produto, ao diferencial em relação aos competidores, ao benefício adicional gerado por uma característica que demanda determinado tempo para o seu desenvolvimento, e assim sucessivamente.

A recomendação para esta decisão conjunta é um tópico que será detalhado em seguida e referese à utilização do Produto Mínimo Viável (MVP) que já possua valor comercial (isto é, quando há clientes pagantes), de modo que o lançamento seja visto como um processo e não como uma data específica.

Quadro 7 - Recomendações relacionadas à unidade de análise de tempo

Recomendações

- Colocar o tempo em evidência na tomada de decisão.

- Criar cronogramas e métricas que indiquem como os demais fatores influenciam o tempo.

- Tomar decisões de priorização entre aspectos adicionais de escopo, custo e tempo (quantificar a perda ou o ganho adicional por unidade de tempo).

- Utilizar o MVP para lançamento.

\subsubsection{Fatores internos}

Os aspectos internos às organizações são aqueles que mais se alteram de acordo com o tamanho da empesa. Um dos temas mais mencionados dentre os fatores internos foram os processos 
estruturados - comuns em grandes corporações e frequentemente ausentes em startups -, entendidos como vantajosos pela ótica da escala e crescimento e desvantajosos pela ótica da burocracia e falta de autonomia. Essa comparação é interessante uma vez que os processos geram eficiência quando são seguidos após serem validados, mas geram ineficiência se são necessários para realizar validações.

Um procedimento que apareceu nas entrevistas como frequente em grandes empresas é o planejamento de todo o produto inicialmente, com a criação de um plano de negócios pouco flexível a mudanças posteriores. As aceleradoras, por outro lado, em geral incentivam a flexibilidade - e a mudança, quando necessário - de acordo com obstáculos e oportunidades ao longo do ciclo de vida do produto. Embora entenda-se a importância do planejamento e estudo de cenários para a concepção do produto, grande parte das decisões relacionadas a precificação, canais de vendas e promoções podem ser postergadas para o momento do lançamento. Ao adiar tais decisões, a organização é capaz de adequar o seu produto à demanda do mercado.

Outro aspecto que aparece de modo frequente em grandes empresas é o modelo estruturado de gestão do novo produto. A maioria das empresas estabelecidas possui políticas de gestão de produtos - que envolvem as campanhas de comunicação, a precificação, os canais de atuação, entre outros - e o novo produto precisa se adequar a esta estrutura. As startups precisam tomar as mesmas decisões. Contudo, uma vez que as startups geralmente estão focadas em um único produto, elas utilizam todos os recursos para geri-lo e todos os processos internos são criados adequados a esse produto - enquanto grandes empresas precisam enquadrá-lo em processos pré-estabelecidos. Corporações também precisam gerenciar recursos internos, equilibrando todo o portfólio. Posto que novos produtos ainda possuem baixo faturamento (ou não possuem faturamento), eles por vezes perdem prioridade frente aos demais no uso de infraestrutura comum a todos os produtos.

Quadro 8 - Evidências e descobertas relacionadas à unidade de análise de fatores internos

\begin{tabular}{|c|c|}
\hline Evidências & Descobertas \\
\hline $\begin{array}{l}\text { EntAcel4: "Para ter eficiência operacional, você precisa de processos mais rígidos e } \\
\text { esses processos mais rígidos matam todo o processo de inovação." }\end{array}$ & $\begin{array}{lr}\text { - Processos } & \text { são } \\
\text { fundamentais } & \text { para }\end{array}$ \\
\hline $\begin{array}{l}\text { EntEmpr4: "[A startup] por mais que ela não tenha recurso, ela tem muita } \\
\text { flexibilidade, não tem medo de arriscar." }\end{array}$ & $\begin{array}{l}\text { organização } \\
\text { comunicação, mas em }\end{array}$ \\
\hline
\end{tabular}




\begin{tabular}{|c|c|}
\hline $\begin{array}{l}\text { EntAcel5: "[...] se você tem que seguir o business plan }[\ldots] \text { cegamente, você acaba } \\
\text { ficando preso a hipóteses que muitas vezes não se confirmaram." } \\
\text { EntAcel4: "[A startup] consegue validar as coisas de uma forma muito mais simples, } \\
\text { eficiente e barata." } \\
\text { EntEmpr5: "[As grandes podem] ter muitos recursos, uma história, uma cultura que } \\
\text { podem facilitar. Por outro lado, todo esse 'mais' pode ser um grande inibidor, uma } \\
\text { barreira... Empresas que ficam lentas pela burocracia, quantidade de pessoas." }\end{array}$ & $\begin{array}{l}\text { excesso causam } \\
\text { burocracia e lentidão. } \\
\text { - Planejamento é } \\
\text { necessário, mas } \\
\text { flexibilidade é } \\
\text { essencial para adequar } \\
\text { o plano inicial. }\end{array}$ \\
\hline $\begin{array}{l}\text { EntAcel5: "[As grandes] têm um relacionamento muito bom com toda a cadeia de } \\
\text { valor [...], estão acostumadas a fazer negócios em grande volume." } \\
\text { EntEmpr4: "[O] vale da morte [...] - que é quando você realmente tem que tracionar } \\
\text { o negócio e eles [grandes empresas] fazem muito bem isso." } \\
\text { EntCorp5: "[o] fato de empresas grandes estarem bem estabelecidas no mercado dá- } \\
\text { lhes uma vantagem em termos de go-to-market. Ter acesso a cliente, ter acesso a } \\
\text { parceiros especializados." }\end{array}$ & $\begin{array}{l}\text { - Contato anterior com } \\
\text { o mercado e histórico } \\
\text { com o cliente facilitam } \\
\text { venda. }\end{array}$ \\
\hline $\begin{array}{l}\text { EntAcel5: “[...] as grandes empresas são muito boas em eficiência de produtos, } \\
\text { processos bem estabelecidos." } \\
\text { EntAcel4: "[...] na medida que vou ganhando escala }[\ldots] \text {, tenho muito a aprender com } \\
\text { a grande empresa de processos estruturados." }\end{array}$ & $\begin{array}{l}\text { Processos } \\
\text { estruturados } \\
\text { favorecem eficiência e } \\
\text { crescimento. }\end{array}$ \\
\hline $\begin{array}{l}\text { EntEmpr5: “[...] uma grande empresa normalmente tem seu sobrenome e eu acho que } \\
\text { isso [...] passa segurança [...]. Como [inovação] é uma coisa incerta, o cliente muitas } \\
\text { vezes busca essa segurança [...], tem uma marca para defender." } \\
\text { EntCorp4: "A grande tem credibilidade no mercado, o financiamento, e expertise de } \\
\text { pessoas que estão há muito tempo no negócio, a experiência." } \\
\text { EntAcel2: "[A grande empresa tem] mais facilidade de aprender porque tem mais } \\
\text { pessoas e dá para testar mais coisas" }\end{array}$ & $\begin{array}{l}\text { - Imagem, marca, base } \\
\text { de clientes e ativos } \\
\text { internos à corporação } \\
\text { são valiosos para o } \\
\text { novo produto. }\end{array}$ \\
\hline $\begin{array}{l}\text { EntCorp3: "[...] muitos produtos competem no fluxo de implementação de projetos } \\
\text { na empresa [...]. Será que vale a pena continuar administrando e ter todo o esforço na } \\
\text { gestão de todos os produtos?" } \\
\text { EntCorp5: "[Os novos produtos] têm que ser ajustados e equilibrados com o resto do } \\
\text { portfólio de produtos existentes." } \\
\text { EntCorp5: "[Pode existir] uma ideia de produto que é funcional tecnicamente ou } \\
\text { teoricamente, por assim dizer, mas depois o seu processo de deployment ou de } \\
\text { comercialização podem tornar o negócio inviável." }\end{array}$ & $\begin{array}{lr}\text { - Inovação precisa } \\
\text { trazer resultados. } \\
\text { - Portfólio de produtos } \\
\text { é gerido de } & \text { modo } \\
\text { conjunto } & \text { em } \\
\text { corporações. } & \end{array}$ \\
\hline
\end{tabular}

A primeira recomendação em relação aos fatores internos é alavancar os ativos da corporação.

Sua credibilidade - advinda com o histórico no mercado e a força da marca - facilita o contato com os clientes; a quantidade de recursos tangíveis e intangíveis disponíveis possibilita mais testes de conceito e maior capacidade de investimento no crescimento do produto; as equipes compostas por centenas de colaboradores permitem uma ampla diversidade de conhecimento. Faz-se necessário, todavia, reconhecer, valorizar e aplicar estas vantagens.

O fato de a corporação já possuir um canal para acessar o cliente (devido a outros produtos comercializados) também é um ativo relevante. A recomendação para alavancá-lo é criar ofertas integradas entre os produtos novos e os tradicionais - como modo de reduzir as barreiras ao novo produto -, assim como destacar os novos produtos na comunicação da marca. A maior 
disponibilidade de ativos financeiros na comparação com as startups também pode ser utilizada para investir nas validações com o mercado e na agilidade da execução de melhorias demandadas pelo mercado (o Referencial Teórico evidencia os constantes trade-offs entre tempo, custo e escopo. Como a corporação possui maior disponibilidade de recursos financeiros, ela também possui maior capacidade de investi-los a favor do tempo quando comparada a empresas menores).

Em relação aos processos, a recomendação é criar processos pouco hierarquizados ou centralizados. Isto porque o fator que gera burocracia é a centralização do poder e a falta de flexibilidade para a mudança, e não o processo em si. Se o processo serve como exemplo, mas é possível não o seguir em determinados momentos ou se é permitido efetuar alterações sobre ele, eles podem ser utilizados para direcionar as equipes e não restringir a sua autonomia. Dessa maneira, o processo passa a agilizar o lançamento do produto. Outra alternativa é criar processos e procedimentos específicos para a inovação, assim como trabalhar com equipes mais autônomas. O acompanhamento constante das métricas e as validações de premissas também são indicados para facilitar o ajuste do produto ao mercado antes de investimentos mais elevados.

Já para as atividades de suporte, a recomendação é alocar recursos para os novos produtos de modo independente ao restante do portfólio. Essa recomendação se deve ao fato de que as inovações em seu estágio inicial frequentemente ainda não envolvem clientes nem geram receita, embora as áreas de apoio exerçam papel determinante para que elas possam ser lançadas.

Quadro 9 - Recomendações relacionadas à unidade de análise de fatores internos

Recomendações

- Criar processos flexíveis (como direcionamento a seguir, e não como obrigação), que agilizem o lançamento.

- Adiar a tomada de decisão de variáveis relacionadas ao lançamento para depois do teste com o mercado.

- Alavancar as vantagens competitivas organizacionais (marca, credibilidade, etc.) na comunicação com os clientes.

- Oferecer combinações de produtos novos e existentes para facilitar a entrada do novo. 


\subsubsection{Stakeholders externos}

As recomendações apresentadas na unidade de stakeholders externos são direcionadas principalmente ao acompanhamento constante do mercado para adaptação da organização minimizando o impacto negativo e maximizando o impacto positivo sempre que possível.

\subsubsection{Oportunidades}

A inovação - na forma de um novo produto ou de melhorias sobre produtos atuais - é frequentemente vista como a única forma de as empresas se manterem competitivas. Além disso, há curiosidade e interesse do mercado em relação à inovação - embora nem sempre gerando receitas (por diferentes motivos, como a indisponibilidade de caixa, a falta de percepção de benefício com o novo produto, entre outros). Para os clientes, a oportunidade advinda com a inovação é o acesso a algum tipo de benefício não existente anteriormente - em geral, preço menor ou qualidade maior.

Para quem comercializa a inovação, a inexistência de concorrência direta (que reduz a competição com base em preço) e o posicionamento da marca são oportunidades relevantes. O valor da inovação está relacionado ao seu diferencial em relação à concorrência no seu sentido amplo, incluindo produtos substitutos.

Quadro 10 - Evidências e descobertas relacionadas à unidade de análise de oportunidades

\begin{tabular}{|c|c|}
\hline Evidências & Descobertas \\
\hline $\begin{array}{l}\text { EntAcel2: “[Inovação] é a única forma de sobreviver, mas ao mesmo tempo é } \\
\text { impossível fazer revenue nos primeiros anos." } \\
\text { EntEmpr4: “[...] está todo mundo querendo inovar." } \\
\text { EntEmpr5: “[...] no momento atual [inovação] é bom porque as empresas estão } \\
\text { buscando. Então, está meio que na moda. Há uns dez anos era sustentabilidade. Hoje } \\
\text { é inovação e empreendedorismo.” } \\
\text { EntEmpr2: “[...] as pessoas se interessam muito por conhecer o novo [...]. [Porém,] } \\
\text { essa curiosidade não vai de um nível do entusiasta para o early adopter. É mais } \\
\text { superficial.” }\end{array}$ & $\begin{array}{l}\text { - Inovação por si só gera } \\
\text { interesse do mercado. } \\
\text { - Nem sempre o } \\
\text { interesse gera negócios. }\end{array}$ \\
\hline
\end{tabular}


EntCorp1: "[...] quando você vende inovação é muito mais difícil ter um produto similar ao seu no mercado, logo você consegue uma diferenciação mais fácil."

EntCorp4: “[O mais importante] é quando você cria facilidades para os clientes [...]. Ganho financeiro [para o cliente] é muito importante também."
- Inovação é associada a ganho (reduz custo, novos benefícios, etc.).

- Diferenciação gera valor.

Posto que as oportunidades são forças externas à organização que trazem benefícios, a recomendação é atentar-se ao ambiente externo para que se percebam tais oportunidades e se possa aproveitá-las de modo eficiente. Para ter capacidade de incorporar os benefícios trazidos com tais oportunidades antes da concorrência (posto que o valor da oportunidade é comparativo), a rapidez de mudança é primordial. Por esse motivo, a flexibilidade e a cultura de incentivo à mudança aparecem novamente como fundamentais.

Por fim, recomenda-se atuar com duas técnicas propostas por entrevistados de modo a agilizar o lançamento. São elas: o effectuation e o selecionismo - a primeira enfatizando a necessidade de se trabalhar com o que está disponível em cada momento e a segunda incentivando a comparação das abordagens para a tomada de decisão do produto.

\section{Quadro 11 - Recomendações relacionadas à unidade de análise de oportunidades}

Recomendações

- Atentar-se ao surgimento de oportunidades por meio do monitoramento de mercado para ser capaz de aproveitá-las.

- Valorizar o pioneirismo (que por sua vez está diretamente relacionado à necessidade de agilidade).

- Otimizar na comunicação do aspecto de inovação e os demais ativos da corporação (credibilidade, base de clientes, entre outros).

\subsubsection{Desafios}

O desafio mencionado com maior recorrência - inerente ao lançamento de um produto bemsucedido - é a criação da proposta de valor. Apesar de o produto já estar desenvolvido voltado a determinado problema e mercado, a proposta de valor é frequentemente ajustada no lançamento - quando o produto entra efetivamente no mercado. O desafio é equilibrar os diversos componentes da proposta de valor (público-alvo, fornecedores, canais, etc.) de modo a viabilizar o produto. Esta dificuldade foi mencionada igualmente por startups e corporações. Ao acessar o mercado, startups apresentam maior dificuldade na divulgação do produto e para 
chegar ao cliente final (por serem menos conhecidas do público); contudo, as aceleradoras cumprem um papel determinante gerando credibilidade às startups. Já as corporações reconhecem como risco o impacto do lançamento de um produto disruptivo sobre o restante do portfólio.

A incerteza da aceitação do produto pelo mercado, da eficácia da proposta de valor, do preço praticado e do tamanho do mercado são outros desafios mencionados pelos entrevistados.

Quanto a situações gerais do ambiente (governo, política, economia, entre outros), estes em geral estão totalmente fora do controle e da zona de influência das empresas; portanto, é necessário priorizar a agilidade para adaptar-se à situação.

Quadro 12 - Evidências e descobertas relacionadas à unidade de análise de desafios

\begin{tabular}{|c|c|}
\hline Evidências & Descobertas \\
\hline 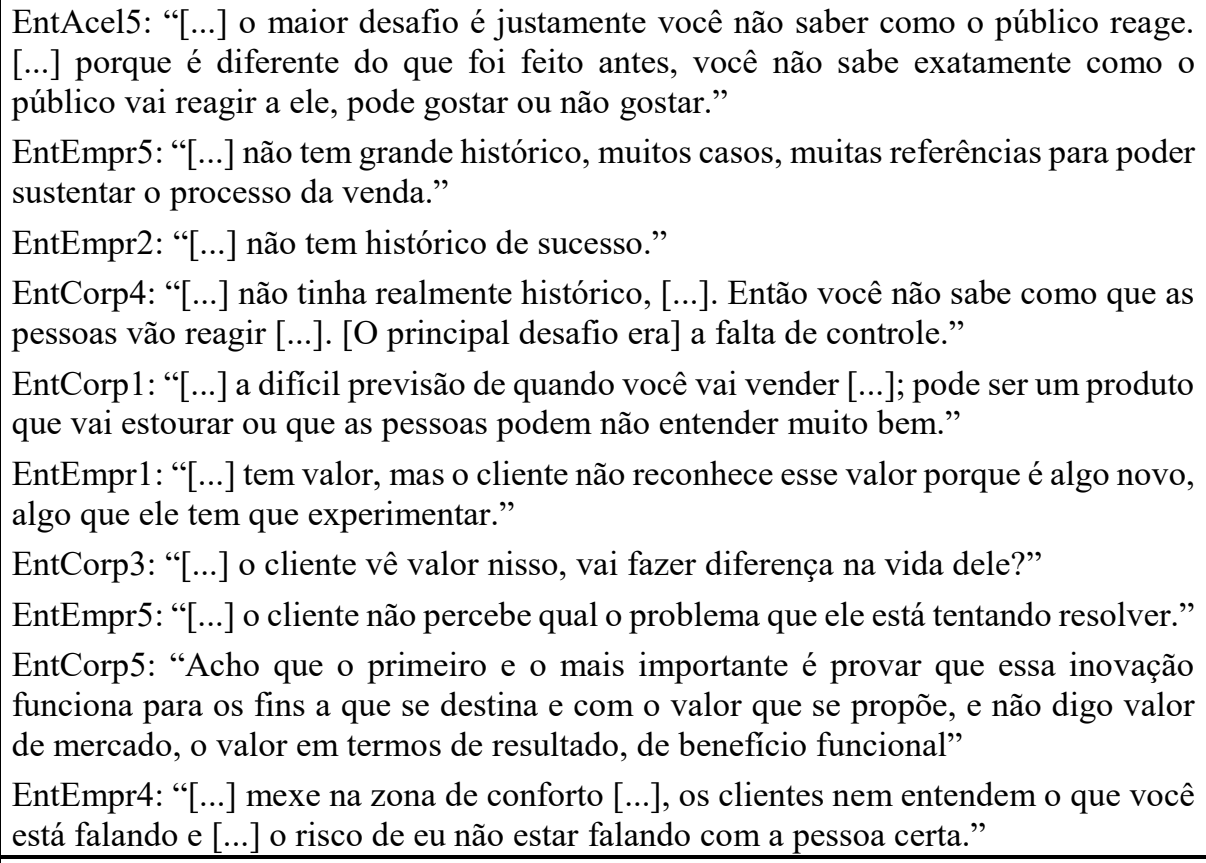 & $\begin{array}{l}\text { - Proposta de valor é } \\
\text { planejada, mas há } \\
\text { incerteza na ida ao } \\
\text { mercado. } \\
\text { - Risco é comumente } \\
\text { visto como incerteza } \\
\text { quanto à reação dos } \\
\text { clientes. } \\
\text { - Risco é inerente, por } \\
\text { falta de histórico com o } \\
\text { novo produto. }\end{array}$ \\
\hline $\begin{array}{l}\text { EntEmpr2: “[...] precisa identificar quem é o primeiro cliente. Ele tem que ser um } \\
\text { pouco de entusiasta da sua solução, saber que tem um problema [...] e aceitar que sua } \\
\text { solução não está completa." } \\
\text { EntCorp5: "Eu tenho algo que identifico um valor, mas não sei quem mais valoriza } \\
\text { isso e como é que isso se valoriza monetariamente; e tem outros que é o contrário: [...] } \\
\text { eu sei que todo mundo tem essa necessidade, mas eu não sei como fazer." } \\
\text { EntAcel1: "[Um desafio] é chegar na pessoa certa porque às vezes você tem mesmo } \\
\text { uma boa ideia, mas se seu cliente é uma empresa, às vezes é muito difícil você chegar } \\
\text { naquele que tem o poder decisão." }\end{array}$ & $\begin{array}{l}\text { - É necessário } \\
\text { identificar o público e o } \\
\text { canal para acessá-lo. } \\
\text { - No B2B, o risco se } \\
\text { estende a outros } \\
\text { stakeholders além do } \\
\text { responsável pela } \\
\text { aquisição. }\end{array}$ \\
\hline
\end{tabular}




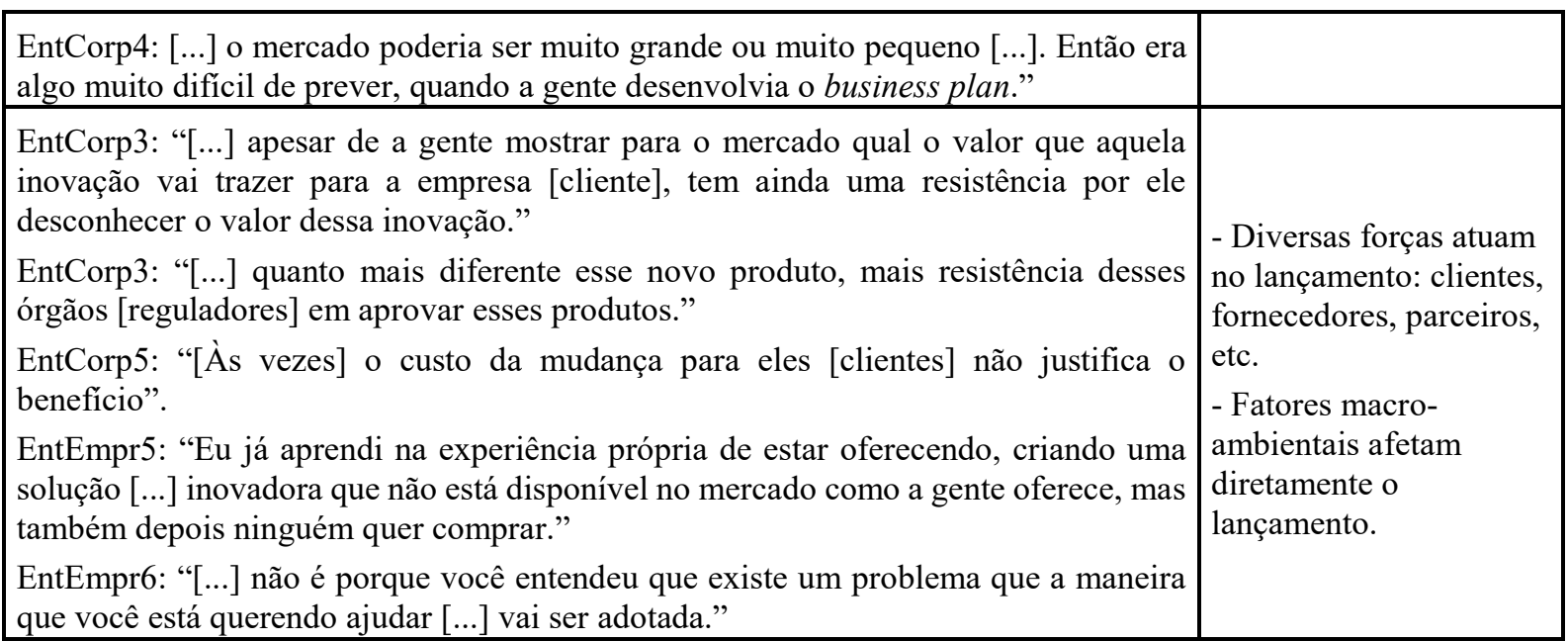

A criação da proposta de valor é um desafio para startups e para corporações. Entretanto, as aceleradoras aconselham às startups validar o produto e aproximar-se dos clientes logo no início do desenvolvimento do produto, enquanto grandes empresas tendem a adiar a aproximação com o cliente para a fase final do lançamento e comercialização. Essa validação inicial é imprescindível para evitar que haja desperdício de recursos (incluído o próprio tempo) devido à execução precipitada de tarefas causadas por foco excessivo na aceleração.

Grandes empresas também deveriam antecipar a aproximação com os clientes. Evidentemente há desafios relacionados a essa aproximação em estágios iniciais - como a perda de confidencialidade do novo produto. A recomendação é trabalhar com MVPs com valor comercial - para que a organização passe a obter retorno financeiro com o produto e para que fique claro aos clientes que os produtos ainda estão em fase de ajustes caso haja algum problema em sua utilização.

Ao utilizar o MVP, o risco em relação à concorrência permanece; porém, deve-se balancear o risco do investimento sobre um produto não-validado quando comparado ao risco de a concorrência também iniciar o desenvolvimento de um novo produto similar. Este cálculo pode ser incluído também como uma das métricas a serem acompanhadas pela organização. Ademais, a competição não é necessariamente negativa à organização: em inovação, o lançamento de um produto por mais de uma empresa pode facilitar o desenvolvimento dos fornecedores para atenderem à nova demanda bem como reduzir o receio da aquisição por parte do cliente. Também, à medida que a organização seja capaz de trabalhar com agilidade superior à concorrência, ela garante o pioneirismo. Ou seja, o tempo gera ainda maior vantagem 
competitiva à organização quando a concorrência conhece a proposta de valor do novo produto, mas ainda assim não seja capaz de lançar o produto antes. Pontua-se aqui a estratégia de algumas empresas de seguir rapidamente as inovações da concorrência (muitas vezes denominada como a estratégia de fast follower) - estratégia na qual a agilidade de lançamento é o ativo de mais valioso.

Outra proposta para reduzir as barreiras de adoção do novo produto por parte do cliente amplamente utilizada para produtos de informação - é permitir um período de teste (ou 'degustação') gratuito - sendo os produtos freemium cada vez mais comuns para diversos produtos de informação. Desse modo, o cliente reconhecerá os benefícios do produto antes de tomar a decisão de investimento, reduzindo o risco da aquisição e aumentando a rapidez de adoção (uma vez que elimina as etapas de compra e aprovação de orçamento). Em produtos de informação - cujo custo marginal de produção é baixo -, essa solução tende a ser particularmente adequada.

Posto que os fatores do ambiente externo estão fora do controle da organização, a recomendação é conceder autonomia à equipe responsável pelo novo produto e descentralizar a tomada de decisão para agilizar a reação a tais fatores.

Uma última sugestão para lidar com os desafios relacionados ao risco é incentivar as parcerias e a inovação aberta. Ambas permitem compartilhar o investimento e o risco do desenvolvimento e lançamento do produto, bem como alavancar os ativos de outras organizações sem que seja necessário desenvolver todas as capacidades internamente. Quando cada organização pode trabalhar com suas competências centrais de modo colaborativo, a tendência é de aumento de eficiência e qualidade do resultado em comparação com o desenvolvimento totalmente interno. É imprescindível, porém, formar alianças com empresas diversas para evitar excessiva dependência de um único parceiro.

Quadro 13 - Recomendações relacionadas à unidade de análise de desafios

Recomendações

- Não lançar o produto antes de validar o interesse do mercado (pois a agilidade inicial poderá incorrer em atrasos futuros devido a retrabalho).

- Priorizar tempo na adaptação às mudanças macroambientais, com equipes autônomas e processos flexíveis.

- Propor pilotos de baixo custo para reduzir o custo de troca para o cliente (incentivar a experimentação).

- Criar oportunidades de inovação aberta, para não depender apenas do crescimento orgânico. 


\subsubsection{Ecossistema}

Os entrevistados envolvidos com aceleradoras citaram consistentemente o ecossistema de inovação, a colaboração e as parcerias como os principais destaques do programa de aceleração. Verificou-se a existência de um ecossistema composto por instituições desempenhando papéis complementares nos quais estão inseridas startups e aceleradoras. Por outro lado, as corporações muitas vezes estão fora desse ecossistema - eventualmente com alguma participação pontual de algum departamento. Foi verificado que muitas vezes há problemas de comunicação até mesmo internos à organização - decorrentes principalmente da quantidade das iniciativas abertas.

Quadro 14 - Evidências e descobertas relacionadas à unidade de análise de ecossistema

\begin{tabular}{|c|c|}
\hline Evidências & Descobertas \\
\hline 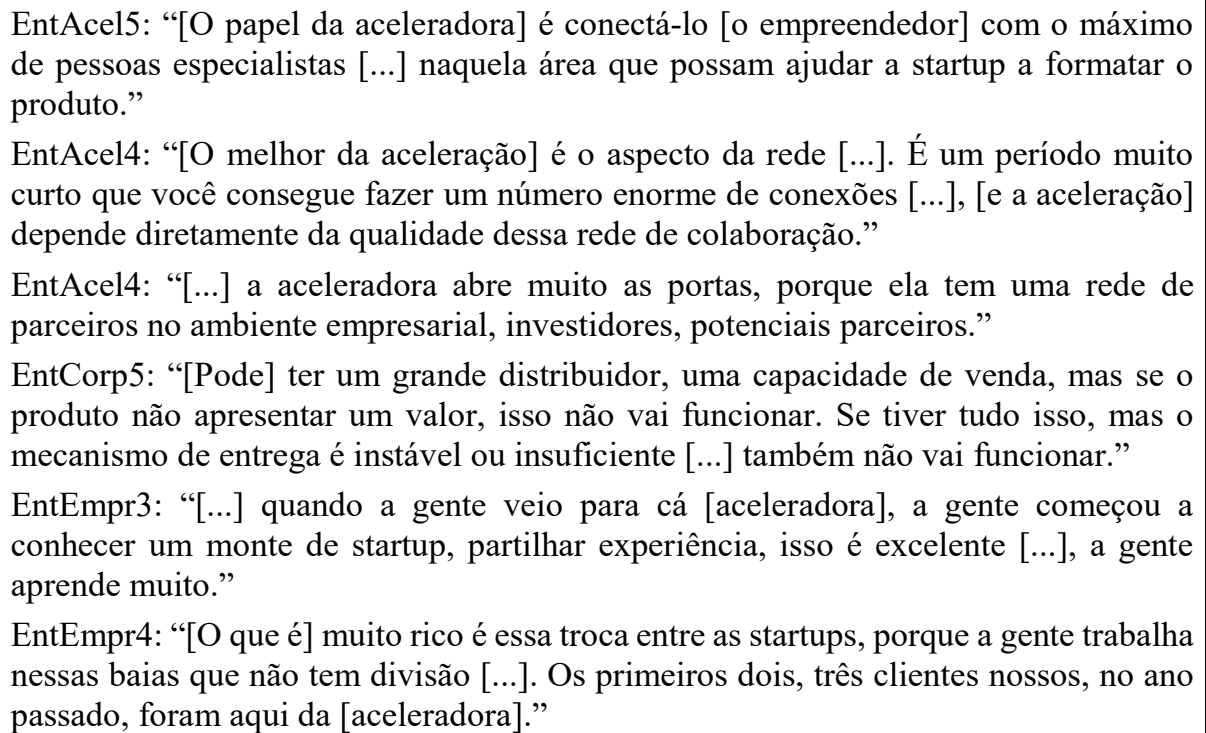 & $\begin{array}{l}\text { - Parceiros aportam } \\
\text { novas competências e } \\
\text { alavancam o } \\
\text { aprendizado. } \\
\text { - É difícil para a } \\
\text { empresa possuir (ou } \\
\text { desenvolver) todas as } \\
\text { competências } \\
\text { internamente e ser } \\
\text { eficiente neste processo. } \\
\text { - Colaboração e } \\
\text { integração ao longo da } \\
\text { cadeia são primordiais. } \\
\text { - Comunicação inter- } \\
\text { departamental e troca de } \\
\text { experiências são } \\
\text { valiosos. }\end{array}$ \\
\hline
\end{tabular}

Às corporações, sugere-se alavancar a inovação com base em ativos de outras empresas, para que não dependam unicamente de seu crescimento orgânico. Além disso, é imprescindível o incentivo à integração dos diversos elos da cadeia de valor, sejam eles as próprias áreas internas, fornecedores, colaboradores ou clientes, para garantir a entrega bem-sucedida. 
A coordenação de eventos abertos tanto aos funcionários como ao público externo - comuns a aceleradoras e universidades - é recomendada como modo de incentivar a troca de experiências. Eventos corporativos internos também são recomendados para estimular a comunicação interdepartamental e fomentar sinergias, uma vez que diferentes áreas organizacionais frequentemente trabalham de modo independente - ainda que reúnam um amplo conhecimento, quando se somam competências e experiências de centenas de colaboradores. O maior ganho em agilidade obtido com esses eventos é o aprendizado por pares e casos de sucesso (benchmarks).

A principal oportunidade relacionada à agilidade em relação ao ecossistema é alavancar os ativos de parceiros com experiência em determinadas atividades para serem utilizados pelo novo produto. Uma vez que outras empresas já trabalham com componentes ou matérias-primas que serão utilizadas pelo novo produto, há um forte ganho em eficiência. Embora haja percepção de risco associado a trabalhar com parceiros externos, aconselha-se utilizar contratos de exclusividade e confidencialidade quando factíveis, bem como gerenciar de modo integrado todos os elos da cadeia de valor, uma vez que essa gestão integrada também apresenta potencial de ser transformada em uma vantagem competitiva.

Quadro 15 - Recomendações relacionadas à unidade de análise de ecossistema

Recomendações
- Criar eventos abertos com foco em troca de experiência (público interno e externo).
- Criar parcerias, ofertas conjuntas e planejar a integração de toda a cadeia de valor, e não apenas elos separados.
- Incentivar o envolvimento dos colaboradores com a inovação.
- Estimular a integração de funcionários de diversas áreas em atividades ou eventos interdepartamentais.

\subsection{Pessoas}

As principais recomendações relacionadas ao componente de Pessoas são associadas à formação de equipes eficazes compostas por profissionais de perfis complementares. 


\subsubsection{Estrutura de pessoas}

A estrutura de pessoas se refere à perspectiva coletiva das pessoas na organização como um todo e em sua cultura.

\subsubsection{Estrutura organizacional}

A estrutura organizacional reflete a maneira como a organização é composta. Tal estrutura é estratégica à medida que facilita, fortalece ou dificulta a comunicação interna, o que também impacta diretamente o tempo para execução das atividades organizacionais. Visto que todas as áreas de negócios dependem de áreas de apoio, a interação entre elas é crucial para o sucesso dos produtos.

Foi verificado no referencial teórico e relato da experiência que equipes que trabalhavam com mais de um tipo de atividade tendiam a priorizar objetivos de curto prazo e escopo fechado em relação aos de longo prazo e escopo ambíguo. Também foi vista a competição pelos recursos internos à organização - sejam estes as áreas de suporte especializado, investimentos, entre outros. Alguns entrevistados apontaram a importância de separar a equipe de Inovação das demais equipes para evitar que as tarefas rotineiras dificultem o desenvolvimento da inovação.

No referencial teórico e nas entrevistas, mencionam-se equipes de cerca de quatro pessoas como preferenciais no início do projeto de uma startup - número que cresce com a evolução da empresa. No entanto, equipes enxutas exigem que os integrantes atuem em variadas funções inclusive aquelas em que não são especialistas e com atividades não previstas no momento da concepção do produto - e precisam ser ágeis para adquirir essas novas competências. Apesar de empresas maiores possuírem mais colaboradores, a constante evolução tecnológica pode exigir perfis especializados que também não estejam disponíveis na equipe. Instituições de grande porte tendem a enfrentar também desafios de comunicação e integração. 
Verificou-se ainda que a estrutura de equipes enxutas favorece a autonomia e reduz a burocracia. A principal desvantagem da autonomia aparece como o risco - que deixa de ser controlado centralmente. O risco - que já foi citado em outras unidades de análise - é com frequência visto como inerente ao processo de inovação, de modo que as grandes empresas deveriam aceitá-lo do mesmo modo como as startups o fazem. Embora o receio excessivo possa impedir a evolução da corporação, é evidente que a diferença da proporção de possíveis perdas entre startups entrando no mercado e grandes instituições com anos de experiência. A postura mais conservadora dessas corporações na comparação com empresas nascentes certamente decorre dessa constatação.

Devido à necessidade de aprendizado constante, as aceleradoras valorizam mentorias, treinamentos especializados, o aprendizado prático ('learn by doing’) e a comunicação fluida entre os pares.

Quadro 16 - Evidências e descobertas relacionadas à unidade de análise de estrutura organizacional

\begin{tabular}{|c|c|}
\hline Evidências & Descobertas \\
\hline $\begin{array}{l}\text { EntEmpr1: "[...] a equipe que você planejou no começo vai ser alterada também }[\ldots] ; \\
\text { a empresa tem que estar configurada para aceitar isso." } \\
\text { EntAcel4: "[...] se a área de inovação da grande empresa tivesse que seguir as mesmas } \\
\text { regras das outras áreas da grande empresa, ela não precisava existir." } \\
\text { EntAcel3: "[...] você cria uma equipe de } 25 \text { pessoas e depois, chega a } 50[\ldots] \text {; no } \\
\text { começo é muito operacional [...], e como eles fazem o operacional muito bem, às } \\
\text { vezes eles nunca conseguem sair do operacional para o estratégico". } \\
\text { EntCorp4: "Virar um barquinho de dois metros é fácil, agora virar um transatlântico } \\
\text { é muito mais difícil." }\end{array}$ & $\begin{array}{l}\text { - Estruturas rígidas } \\
\text { dificultam mudanças. } \\
\text { - A flexibilidade na } \\
\text { estrutura é fundamental } \\
\text { e precisa ser planejada } \\
\text { para ser efetiva. }\end{array}$ \\
\hline $\begin{array}{l}\text { EntAcel4: "[Em] sua estrutura de RH, incentivo, a empresa é toda feita para entregar } \\
\text { o que ela tem que entregar [...]; quem está comprometido com o processo de inovação } \\
\text { precisa estar comprometido com esse longo prazo." } \\
\text { EntAcel4: "[As metas para os executivos] são metas de curto prazo; qualquer coisa } \\
\text { que não vai ajudá-lo a bater a meta dele é secundário. E a inovação não vai resolver } \\
\text { nada a curto prazo." } \\
\text { EntEmpr6: "[...] aquele product owner lá, ele não é nem product nem owner. Porque } \\
\text { ele não está trabalhando em produto, ele está trabalhando em projeto, e não tem } \\
\text { ownership para tomar decisão." }\end{array}$ & $\begin{array}{l}\text { - Objetivos de curto } \\
\text { prazo e escopo fechado } \\
\text { tendem a ser priorizados } \\
\text { em relação aos de longo } \\
\text { prazo com escopo aberto } \\
\text { (como a inovação). } \\
\text { - A inovação por vezes } \\
\text { está ausente na estrutura } \\
\text { de incentivos das } \\
\text { corporações. }\end{array}$ \\
\hline
\end{tabular}


\begin{tabular}{|l|l|}
\hline $\begin{array}{l}\text { EntCorp2: “[...] essa cultura [da startup enxuta] precisa ser do topo para a base [...]; é } \\
\text { difícil vender esse conceito para líderes seniores que nunca trabalharam com isso2.”" }\end{array}$ & $\begin{array}{l}\text { - A liderança exerce } \\
\text { EntAcel4: “[São necessários] comprometimento da alta direção [...], processos } \\
\text { forte influência na } \\
\text { específicos [...] - mais flexíveis que os processos tradicionais - e um entendimento de tarefas. } \\
\text { dos gestores e da equipe de que é preciso dedicar um pouco de tempo para isso.” }\end{array}$ \\
\hline $\begin{array}{l}\text { EntAcel3: "[São necessários] estruturação legal, a parte contábil, a parte de vendas, } \\
\text { tem que estruturar um time, começa a vender.” }\end{array}$ & $\begin{array}{l}\text { - Diversas atividades de } \\
\text { apoio são necessárias } \\
\text { para lançar um produto. }\end{array}$ \\
\hline
\end{tabular}

A primeira recomendação à estrutura de pessoas para o lançamento de produtos é separar as equipes de produtos novos e tradicionais, visto que elas lidam com diferentes objetivos e atividades. A separação não deve estar presente apenas para a equipe direta, mas também para as áreas de suporte. Essa sugestão se deve ao fato de que os desafios relacionados à inovação são frequentemente distintos daqueles dos produtos atuais. Por exemplo, as inovações em geral demandam tarefas estratégicas e de longo prazo - relacionadas a definição das características do produto, contabilização de receitas, regulamentação e outros assuntos associados à concepção do produto. Os demais produtos do portfólio já passaram por essas decisões (apesar de estarem sujeitos a mudanças), e frequentemente demandam apoio no atendimento ao cliente, campanhas de comunicação, entre outros - tarefas ainda pouco aplicáveis entre novos produtos. Essa especialização em inovação das áreas de suporte também gera eficiência e reduz problemas de competição por recursos baseadas apenas com base na performance atual do produto.

Devido à instabilidade e à constante necessidade de mudanças, a flexibilidade deve ser priorizada. A despeito da flexibilidade ser mencionada como oposta à eficiência por alguns entrevistados, entende-se que equipes mais flexíveis e autônomas, por exemplo, permitem reduzir camadas hierárquicas de aprovação e portanto impactam positivamente na eficiência. Ademais, é imprescindível que os novos produtos estejam presentes na estrutura de incentivos e bonificação das equipes para que sejam priorizados. Embora os resultados financeiros do novo produto venham a médio prazo, deve-se utilizar indicadores de curto prazo que meçam a sua evolução. As recomendações de indicadores serão detalhadas no tópico de Métricas.

\footnotetext{
2 “"...] a culture of lean startup has to come top-down [...]; it is very difficult to sell this concept to senior leaders
} who have never worked with that before." 
A flexibilidade - já recomendada na solução de outros problemas relacionados à agilidade também deve estar presente na composição dos times. Ao longo do ciclo de vida do produto, as atividades a serem executadas se alteram substancialmente. É adequado incentivar o job rotation e o trabalho por projetos em detrimento de funções fixas - de modo a estimular a comunicação interdepartamental, favorecer o desenvolvimento e o aprendizado dos colaboradores e permitir que cada especialista aporte conhecimento em diversos projetos (não apenas na área em que estão alocados). Essa estrutura sugerida é similar àquela de consultorias de estratégia. A despeito da complexidade de implantação dessa recomendação no curto prazo, destaca-se sua centralidade na eficiência organizacional.

Quadro 17 - Recomendações relacionadas à unidade de análise de estrutura organizacional

Recomendações

- Alocar recursos de infraestrutura específicos a cada novo produto, para evitar a necessidade de aprovações em cada fase do processo.

- Permitir estrutura que aceite facilmente mudanças internas à equipe (job rotation).

- Criar incentivos à inovação no curto prazo, ainda que resultados sejam no médio-longo prazo.

- Estabelecer indicadores intermediários da inovação (como satisfação dos clientes).

\subsubsection{Cultura}

Os principais aspectos culturais levantados se relacionam à cultura empreendedora. Ressaltamse a experimentação, a aceitação do risco e todos os fatores que decorrem dessa cultura. A responsabilidade e a tomada de decisão em todos os níveis hierárquicos estão presentes novamente sob a perspectiva da cultura do empoderamento.

Ademais, cabe ressaltar o papel central da própria organização em criar e estimular uma cultura alinhada a seus princípios e valores. Ou seja, esse é um aspecto que a própria organização é capaz de intervir diretamente, e que direciona as ações de todos os colaboradores. Nota-se, porém, a maior complexidade de mudança de cultura em uma empresa de grande porte quando comparada à complexidade de criar uma nova cultura em uma empresa nascente. $\mathrm{O}$ incentivo à cultura também deve ser refletido em metas. 
Quadro 18 - Evidências e descobertas relacionadas à unidade de análise de cultura

\begin{tabular}{|c|c|}
\hline Evidências & Descobertas \\
\hline $\begin{array}{l}\text { EntCorp2: "Acho que o RH [...] tem um papel fundamental em cultura. E se eles são } \\
\text { capazes de multiplicar uma boa cultura em toda a companhia [...] fazem com que os } \\
\text { colaboradores queiram ser melhores." } \\
\text { EntEmpr6: "É uma cultura de empoderar os times e criar uma governança para esse } \\
\text { empoderamento ser possível." } \\
\text { EntCorp2: "[...] criar uma cultura em que os funcionários saibam que têm tempo para } \\
\text { atualizar-se utilizando conhecimento online é muito importante." }\end{array}$ & $\begin{array}{l}\text { - A cultura é } \\
\text { estabelecida pela } \\
\text { própria instituição. } \\
\text { - Autonomia } \\
\text { (“empoderamento"), } \\
\text { colaboração e } \\
\text { motivação são centrais. }\end{array}$ \\
\hline $\begin{array}{l}\text { EntEmpr3: "[...] se você cresce muito rápido, também mais do que você tem capacidade } \\
\text { de absorver cultura, você acaba perdendo a sua cultura e isso é péssimo para a empresa." } \\
\text { EntEmpr6: "[...] quando a gente cria o modelo das garagens, das startups internas, o que } \\
\text { a gente está fazendo é o tal change management, é a gestão da mudança cultural dentro } \\
\text { da empresa." } \\
\text { EntCorp5: "Em inovação, falhar em alguns componentes e não levar ao sucesso } \\
\text { imediato não é obrigatoriamente uma coisa má sempre quando esses ensinamentos, } \\
\text { esses conteúdos, possam ser realimentados na cadeia." } \\
\text { EntAcel2: "[...] você precisa de uma mente muito aberta ao novo." }\end{array}$ & $\begin{array}{l}\text { - A cultura é parte } \\
\text { central da inovação. } \\
\text { - A mentalidade de } \\
\text { experimentação e } \\
\text { aceitar falhas é } \\
\text { fundamental à inovação. }\end{array}$ \\
\hline
\end{tabular}

A principal recomendação para a unidade de análise de cultura é posicioná-la como estratégica na organização. Em uma instituição estabelecida que já possua uma cultura forte, o planejamento da cultura deve identificar o que precisa ser alterado, o que precisa ser mantido e as ações necessárias à sua implantação. A cultura pode ser promovida por diversas ações, sendo crucial o seu reforço e exemplo pelos gestores de equipes - inclusive sob a forma de políticas de remuneração variável e promoção de cargos.

A agilidade aparece de maneira clara na cultura empreendedora - que por vezes utiliza os próprios métodos da metodologia Ágil. Aconselha-se, assim, valorizar as características da cultura empreendedora que promovem agilidade e eficiência, a ressaltar: autonomia das equipes, mentalidade de experimentação, aceitação da falha, colaboração entre pares, incentivo

\footnotetext{
3 "I think HR has a massive role to play there [in accelerated learning]. I think too often people think HR role is very administrative, but they have a massive cultural role. And if they are able to spread a good culture around the company, with a variety of measures, that allows us to speed up learning and to make employees more curious, make employees want to be better."
}

\footnotetext{
4 "[...] creating a culture where employees know they have time to update themselves in that way using online
} knowledge is really really important." 
ao aprendizado constante e contínua mensuração do ciclo de desenvolvimento. A mentoria que será detalhada no tópico de Gestão - também deve ser estimulada.

Quadro 19 - Recomendações relacionadas à unidade de análise de cultura

Recomendações

- Planejar a cultura como parte da estratégia corporativa.

- Incentivar a cultura empreendedora (experimentação, autonomia, aceitação de risco, colaboração, aprendizado, mensuração da evolução e mentoria).

- Planejar incentivos ao alinhamento com a cultura (metas, remuneração variável).

\subsubsection{Equipe}

O tópico de equipe aborda a questão de Pessoas sob a perspectiva dos times e dos indivíduos responsáveis pela inovação. Isto é, complementando a estrutura e a cultura organizacionais, esse tópico aborda motivações, capacidades e características para a inovação.

\subsubsection{Gestão e composição das equipes}

As equipes de inovação são as pessoas efetivamente responsáveis pelo lançamento do novo produto. A diversidade das atividades a serem executadas e o difícil planejamento destas atividades inicialmente requerem equipes multidisciplinares capazes de aprenderem rapidamente trabalhando de modo colaborativo para alcançar o objetivo proposto.

As aceleradoras também destacam a centralidade do perfil do empreendedor para o sucesso do empreendimento. Essa descoberta é interessante uma vez que as aceleradoras treinam, ensinam e apoiam os empreendedores. Porém, a atitude desses empreendedores é vista como determinante, sendo a seleção das equipes pelas aceleradoras vista por alguns especialistas até como mais importante que o produto desenvolvido. O processo de seleção de startups em aceleradoras é apresentado como similar ao funil de inovação em grandes empresas por um dos 
entrevistados à medida que as características da equipe e do mercado são avaliadas e comparadas sob diversas perspectivas comerciais e operacionais.

A motivação, o interesse em explorar ideias novas e a capacidade de aprender continuamente são imprescindíveis em todos os integrantes da equipe. Destaca-se a necessidade de aprendizado constante, principalmente de modo informal (isto é, durante as atividades rotineiras e não só por meio de cursos ou treinamentos).

Outros comportamentos citados como cruciais foram a tolerância de trabalhar com a ambiguidade, a mentalidade de adaptação e a capacidade de criar melhorias a partir do feedback dos clientes. Alguns entrevistados relataram a necessidade de adequar continuamente o planejamento às mudanças do mercado - exigindo uma equipe flexível e aberta.

Quadro 20 - Evidências e descobertas relacionadas à unidade de análise de gestão e composição de equipe

\begin{tabular}{|c|c|}
\hline Evidências & Descobertas \\
\hline $\begin{array}{l}\text { EntCorp2: "[...] a diversidade é muito, muito importante para a inovação. Acho que } \\
\text { a maioria das empresas de tecnologia mais bem-sucedidas hoje são as que possuem } \\
\text { as equipes mais internacionais." } \\
\text { EntEmpr3: “A gente precisa de gente diferente da gente e a gente tem uma tendência } \\
\text { a buscar pessoas mais parecidas. [...] tem conflito no dia-a-dia, na tomada de decisão } \\
\text { porque às vezes surgem ideias totalmente diferentes, mas é importante." } \\
\text { EntAcel5: "As startups são times muito enxutos com recursos bastante limitados, o } \\
\text { que faz com que cada pessoa desse time seja muito importante e que tenha que } \\
\text { desempenhar muitas funções diferentes." } \\
\text { EntEmpr6: "[...] times multidisciplinares trabalhando numa cultura mais de } \\
\text { resultado, mais de métricas de sucesso, de colaboração." } \\
\text { EntCorp2: "[...] ter trabalhado em diferentes empresas, estado em diferentes } \\
\text { mercados, entender como os produtos são aceitos ou rejeitados em diferentes locais } \\
\text { realmente ajuda a acelerar a inovação." }\end{array}$ & $\begin{array}{l}\text { - Equipes diversificadas } \\
\text { agregam valor à inovação. } \\
\text { - O aprendizado é } \\
\text { essencial às equipes ao } \\
\text { longo de todo o processo } \\
\text { da entrada de um novo } \\
\text { produto no mercado. }\end{array}$ \\
\hline $\begin{array}{l}\text { EntAcel5: "[O que a aceleradora] não consegue fazer é fazer pelo empreendedor." } \\
\text { EntEmpr3: “[A] startup tem que ser muito mais proativa porque o programa não vai } \\
\text { ficar punindo." }\end{array}$ & $\begin{array}{l}\text { - Apesar das técnicas de } \\
\text { gestão da inovação, a } \\
\text { equipe é tão importante }\end{array}$ \\
\hline
\end{tabular}

5 "[...] diversity is really, really important for innovation. I think that the most successful tech companies at the moment have the most international workforces."

6 “[...] having worked in different companies, having been in different markets, understanding how products have been accepted or rejected in different countries really helps to speeds up innovations." 


\begin{tabular}{|c|c|}
\hline $\begin{array}{l}\text { EntEmpr3: "[...] no início é mão na massa. Não adianta você querer fazer só um tipo } \\
\text { de tarefa. Você tem que ser hands-on em tudo." }\end{array}$ & $\begin{array}{l}\text { quanto o produto para o } \\
\text { sucesso da inovação }\end{array}$ \\
\hline 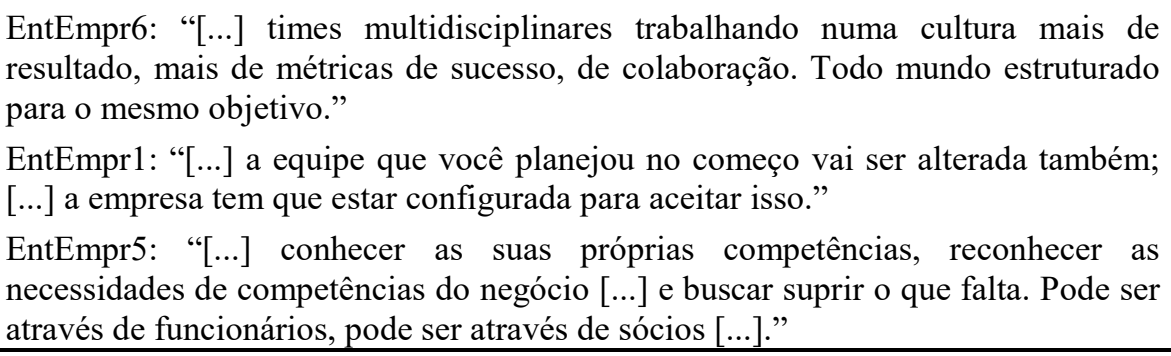 & $\begin{array}{l}\text { - A formação dos times } \\
\text { deve prever a } \\
\text { flexibilidade. } \\
\text { - Competências podem ser } \\
\text { adquiridas na composição } \\
\text { da equipe ou por terceiros. }\end{array}$ \\
\hline $\begin{array}{l}\text { EntEmpr3: “[...] quando você está fazendo um negócio novo, o ciclo de aprendizado } \\
\text { é quase infinito. Você está sempre fazendo coisa nova." } \\
\text { EntAcel5: "[...] há funções em que o empreendedor vai ser especialista, mas em } \\
\text { várias outras ele não vai ser e estará fazendo aquilo pela primeira vez; então ele vai } \\
\text { ter que aprender muito nesse processo.” }\end{array}$ & $\begin{array}{l}\text { - O aprendizado é central } \\
\text { e precisa ser atualizado } \\
\text { constantemente na } \\
\text { inovação. }\end{array}$ \\
\hline $\begin{array}{l}\text { EntAcel2: “[...] você precisa de pessoas que são eager, que querem fazer, que estão } \\
\text { dispostas a explorar as coisas, que tenham essa mentalidade". } \\
\text { EntCorp5: "Disciplina, conhecimento de mercado, conhecimento do produto." }\end{array}$ & $\begin{array}{l}\text { - Motivação, curiosidade e } \\
\text { conhecimento dos } \\
\text { integrantes da equipe são } \\
\text { cruciais. }\end{array}$ \\
\hline
\end{tabular}

Recomenda-se principalmente às grandes empresas valorizar a diferença, facilitar as mudanças, e prezar pela capacidade de aprendizado dos integrantes da equipe. Essas recomendações atuam diretamente na agilidade do lançamento, posto que permitem mais rápida adaptação ao mercado.

É fundamental ao gestor da equipe definir as competências necessárias em cada fase do projeto, para que planeje como desenvolvê-las na equipe ou obtê-las externamente, por meio de contratações ou parcerias. Ressalta-se, entretanto, que a dificuldade de previsão está presente também nesse planejamento de competências da equipe. Por isso valorizam-se os perfis $T$ shaped. Esses profissionais são especialistas em um determinado assunto - em geral com um viés mais técnico - mas também são capazes de atuar em outras áreas complementares. Embora nas grandes organizações haja maior especialização de tarefas, aumenta-se a agilidade quanto mais capaz a equipe é de tomar as suas decisões e realizar suas atividades de modo autônomo. Apesar de ser indicado que as equipes trabalhem de maneira descentralizada, recomenda-se o mapeamento das competências dos indivíduos centralmente de modo que um mesmo profissional possa estar envolvido em projetos em diferentes departamentos 
Quadro 21 - Recomendações relacionadas à unidade de análise de gestão e composição de equipe

Recomendações

- Formar equipes multifuncionais e multiculturais, com alta capacidade de aprendizado e de adaptação.

- Planejar a equipe que melhor se adéque a cada momento do processo de inovação e configurá-la de modo que ela possa ser alterada ao longo do projeto.

- Criar oportunidades de job rotation e estruturas de projetos interfuncionais que utilizem as competências dos colaboradores em diferentes momentos.

- Valorizar profissionais T-shaped que sejam capazes de trabalhar em mais de uma função e aprender continuamente - devido à diversidade e dinamicidade de tarefas e conhecimentos necessários à inovação.

\subsubsection{Mentoria}

A mentoria não ocorre apenas em aceleradoras e em startups. Grandes empresas também possuem programas de mentoria e não apenas na área de Inovação. A descoberta da pesquisa foi a utilização constante da mentoria, em modelos variados (individuais, pequenos grupos, especializadas em assuntos técnicos ou generalistas), e a sua presença e centralidade em todos os programas de aceleração estudados. Houve menções no Referencial Teórico e nas entrevistas de que a mentoria é o fator mais relevante nos programas de aceleração.

A mentoria agiliza o lançamento de produtos à medida que permite que o responsável pelo lançamento possa aprender com profissionais que já passaram pelo mesmo desafio anteriormente e que poderão direcionar o profissional para os caminhos mais eficazes. $\mathrm{O}$ valor da mentoria aparece como a troca de experiências com profissionais que já passaram pela mesma experiência anteriormente ou especialistas na indústria. Embora as grandes empresas possuam equipes maiores e muitas vezes mais diversificadas que as pequenas, não é comum nestas instituições a abertura e a comunicação típicas da cultura empreendedora. As áreas de Comunicação Interna tendem a trabalhar em uma comunicação de um para muitos enfatizando as comunicações oficiais da empresa, ainda que algumas empresas de grande porte já tenham tomado consciência do valor da comunicação aberta e estejam buscando alterar essa situação, por exemplo criando redes sociais para a comunicação entre pares. 
Quadro 22 - Evidências e descobertas relacionadas à unidade de análise de mentoria

\begin{tabular}{|c|c|}
\hline Evidências & Descobertas \\
\hline $\begin{array}{l}\text { EntAcel5: "O processo de mentoria pode ser desde uma mentoria individual }[\ldots] \text { ou a } \\
\text { gente pode trazer muitos mentores }[\ldots] \text {, ou a gente pode fazer algumas mentorias } \\
\text { coletivas." }\end{array}$ & \multirow{5}{*}{$\begin{array}{l}\text { - O valor da mentoria é a } \\
\text { troca de experiências. } \\
\text { - A mentoria pode ser } \\
\text { formal ou informal, } \\
\text { individual ou em grupo, } \\
\text { com objetivos } \\
\text { específicos ou } \\
\text { generalistas. }\end{array}$} \\
\hline $\begin{array}{l}\text { EntAcel3: "[A aceleradora] traz um pessoal de mercado, a gente desembolsa um } \\
\text { budget a mais para as empresas terem esses mentores one-to-one que não são } \\
\text { simplesmente palestras, empreendedores famosos, etc., mas sim um programa } \\
\text { estruturado." }\end{array}$ & \\
\hline $\begin{array}{l}\text { EntCorp2: "A mentoria nas companhias é muito importante. Tradicionalmente, as } \\
\text { pessoas pensam em mentoria como vinda de alguém mais experiente a alguém menos } \\
\text { experiente, mas é possível fazer o reverso. [...] entender as dificuldades [do outro } \\
\text { lado]"7. }\end{array}$ & \\
\hline $\begin{array}{l}\text { EntAcel1: "Entre eles [empreendedores acelerados], como eles estão aqui nesse } \\
\text { espaço, eles se ajudam o tempo inteiro, aprendem até com o erro um do outro". }\end{array}$ & \\
\hline $\begin{array}{l}\text { EntEmpr4: "[...] mentores que podem dar um conselho, mas quem toma a decisão é } \\
\text { você." }\end{array}$ & \\
\hline
\end{tabular}

A recomendação nesse tópico é favorecer a troca de experiência entre diferentes áreas da organização e campos de conhecimento. Estas atividades de troca podem ser inicialmente estruturadas pelas áreas de Recursos Humanos a partir de programas formais; no entanto, notase que a mentoria ocorre também de modo informal e possivelmente haja maior engajamento quando os mentores são automotivados em participar desses projetos. Para incentivar as primeiras mentorias, os programas formalmente estruturados poderão facilitar o envolvimento dos colaboradores. Uma vez que elas passem a ser parte da cultura da empresa, porém, a necessidade de formalização tende a decrescer, mas permanece a indicação de apoiá-los.

Assim como visto no modelo de aceleradoras, a mentoria deverá ocorrer não apenas de maneira unidirecional, mas também sob a forma de conversa entre pares, especialistas em diferentes funções e assim sucessivamente. É evidente que mais do que o programa de mentoria em si, o

7 "Mentoring within companies, I think it is really really important. Traditionally people think of mentoring relationships to be from someone more experienced to someone less experienced, but you can do reverse mentoring. [...] Mentoring relationships can make them understand a lot about the difficulties [of the team]". 
que deve ser valorizada é a comunicação interdepartamental e a reflexão crítica acerca dos temas de conversa sob perspectivas diferentes e complementares.

Quadro 23 - Recomendações relacionadas à unidade de análise de mentoria

Recomendações

- Incentivar a mentoria entre pares.

- Favorecer a comunicação interdepartamental.

- Encorajar a mentoria, embora não necessariamente de modo estruturado.

\subsection{Gestão}

O terceiro componente de análise é a Gestão. Esse elemento é compreendido como o modelo de atuação do negócio. Após entendido o ecossistema da inovação e definidas as equipes para trabalhar com o novo produto, é necessário estabelecer os modelos de integração dos componentes do negócio, identificar as técnicas de gestão de ideias e criar programas internos de incentivo à inovação. Ressalta-se que no capítulo de Análise de Dados havia uma unidade de análise explorando os programas de aceleração. Essa unidade não estará presente neste capítulo pelo fato de que se refere exclusivamente às aceleradoras. No entanto, diversos dos tópicos tratados neste âmbito aparecerão como recomendação nas unidades de análise de Métodos e Métricas.

\subsubsection{Métodos de gestão de novos produtos}

O componente de métodos foi apresentado primeiramente com os métodos gerais e depois com o modelo da startup enxuta no capítulo de Análise de Dados. Neste capítulo de Recomendações, no entanto, eles serão apresentados na ordem inversa, uma vez que a ordem seguia as perguntas dos entrevistados no capítulo anterior e que seguirá as recomendações prioritárias neste 
capítulo. Isto é, entende-se que o modelo de startup enxuta deve ser a base do modo de gestão de novos produtos e que outros métodos poderão complementá-la.

\subsubsection{Modelos para aceleração de projetos e inovação}

O papel das aceleradoras sobressai como o suporte metodológico aos processos de inovação e uma perspectiva externa menos enviesada e mais objetiva relacionada ao produto. Além disso, elas são compostas por times com experiência em empreendedorismo e em diversas áreas de atuação que aportam expertise às startups. Para auxiliar os empreendedores ao longo do desenvolvimento comercial dos novos produtos, são utilizados diversos métodos e benchmarks.

Dentre os métodos mencionados pelos entrevistados, gestores de aceleradoras afirmam utilizar uma combinação de diversas referências - sejam elas conceitos, técnicas, obras literárias ou exemplos de outras empresas. Mais importante do que o tipo da referência é a sua adequação ao problema da startup. Compreendido o fato de que cada técnica é adequada a cada problema, as aceleradoras auxiliam as startups ao unificar as diversas referências em modelos que são aplicados de forma customizada durante o processo de aceleração. Portanto, as aceleradoras oferecem um módulo relevante de educação, não só no formato de palestras e mentorias de terceiros, mas também sob a forma de know-how interno e referências específicas.

Uma linha apontada por alguns entrevistados que inicialmente parece contraditória a essa perspectiva é a de não usar metodologias formais. Contudo, é importante esclarecer que esses entrevistados acreditam que o problema da metodologia é simplificar excessivamente as atividades necessárias à empresa, como se bastasse seguir alguns passos pré-estabelecidos por determinada metodologia para resolver todos os problemas do produto.

Quadro 24 - Evidências e descobertas relacionadas à unidade de análise de outros métodos

\begin{tabular}{|l|l|}
\hline Evidências & Descobertas \\
\hline $\begin{array}{l}\text { EntAcel4: “[...] que mercado é esse, como é esse mercado, quais são as personas } \\
\text { envolvidas, quais são as dores, quais os processos, ferramentas de design thinking, } \\
\text { pesquisa etnográfica, trabalho de campo.” } \\
\text { EntAcel3: “[...] tenta um pouquinho de cada coisa, na verdade.” }\end{array}$ & $\begin{array}{l}\text { usemcias são } \\
\text { empreendedores e } \\
\text { aceleradoras no processo de } \\
\text { inovação. }\end{array}$ \\
\hline
\end{tabular}




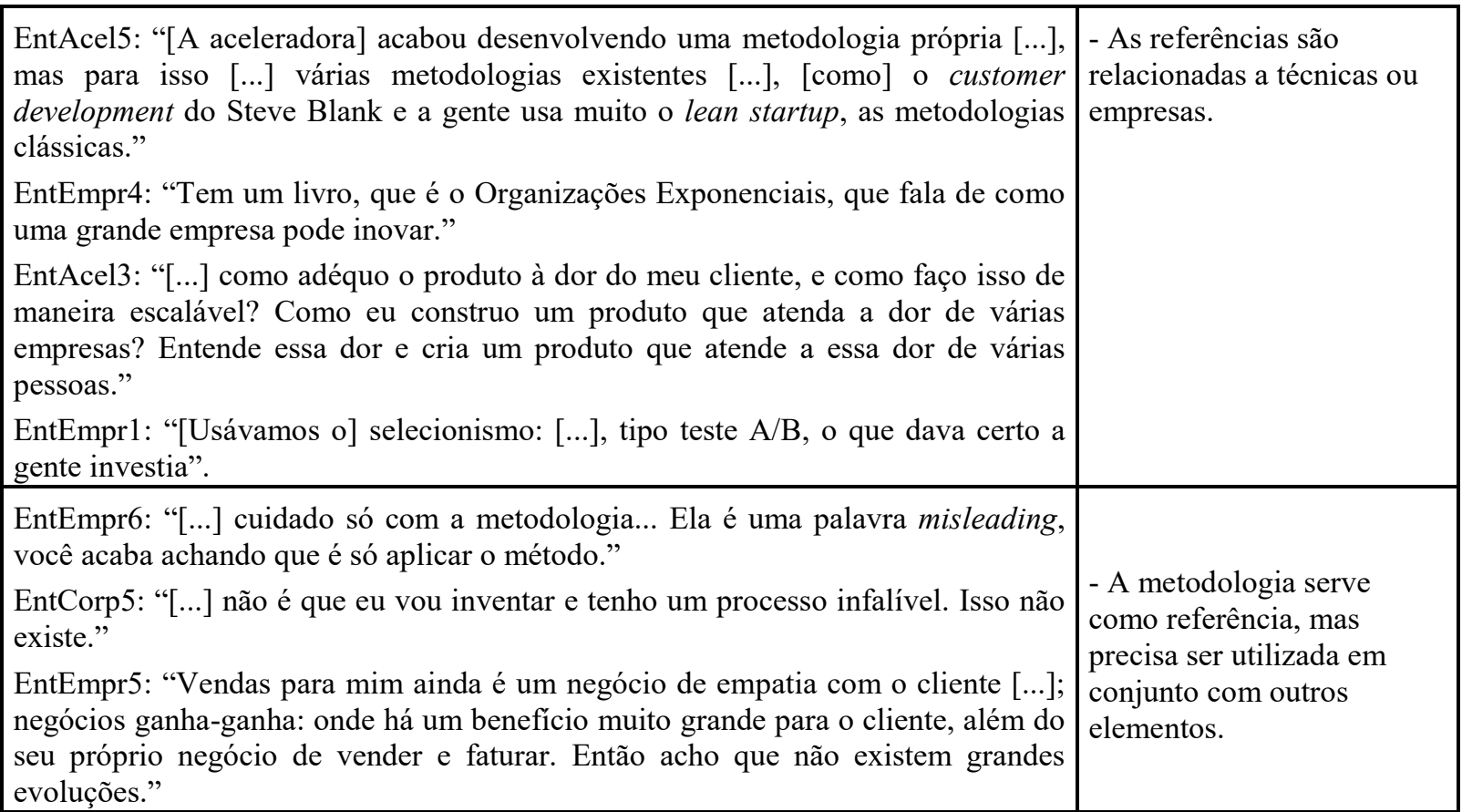

Compreende-se que o método sozinho é incapaz de resolver todos os problemas do lançamento de produtos. No entanto, o conhecimento da literatura existente e de referências anteriores são de grande valia aos profissionais. Desse modo, treinamentos formais para os colaboradores acerca das principais metodologias de lançamento utilizadas pelo mercado são recomendados a corporações, assim como uma base bibliográfica de cunho prático que possa direcionar os desafios que a empresa tenha futuramente.

Além de treinamentos, valoriza-se o aprendizado em si e a capacidade de tomar as decisões com base no que foi estudado. $\mathrm{O}$ entendimento de como criar produtos que tenham valor para o cliente, como planejar o modelo de negócios mais adequado a cada produto e assim sucessivamente.

A maior velocidade na entrada de produtos no mercado está associada a conhecer na literatura acadêmica e empírica a experiência de outros profissionais ou acadêmicos e o modo como eles lidaram com os problemas em circunstâncias semelhantes. Conforme afirmou um dos entrevistados de aceleradora, o aprendizado possibilita aos gestores de novos produtos saltar algumas etapas e reconhecer em quais referências se basear em cada momento. 
Quadro 25 - Recomendações relacionadas à unidade de análise de outros métodos

Recomendações

- Entender o problema do cliente deve ser o ponto de partida do lançamento, para evitar perda de recursos (tempo em si, pessoas, dinheiro) investidos em projetos que se mostrarão futuramente inadequados.

- Identificar as práticas do mercado para diferentes tipos de problemas que a organização possui, como modo de acelerar o aprendizado e de permitir agilidade na tomada de decisão após conhecer como outras instituições trataram problemas semelhantes anteriormente.

- Reconhecer que as metodologias são referências, mas precisam ser adequadas a cada momento.

\subsubsection{Startup enxuta}

A startup enxuta e suas técnicas foram trazidas de modo espontâneo por diversos entrevistados. Mais do que técnicas específicas, porém, nota-se que a mentalidade associada à metodologia é preponderante. A constante interação com o mercado e o ciclo de melhorias, bem como a utilização de indicadores e métricas, são trazidos por diversos entrevistados.

Quadro 26 - Evidências e descobertas relacionadas à unidade de análise de startup enxuta

\begin{tabular}{|c|c|}
\hline Evidências & Descobertas \\
\hline 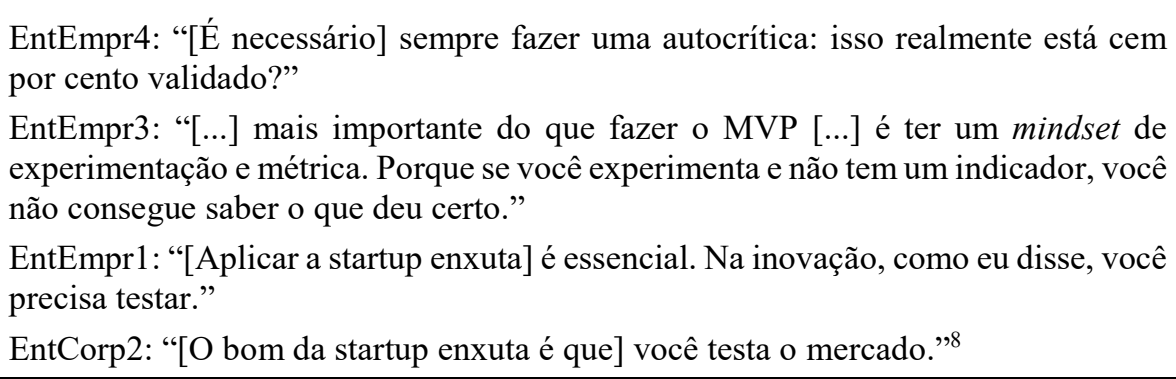 & $\begin{array}{l}\text { - A startup enxuta é vista } \\
\text { frequentemente como } \\
\text { uma mentalidade mais do } \\
\text { que técnicas específicas. } \\
\text { - Experimentação, } \\
\text { métricas e validações são } \\
\text { vistas como centrais na } \\
\text { metodologia da startup } \\
\text { enxuta. }\end{array}$ \\
\hline $\begin{array}{l}\text { EntEmpr4: "[A vantagem da startup enxuta é] esse mindset de testar, medir e } \\
\text { aprender." } \\
\text { EntCorp1: "[A vantagem da startup enxuta é] custo e de não fazer retrabalho, porque } \\
\text { muitas vezes você está investindo uma grande quantia de investimento, de dinheiro, } \\
\text { de tempo em um produto que você ainda nem colocou no mercado." }\end{array}$ & $\begin{array}{l}\text { - As vantagens da startup } \\
\text { enxuta são } \\
\text { frequentemente } \\
\text { relacionadas a validações } \\
\text { e redução de risco. }\end{array}$ \\
\hline
\end{tabular}

\footnotetext{
8 "The benefit [of lean startup and MVP] is that you test with the market"
} 


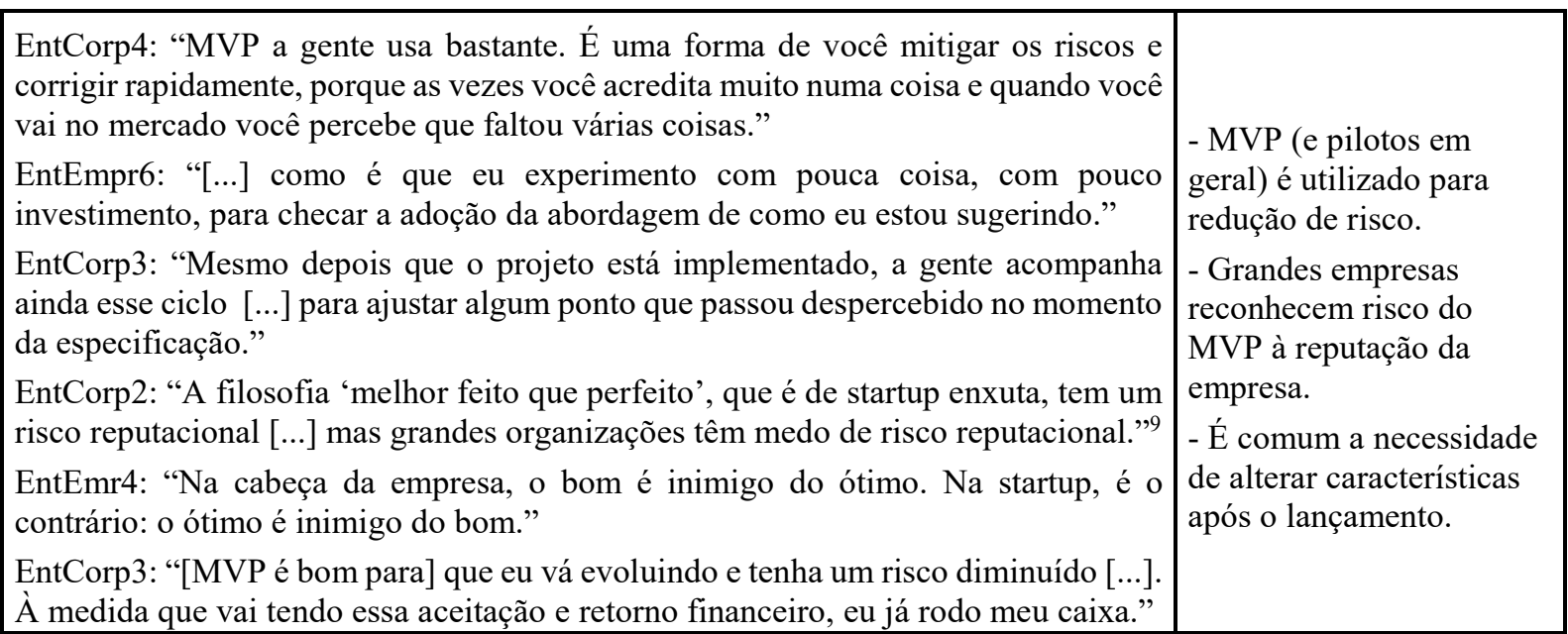

A principal recomendação da autora relacionada à startup enxuta é compreender o lançamento como uma atividade contínua. Enquanto grandes empresas frequentemente agendam datas específicas e eventos de lançamento, as startups estão em constante interação com o mercado desde os primeiros protótipos - e com constantes lançamentos de novas características do produto. As características adicionais ao produto inicial podem ser lançadas como testes disponíveis apenas para determinados clientes ou como testes $\mathrm{A} / \mathrm{B}$ para verificar o interesse na nova funcionalidade. A mentalidade de pequenos lançamentos agiliza e facilita a entrada no mercado, pois entende-se que haverá novas versões ou funcionalidades no curto prazo, que diversos ajustes poderão ser executados em pouco tempo e assim sucessivamente.

Para minimizar o risco à reputação, indica-se a utilização de produtos mínimos viáveis com públicos-alvo específicos mais interessados em inovações e com baixa aversão ao risco. Ao segmentar o mercado consumidor de acordo com o nível de aceitação de risco dos clientes, é possível interagir e testar as inovações com os clientes mais engajados na criação e evitar a insatisfação de clientes que desejam produtos já mais completos. Também há oportunidade de oferecer preços inferiores para os clientes que validarão o produto inicial, como incentivo.

\footnotetext{
9 "So, the philosophy of 'better done than perfect', which is lean startup, has a reputational risk [...], but big organizations fell very afraid of their reputation risk."
} 
Visto que produtos de informação em geral são mais flexíveis de serem alterados que produtos manufaturados, indica-se priorizar essa flexibilidade no lançamento, em termos de preços, promoções, versões do produto e funcionalidades disponíveis.

Seguir a metodologia da startup enxuta agiliza o lançamento de novos produtos à medida que o ciclo de retroalimentação e de experimentação acelera a validação de hipóteses - de modo a acelerar também o erro e o aprendizado. Quanto mais rapidamente a equipe é capaz de rodar o ciclo de construção, mensuração e aprendizado, mais rápido (e adequado) será o lançamento do produto.

Quadro 27 - Recomendações relacionadas à unidade de análise de startup enxuta

Recomendações

- Compreender o lançamento de um novo produto como um ciclo e não como um fim (isto é, uma data específica), enfatizando a melhoria contínua - de modo a agilizar a entrada do produto no mercado, ainda que haja lançamento de novas funcionalidades no futuro.

- Segmentar o público interessado em validar os testes iniciais e protótipos, compreendendo a partir de quando o MVP já possua valor comercial.

\subsubsection{Métricas}

As métricas podem ser entendidas como parte do ciclo de retroalimentação da startup enxuta (em que após a construção, deve-se medir a evolução). Entretanto, elas existem também em outros modelos e apresentam papel de destaque em diversos métodos e teorias associados à gestão de novos produtos. Por este motivo, são aqui apresentadas separadamente.

\subsubsection{Definição das métricas para novos produtos}

As métricas são cruciais no lançamento de um novo produto. Verificou-se a necessidade de utilizar indicadores para medir a evolução ao longo do projeto e de clareza em relação aos objetivos para o estabelecimento de metas. 
O indicador específico mais recorrente nas entrevistas para medir o sucesso de um novo produto aparece como a satisfação do cliente. Os entrevistados mencionam a utilização do produto, a frequência de uso e a existência de clientes pagantes para medir a satisfação.

Exemplos específicos de métricas não apenas relacionadas a vendas mas à viabilidade do produto a médio e longo prazo que podem ser utilizados em pequenas e grandes empresas são: o custo de aquisição dos clientes, a aceitação da solução (clientes reconhecem que ela soluciona o problema a que se propôs resolver), a fidelização (quantidade de clientes que continuam usando o produto ao longo do tempo e frequência de utilização) e o valor do cliente ao longo do seu ciclo de vida, bem como métricas tradicionais de receita, lucro e crescimento. As métricas apresentadas relacionam-se a diversas frentes de atuação e permitem a análise de indicadores cruzados, embora precisem ser adaptadas a cada situação e indústria.

Quadro 28 - Evidências e descobertas relacionadas à unidade de análise de métricas

\begin{tabular}{|c|c|}
\hline Evidências & Descobertas \\
\hline $\begin{array}{l}\text { EntAcel5: "[...] cada startup vai ter métricas muito específicas }[\ldots] \text {. O que eu acho } \\
\text { fundamental é que as startups sejam muito baseadas, muito orientadas a métricas." } \\
\text { EntEmpr4: "[...] se você não mede, você não aprende nada. E além de medir, você } \\
\text { ser questionador, fazer as perguntas certas, sempre se questionar [...]." } \\
\text { EntCorp5: "[...] falhar em determinada hipótese, em determinado experimento não } \\
\text { é uma coisa má contanto que ela seja rápida e pragmática nessa percepção." }\end{array}$ & $\begin{array}{l}\text { - A métrica é central ao } \\
\text { lançamento do produto. } \\
\text { - A métrica deve ser } \\
\text { utilizada para acompanhar } \\
\text { a evolução e validar } \\
\text { premissas. }\end{array}$ \\
\hline $\begin{array}{l}\text { EntAcel1: “[...] logo no começo acho que a métrica é muito mais subjetiva que } \\
\text { objetiva }[. . .] \text {, talvez a primeira métrica tenha que ser deixar a casa arrumada, o } \\
\text { primeiro acesso ao mercado, ter o primeiro cliente." } \\
\text { EntAcel3: "Na verdade, a gente usa metodologia de OKR com as startups. Essa é a } \\
\text { nossa única padronização para acompanhar a evolução da startup". }\end{array}$ & $\begin{array}{l}\text { - É imprescindível que as } \\
\text { métricas estejam } \\
\text { associadas a objetivos } \\
\text { específicos. }\end{array}$ \\
\hline $\begin{array}{l}\text { EntEmpr2: “[A satisfação] é quanto o produto atende da necessidade.” } \\
\text { EntEmpr1: "Você às vezes cria uma coisa que é interessante, mas que o cliente não } \\
\text { vê valor." } \\
\text { EntEmpr5: "[...] sempre importante entender a dor do cliente." } \\
\text { EntAcel3: “[...] o mais importante no começo e você saber se realmente as pessoas } \\
\text { estão usando seu produto de fato. O crescimento sustentável." } \\
\text { EntCorp3: "[...] um ponto em comum entre todos os produtos é entender se você } \\
\text { está solucionando e se as pessoas ali vendo valor onde você queria solucionar." } \\
\text { EntAcel2: "[A métrica deve ser] a necessidade do cliente. As empresas precisam } \\
\text { saber se alguém quer isso, precisa disso. Algumas empresas criam produtos porque } \\
\text { acham que eles fazem isso bem, mas algumas vezes eles esquecem de pensar no } \\
\text { cliente.” }\end{array}$ & $\begin{array}{l}\text { - Há concordância que a } \\
\text { principal métrica é } \\
\text { verificar se o cliente está } \\
\text { satisfeito com o produto. } \\
\end{array}$ \\
\hline $\begin{array}{l}\text { EntAcel4: "[...] em cinco semanas você consegue validar muita coisa, apesar de ser } \\
\text { pouco tempo, a gente tem metodologia bastante intensa e essa pressão acaba gerando } \\
\text { overperformance." }\end{array}$ & $\begin{array}{l}\text { - Métricas relacionadas ao } \\
\text { tempo incentivam a } \\
\text { agilidade e eficiência. }\end{array}$ \\
\hline
\end{tabular}




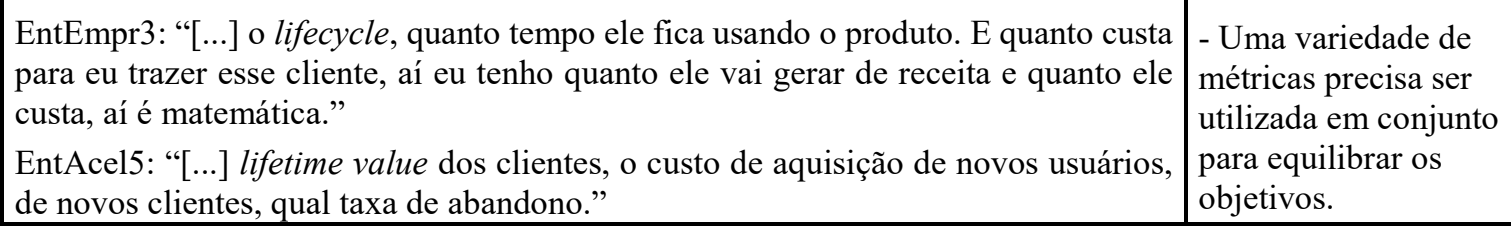

Aparece como fundamental a necessidade de as métricas serem objetivas - ainda que não necessariamente quantitativas - para que possam ser acompanhadas. Também são essenciais indicadores cruzados para monitorar o desempenho da organização como um todo, evitando excessiva atenção a alguns resultados e deixando de priorizar outros. Ademais, nota-se que as métricas no lançamento precisam ser diferentes daquelas dos demais produtos já existentes no portfólio, e adequadas a cada indústria e público-alvo.

Ressalta-se a necessidade não apenas de métricas, mas de esclarecer os objetivos associados a cada métrica, como mencionado no conceito de OKR trazido por um dos entrevistados e que evidencia o papel da métrica: medir a evolução do produto em relação ao objetivo ao qual se associa a medida. Também, uma vez que o objetivo dessa dissertação é acelerar o lançamento de produtos, indica-se a utilização de métricas associadas ao tempo de lançamento, além de prazos e cronogramas para as demais métricas.

Como uma das recomendações para quantificar a satisfação dos clientes, orienta-se identificar os segmentos principais de mercado e medir o potencial de produto em cada segmento. Entender quantos são os clientes potencialmente interessados na proposta de valor do produto, mapear o estágio da indústria (em crescimento, madura, etc.), bem como o orçamento direcionado a resolver os problemas do tipo que o novo produto se propõe a resolver. Desse modo, é possível quantificar o sucesso em cada segmento e a evolução - para então medir a satisfação dos clientes em cada um deles. Essa recomendação é particularmente adequada quando o produto apresenta inovação incremental, visto ser significativamente mais complexo quantificar o orçamento em mercados completamente novos.

Quadro 29 - Recomendações relacionadas à unidade de análise de métricas

Recomendações

- Usar métricas ao longo de todo o processo da inovação para avaliar o atingimento dos objetivos e o direcionamento correto, assim como identificar indicadores complementares.

- Identificar métricas que acompanhem a satisfação dos clientes.

- Criar métricas associadas ao tempo e também colocar prazos nas demais metas para valorizar a agilidade. 


\subsection{Resumo das Recomendações}

Inicia-se o resumo das recomendações com as descobertas relacionadas ao valor do tempo, verificadas na Análise de Dados. A centralidade do tempo na inovação é vista por perspectivas diversas, de modo que o tempo: define a inovação, precisa ser gerido de modo conjunto com demais recursos e objetivos do novo produto, possui valor comparado (sendo necessário entender o que priorizar na aceleração, frente à limitação de recursos), pode ser a única vantagem competitiva do produto em determinadas situações, é um recurso cuja utilização influencia diretamente a eficiência do projeto, possui valor no investimento a longo prazo mesmo quando a agilidade é preconizada e é inerente a todas as decisões corporativas.

Essas descobertas certamente guiam as principais recomendações desse estudo, que podem ser resumidas como:

- quantificar o valor do tempo, de forma que as decisões comparativas entre o tempo e os aspectos burocráticos de um lançamento em uma grande empresa possam ser balizados;

- utilizar o produto mínimo viável (MVP) para validar a comercialização do novo produto;

- criar processos flexíveis, tendo em vista que é fundamental a experimentação com o mercado no momento de lançamento;

- avalancar a marca e os produtos já existentes no portfólio da empresa no lançamento, evidenciando as vantagens da corporação na comunicação;

- criar parcerias e estimular a inovação aberta para não depender apenas do crescimento orgânico;

- incentivar o envolvimento de colaboradores com o projeto do novo produto, de modo interdepartamental, criando possibilidades de job rotation e adequando a composição da equipe a cada fase do projeto; 
- alocar recursos específicos a cada novo produto, para evidenciar prazos claros e evitar as necessidades burocráticas comuns a grandes empresas;

- encorajar a mentoria entre dirigentes da empresa e a equipe do novo produto;

- entender o problema do cliente como o ponto de partida do lançamento;

- usar métricas ao longo de todo o processo da inovação para avaliar o atingimento dos objetivos e o direcionamento correto, assim como identificar indicadores complementares. 


\section{CONCLUSÃO}

Essa dissertação estudou a relevância do tempo no lançamento de novos produtos de informação em corporações, e comparou atividades de agilidade na entrada no mercado em corporações, startups e aquelas propostas por programas de aceleração.

Observando-se primeiramente que por vezes as corporações levam tempo superior às startups no lançamento de produtos de informação - apesar de frequentemente disporem de mais recursos - buscou-se primeiramente identificar as semelhanças e diferenças no contexto de pequenas e grandes empresas em relação a desafios, oportunidades, pontos positivos e pontos negativos. A partir da análise comparativa, a pesquisa visou à identificação de como as corporações poderiam aprender com os processos e métodos utilizados por aceleradoras e startups para agilizar o seu próprio processo de lançamento de produtos de informação. Em alguns momentos, foi complexa a identificação de qual unidade de análise associar a determinadas atividades, pelo fato de existir forte inter-relação entre elas.

Como destaques das recomendações para a aceleração do lançamento de produtos de informação - principal objetivo dessa dissertação - evidencia-se a necessidade de uma abordagem multidisciplinar no lançamento do produto (seja esse produto de informação ou não). Também é evidente o fato de que algumas recomendações são aplicáveis na solução de problemas de natureza distinta. Uma equipe capaz de alterar rapidamente o direcionamento do produto ao verificar uma oportunidade e a capacidade de adaptação contínua (decorrente das habilidades da equipe apropriadas, ferramentas de gestão adequadas e processos internos propícios à inovação) parecem cruciais no lançamento de produtos.

Também é relevante nessa conclusão notar que empresas de pequeno e grande porte por vezes enfrentam situações similares no lançamento de produtos de informação sob a perspectiva externa, apesar de apresentarem diferenças internas significativas - que demonstram a oportunidade de aprendizado de ambas as partes. 


\subsection{Limitações do estudo e recomendações para estudos futuros}

Uma limitação já prevista no capítulo de Metodologia referia-se à não-aleatoriedade da amostra, de modo que há a possibilidade de situações no lançamento de produtos de informação não cobertas por este estudo.

Para estudos futuros, é possível aplicar e quantificar o impacto de cada recomendação deste estudo na agilidade do lançamento. O capítulo de metodologia apresenta um ciclo composto por três fases na criação de uma teoria. Acredita-se que a aplicação prática dessa pesquisa poderá complementar significativamente esse estudo.

Ademais, a despeito de todas as recomendações apresentadas nessa dissertação aparecerem de modo semelhante, verifica-se diferenças na complexidade de aplicação e no potencial de retorno de cada uma delas. Portanto, são de grande valor a análise e a mensuração da eficácia de cada ação recomendada. Efetivamente, a criação de métricas do impacto em eficiência obtido com a aplicação de cada recomendação poderá gerar um valor significativo.

Propõe-se, por fim, comparar ou validar as recomendações para outros tipos de produtos. 


\section{REFERÊNCIAS}

BABBIE, Earl. The practice of social research. 9th ed. Belmont: Wadsworth, 2001.

BARREHAG, Lisa et al. Accelerating success: a study of seed accelerators and their defining characteristics. Gothenburg, 2012. Tese (Bacharelado em Engenharia Industrial e Gestão) Programa de Graduação em Engenharia Industrial e Gestão, Departamento de Gestão de Tecnologia e Economia da Chalmers University of Technology.

BALIK, Rachel. Bringing the lean process to big finance corporations. Lean Startup Co, [S.1.], 04/02/2016. Disponível em: <https://leanstartup.co/bringing-the-lean-process-to-big-financecorporations/>. Acesso em: 30/12/2016.

BAYUS, Barry L. Speed-to-market and new product performance trade-offs. Journal of Product Innovation Management. New York: Wiley-Blackwell, v. 14, n.6, p. 485-497, $11 / 1997$.

BENEDETTO, Anthony Di. Identifying the key factors in new product development. Journal of Product Innovation Management. New York: Wiley-Blackwell, v. 16, n.6, p. 530-544, 1999.

BIANCOLINO, César Augusto et al. Protocolo para Elaboração de Relatos de Produção Técnica. Revista de Gestão de Projetos. São Paulo: v.3, n.2, p. 294-307, 05-08/2012.

BOUND, Kirsten; MILLER, Paul. The startup factories: the rise of accelerator programmes to support new technology ventures. London: NESTA, 06/2011.

BOUZAS, Diana Gavilán; MIRANDA, Jesús García Madariaga. ¿Esperamos porque es mejor o es mejor porque esperamos? Un estudio exploratorio de la relación entre el tiempo de espera y el valor percibido. Universia Business Review. Madrid: Universia, n. 22, p. 56-73, 2009.

BRADFORD, Jon. Corporate-run startup accelerators: the good, the bad and the plain ugly. Tech.eu, [S.1.], 14 /03/2014. Disponível em: <http://tech.eu/features/779/corporate-runstartup-accelerators-good-bad-plain-ugly/>. Acesso em: 17/03/2017.

BURNHAM, Thomas et al. Consumer switching costs: a typology, antecedents, and consequences. Academy of Marketing Science Journal. Ruston: Springer, v. 31, n. 2, p. 109126, spring 2003. 
CALANTONE, R.G.; MONTOYA-WEISS, M. M. Product launch and follow on. In: SOUDER, W.M.E., SHERMAN, J.D. (Org.). Managing new technology development. New York: McGraw Hill, 1993.

CALEY, Elizabeth; KULA, Helen. Seeding success: Canadian startup accelerators. Toronto: MaRS Data Catalyst, 2013.

CASSELL, Catherine; GILLIAN, Symon. Qualitative methods in organizational research: a practical guide. London: Sage, 1994.

CHAKRAVORTI, Bahaskar. The new rules for bringing innovations to the market. Harvard Business Review. Boston: Harvard Business Publishing, n. 6247, 03/2004.

CHIU, Yi-Chia et al. An evaluation model of new product launch strategy. Technovation. [S.1.: s.n.], v.26, p. 1244-1252, 2006.

CHRISTIANSEN, Jed D. Copying Y Combinator: a framework for developing seed accelerator programmes. Cambridge, 2009. Dissertação (Mestrado em Administração de Empresas) - Judge Business School \& Jesus College, University of Cambridge.

CHRYSSOCHOIDIS, George M; WONG, Veronica. Rolling out new products across country markets: An empirical study of causes of delays. Journal of Product Innovation Management. New York: Wiley-Blackwell, v. 15, n.1, p. 16-41, 01/1998.

COHEN, David. The Mentor Manifesto. David Cohen Blog, 28/08/2011. Disponível em: $<$ http://davidgcohen.com/2011/08/28/the-mentor-manifesto/>. Acesso em: 02/12/2017.

COHEN, Morris A. et al. New product development: the performance and time-to-market tradeoff. Management Science. Cantonsville: Informs, v. 42, n. 2, p. 173-186, 02/1996.

COHEN, Susan L. What do accelerators do? Insights from incubators and angels. Innovations: Technology, Governance, Globalization. Cambridge: MIT Press, v. 8, n. 3-4, p. 19-25, summer-fall 2013.

COHEN, Susan G.; HOCHBERG, Yael V. Accelerating startups: the seed accelerator phenomenon. SSRN Journal. Rochester: Elsevier, p. 1-16, 03/2014.

COOPER, Robert et al. Portfolio management for new product development: results of an industry practices study. R\&D Management. New York: Industrial Research Institute, v. 31, n. 4, p.361-380, 2001.

CORBIN, Juliet; STRAUSS, Anselm. Basics of qualitative research: techniques and procedures for developing grounded theory. 3 ed. Thousand Oaks: SAGE, 2007. 
CORSO, Mariano et al. Knowledge management in product innovation: an interpretative review. International Journal of Management Review. London: British Academy of Management, v. 3, n. 4, p. 341-352, 12/2001.

CRAWFORD, C. Merle. The hidden costs of accelerated product development. Journal of Product Innovation Management. New York: Wiley-Blackwell, v. 9, n.3, p. 188-199, 09/1992.

CROLL, Alistair; YOSKOVITZ, Benjamin. Lean analytics: use data to build a better startup faster. Sebastopol: O'Reilly Media, 2013.

DACKO, Scott G. et al. A typology of marketing windows and antecedents of firm readiness in the launching of multiple generations of new products. In: SPOTTS, Harlan. Proceedings of the 2002 Academy of Marketing Science (AMS) Annual Conference. Springfield: Springer, 2015.

DEMPWOLF, Scott C. et al. Innovation accelerators: Defining characteristics among startup assistance organizations. College Park: Optimal Solutions Group, 10/2014. Disponível em: $<$ https://www.sba.gov/advocacy/innovation-accelerators-defining-characteristics-amongstartup-assistance-organizations $>$. Acesso em: 11/08/2016.

DYBA $^{\circ}$, Tore; DINGSØYR, Torgeir. Empirical studies of agile software development: $a$ systematic review. Information and Software Technology. Alberta: Elsevier, v. 50, n. 9-10, p. 833-859, 08/2008.

ELBERT, Cristof. Understanding the product life cycle: four key requirements engineering techniques. IEEE Software. Reston: IEEE, v.23, n.3, p. 19-25, 05-06/2006.

ELLIOT, Robert; TIMULAK, Ladislav. Descriptive and interpretive approaches to qualitative research. In: MILES, Jeremy; GILBERT, Paul. A handbook of research methods for clinical and health psychology. New York: Oxford University Press, 2005.

ESPINAL, Carlos Eduardo. The product-market fit cycle. The Drawing Board, 03/05/2013. Disponível em: <http://thedrawingboard.me/2013/05/03/the-product-market-fit-cycle/>. Acesso em: 23/12/2016.

FINNERNAN, John. The fat startup: learn the lessons of my failed lean startup. John Finnernan Blog, 01/04/2013. Disponível em: <http://www.johnffinneran.com/blog/fatstartup-learn-the-lessons $>$. Acesso em: 28/02/2017.

FOLKESTAD, Bjarte. Analysing interview data: possibilities and challenges. Eurosphere Online Working Paper Series. Bergen: [s.n.], n. 13, 12/2008. 
FYLAN, Fiona. Semi-structured interviewing. In: MILES, Jeremy; GILBERT, Paul. $\boldsymbol{A}$ handbook of research methods for clinical and health psychology. New York: Oxford University Press, 2005.

GJERDING, Allan Næs. The evolution of the flexible firm: New concepts and a Nordic comparison. In: CONFERENCE ON NATIONAL INNOVATION SYSTEMS, INDUSTRIAL DYNAMICS AND INNOVATION POLICY. Rebild: 09-12/06/1999.

GUILLHAM, Bill. Case study research methods. London: Bloomsbury Academic, 2000.

GUILTINAN, Joseph P. Launch strategy, launch tactics, and demand outcomes. Journal of Product Innovation Management. New York: Wiley-Blackwell, v. 16, n.6, p. 509-529, 11/1999.

GUPTA, Ashok K.; WILEMON, David L. Accelerating the development of technology-based new products. California Management Review. Berkeley: SAGE, v. 32, n.2, p.24-44, winter 1990.

HAINES, Julia Katherine. Iterating an innovation model: challenges and opportunities in adapting accelerator practices in evolving ecosystems. Ethnographic Praxis in Industry Conference Proceedings. Malden: John Wiley \& Sons, v. 2014, n.1, p. 282-295, 2014.

HALLEN, Benjamin L. et al. Do accelerators accelerate? The role of indirect learning in new venture development. Social Science Research Network. Rochester: Elsevier, 08/07/2016.

HENDERSON-SELLERS, B.; SEROUR. M. K. Creating a dual-agility method: The value of method engineering. Journal of Database Management. Hershey: Idea Group, v. 16, n. 4, p. $1-23,2005$.

HENDRICKS, Kevin B.; SINGHAL, Vinod R. Delays in new product introductions and the market value of the firm: the consequences of being late to the market. Management Science. Cantonsville: Informs, v. 43 n. 4, p. 422-436, 04/1997.

HOFFMAN, David Lynn; KELLEY, Nina Radojevich. Analysis of accelerator companies: An exploratory case study of their programs, processes, and early results. Small Business Institute Journal. Clinton: Small Business Institute, v. 8, n. 2, p. 54-70, 2012.

JICK, Todd D. Mixing qualitative and quantitative methods: Triangulation in action. Administrative Science Quarterly. Ithaca: Sage, v. 24, n.4, p. 602-611, 12/1979.

JORGENSON, D. L. Participant observation: a methodology for human studies. Newbury Park: Sage, 1989. 
KIRSNER, Scott. The barriers big companies face when they try to act like lean startups. Harvard Business Review. Boston: Harvard Business Publishing, 08/2016.

KOHLBACHER, Florian. The use of qualitative content analysis in case study research. Qualitative Social Research. Berlin: Institute for Qualitative Research and Center for Digital Systems, v. 7, n. 1, 01/2006.

KONCZAL, Jared. Evaluating the effects of accelerators? Not so fast. Forbes. Jersey: 08/08/2012. Disponível em: <http://www.forbes.com/sites/kauffman/2012/08/08/evaluatingthe-effects-of-accelerators-not-so-fast/>. Acesso em: 12/01/2017.

KOTTER, John P. Accelerate! Harvard Business Review. Boston: Harvard Business Publishing, 11/2012.

LADD, Ted. The limits of the lean startup method. Harvard Business Review. Boston: Harvard Business Publishing, 07/03/2016.

LEAN ENTERPRISE INSTITUTE. Disponível em: <https://www.lean.org/WhatsLean/>. Acesso em: 03/12/2016.

LEE, G.; XIA, W. Toward agile: an integrated analysis of quantitative and qualitative field data on software development agility. MIS Quarterly. Minneapolis: Management Information Systems Research Center, v. 34, n.1, p. 87-114, 03/2010.

LEVY, S. Y Combinator is bootcamp for startups. Wired. New York: Condé Nast Publications, 17/05/2011. Disponível em: $<$ http://www.wired.com/magazine/2011/05/ff_ycombinator/all/1>. Acesso em: 19/10/2016.

LINCOLN, Yvonna S.; GUBA, Egon G. Naturalistic inquiry. Newbury Park: Sage, 1985.

LYNN, Gary S. et al. Practices that support team learning and their impact on speed to market and new product success. Journal of Product Innovation Management. New York: WileyBlackwell, v. 16, n.5, p. 439-454, 1999.

LYNHAM, Susan. A. The general method of theory-building research in applied disciplines. Advances in Developing Human Resources. Edina: Sage, v.4, p. 221-241, ago/2002.

MALHOTRA Naresh K. Pesquisa de Marketing: uma orientação aplicada. 6. ed. Porto Alegre: Bookman, 2012.

MARCH, James G. Exploration and exploitation in organizational learning. Organization Science. Park City: Informs, v. 2, n. 1, p. 71-87, 02/1991. 
MaRS DISCOVERY DISTRICT. Disponível em: < https://www.marsdd.com/ > Acesso em: 02/12/2016.

MEYER, C.; PURSER, R. E. Six steps to becoming a fast-cycle-time competitor. ResearchTechnology Management. Arlington: Industrial Research Institute, v. 32, n.41, p. 41-48, 0910/1993.

MILES, M. B.; HUBERMAN, A. M. Qualitative data analysis: an expanded sourcebook, Thousand Oaks: Sage, 1994.

NESTA. Startup accelerator programmes: a practice guide. London, 2014.

O'CONNELL, B. Start X: Training ground for Stanford's best and brightest. London: Kauffman Foundation, 2011.

OSTROWER, Daniel. Minimum lovable products: making MVP work for hardware. Wired. New York: Condé Nast Publications, 03/10/2014. Disponível em: $<$ http://insights.wired.com/profiles/blogs/making-mvp-work-forhardware\#ixzz4a1S3WYfU>. Acesso em: 28/02/2017.

POLIJANIUK, Paweł; STRINSJÖ, Jens. How the new product development team should be formed and function given the radicalness of the innovation. Lund, 2014. Tese (Mestrado em Empreendedorismo) - Programa de Empreendedorismo Corporativo e Inovação, Escola de Economia e Administração, Lund University.

PROJECT MANAGEMENT INSTITUTE - PMI. Project Management Body of Knowledge. 5. ed. Newtown Square: Project Management Institute, 2012.

RADAS, Sonja; SHUGAN, Steven M. Seasonal marketing and timing new product introductions. Journal of Marketing Research. Chicago: American Marketing Association, v. 35 , n.3, p. 296-315, 08/1998.

RIES, Eric. The lean startup. New York: CrownBusiness, 2011.

RYAN, Gery W.; BERNARD, Russell. Techniques to identify themes. Field methods. Gainesville: Sage, v. 15, n. 1, p. 85-109, fev. 2003. Disponível em: $<$ http://qualquant.org/wpcontent/uploads/text/Ryan\%20\&\%20Bernard\%202003.pdf>. Acesso em: 03/01/2016.

SATELL, Greg. A dedicated team of problem solvers can help big companies act like lean startups. Harvard Business Review. Boston: Harvard Business Publishing, 24/12/2016.

SENGE, Peter M. The fifth discipline: the art \& practice of the learning organization. New York: Double Day, 1990. 
SHAH, Sonali K.; CORLEY, Kevin G. Building better theory by bridging the quantitativequalitative divide. Journal of Management Studies. Hoboken: Wiley-Blackwell, v. 48, n. 8, p. $1821-1835,12 / 2006$

SMITH, Robert P. EPPINGER, Steven D. Deciding between sequential and concurrent tasks in engineering design. Concurrent Engineering Research and Applications. Tustin: Sage, v. 6, n. 1, p. 15-25, 03/1998.

SMITH, Sheryl Winston; HANNIGAN, Thomas J. Swinging for the fences: How do top accelerators impact the trajectories of new ventures? In: DRUID15, 15-17/06/2015, Roma.

STALK JR, George. Time: The next source of competitive advantage. Harvard Business Review. Boston: Harvard Business Publishing, p. 41-51, 07-08/1988.

STATA, R. Organizational learning: the key to management innovation. Sloan Management Review. Cambridge: Massachusetts Institute of Technology, v. 30, n. 3, p. 63-74, spring 1989.

TOYOTA. Toyota Production System. Disponível em: <http://www.toyotaglobal.com/company/vision_philosophy/toyota_production_system/>. Acesso em: 20/01/2017.

$\mathrm{UN}$, Annique et al. $R \& D$ collaborations and product innovation. Journal of Product Innovation Management. New York: Wiley-Blackwell, v. 27, n.5, p. 673-689, 2010.

VOLBERDA, Henk W. Building flexible organizations for fast-moving markets. Long Range Planning. London: Elsevier, v. 30, n. 2, p. 169-183, 04/1997.

WALTON, Helen. Lean start-up, and how it almost killed our company. InfoQ, 14/05/2015. Disponível em: $<$ https://www.infoq.com/articles/lean-startup-killed $>$. Acesso em: 28/08/2017.

YIN, Robert K. Estudo de caso: planejamento e métodos. 4. ed. Porto Alegre: Bookman, 2010.

YUSUF, Y.Y. et al. Agile manufacturing: the drivers, concepts and attributes. International Journal of Production Economics. [S.1.]: C4Media, v. 62, n. 1-2, p. 33-43, 02/1999. 


\section{APÊNDICE}

\section{APÊNDICE A - Protocolos de entrevista}

As entrevistas com os três perfis profissionais duraram cerca de 30 minutos. A maioria das entrevistas foi realizada pessoalmente, porém utilizou-se também Skype e telefone.

\section{Protocolo da entrevista semiestruturada com gestores de inovação em corporações}

O objetivo da entrevista com gestores das corporações era obter um panorama elencando os fatores de impacto no tempo do lançamento de produtos de informação, a opinião acerca dos principais desafios e oportunidades e conhecer modelos e sugestões de trabalho relacionados ao lançamento.

\begin{tabular}{|l|l|}
\hline Pergunta & Objetivo \\
\hline $\begin{array}{l}\text { Você entende que trabalha ou já } \\
\text { trabalhou com Inovação? }\end{array}$ & $\begin{array}{l}\text { Compreender se o entrevistado possui o perfil adequado à entrevista. Se o } \\
\text { entrevistado não possuir experiência na área, agradecer e terminar a } \\
\text { pesquisa. }\end{array}$ \\
\hline $\begin{array}{l}\text { Em que área? Comente } \\
\text { brevemente sua experiência. }\end{array}$ & $\begin{array}{l}\text { Comparar possíveis diferenças em opiniões de acordo com a área em que } \\
\text { cada entrevistado trabalha. }\end{array}$ \\
\hline $\begin{array}{l}\text { Quais são os principais desafios, } \\
\text { na sua opinião, na venda de } \\
\text { produtos de inovação em sua fase } \\
\text { inicial (lançamento)? }\end{array}$ & $\begin{array}{l}\text { Pergunta exploratória coma busca de entender perspectivas não abordadas } \\
\text { pela no Referencial Teórico. }\end{array}$ \\
\hline $\begin{array}{l}\text { Quais são as principais diferenças } \\
\text { entre vender produtos de inovação } \\
\text { e vender produtos tradicionais? }\end{array}$ & $\begin{array}{l}\text { Esclarecer as diferenças na venda de inovação e outros produtos já no } \\
\text { início da entrevista para direcionar o entrevistado ao tema. } \\
\text { Caso o entrevistado não o faça espontaneamente, especificar a pergunta } \\
\text { acerca de oportunidades e desafios, indicando o tema de modo } \\
\text { semiestruturado e exploratório. }\end{array}$ \\
\hline
\end{tabular}




\begin{tabular}{|c|c|}
\hline $\begin{array}{l}\text { Quais são os pontos positivos } \\
\text { (oportunidades) } \text { e negativos } \\
\text { (desafios) de se vender inovação? }\end{array}$ & \\
\hline $\begin{array}{l}\text { Você conhece o conceito de startup } \\
\text { enxuta? }\end{array}$ & $\begin{array}{l}\text { Alinhar o conceito da metodologia para as perguntas que virão em } \\
\text { seguida. Caso o entrevistado não o conheça, abordar o conceito do produto } \\
\text { mínimo viável e o ciclo de construção, mensuração e aprendizado. }\end{array}$ \\
\hline $\begin{array}{l}\text { Você já aplicou este ciclo? Qual a } \\
\text { sua opinião sobre ele? }\end{array}$ & $\begin{array}{l}\text { Identificar a opinião do entrevistado sobre o modelo de acordo com a sua } \\
\text { experiência prática ou teórica. }\end{array}$ \\
\hline $\begin{array}{l}\text { Este ciclo foi originado a partir da } \\
\text { experiência de um empreendedor } \\
\text { em uma startup. Você acredita que } \\
\text { seja possível implantá-lo em uma } \\
\text { empresa de grande porte? E na sua } \\
\text { opinião seriam necessárias quais } \\
\text { adaptações para a sua adoção? }\end{array}$ & $\begin{array}{l}\text { Compreender a perspectiva do entrevistado sobre o ciclo de inovação da } \\
\text { startup enxuta e explorar aspectos importantes à sua adoção. }\end{array}$ \\
\hline $\begin{array}{l}\text { O que você acha que seria } \\
\text { importante medir na entrada do } \\
\text { produto no mercado (na estratégia } \\
\text { do lançamento, antes ou logo em } \\
\text { seguida)? }\end{array}$ & $\begin{array}{l}\text { Visto que a métrica integra o ciclo da startup enxuta e há diferença entre } \\
\text { métricas para produtos novos e tradicionais, entender o que o entrevistado } \\
\text { propõe. }\end{array}$ \\
\hline $\begin{array}{l}\text { A última etapa do ciclo da startup } \\
\text { enxuta antes que ele seja } \\
\text { retroalimentado é 'validar o } \\
\text { aprendizado'. Isto é, o aprendizado } \\
\text { obtido com a experiência - ainda } \\
\text { que frustrada - pode gerar uma } \\
\text { experiência que permite melhorias } \\
\text { na próxima interação. Quais os } \\
\text { tipos de aprendizado você acredita } \\
\text { que são necessários no lançamento } \\
\text { de produtos e inovação? }\end{array}$ & $\begin{array}{l}\text { Levantar os destaques que cada entrevistado acredita ser importante no } \\
\text { lançamento de produtos, abordando seus principais aprendizados. }\end{array}$ \\
\hline $\begin{array}{l}\text { Como você acredita que seria } \\
\text { possível acelerar o aprendizado da } \\
\text { equipe? }\end{array}$ & $\begin{array}{l}\text { Elencar algumas propostas dos gestores para avaliação nas } \\
\text { recomendações. }\end{array}$ \\
\hline $\begin{array}{l}\text { Em sua experiência no lançamento } \\
\text { de produtos, quais são as lições que } \\
\text { você daria (de experiências bem ou } \\
\text { malsucedidas)? } \\
\text { Você gostaria de colocar mais } \\
\text { algum ponto que não foi } \\
\text { perguntado? }\end{array}$ & $\begin{array}{l}\text { Finalizar a entrevista com uma pergunta genérica de modo a deixar o } \\
\text { entrevistado dizer algo que ainda não tenha dito antes. }\end{array}$ \\
\hline
\end{tabular}

\title{
Protocolo da entrevista com empreendedores ou gestores de inovação em startups
}

\author{
O objetivo da entrevista com empreendedores e gestores de inovação em startups era \\ principalmente comparar a sua perspectiva de inovação com aquela dos gestores de
}


corporações. Buscou-se explorar a experiência prática do entrevistado e a sua opinião comparando o lançamento de inovações em empresas nascentes e corporações estabelecidas.

\begin{tabular}{|c|c|}
\hline Pergunta & Objetivo \\
\hline $\begin{array}{l}\text { Qual a sua função na startup? } \\
\text { Em que área da startup você } \\
\text { trabalha? }\end{array}$ & Compreender a experiência do entrevistado. \\
\hline $\begin{array}{l}\text { Quantos anos decorreram desde } \\
\text { a fundação da sua startup? } \\
\text { Quantos funcionários ela tem? } \\
\text { A startup já vendeu algum } \\
\text { produto? Caso positivo, quando } \\
\text { foi a primeira venda? }\end{array}$ & Entender o nível de maturidade da startup. \\
\hline $\begin{array}{l}\text { Quais são os principais } \\
\text { desafios, na sua opinião, na } \\
\text { venda de produtos de inovação } \\
\text { em sua fase inicial } \\
\text { (lançamento)? }\end{array}$ & Entender perspectivas não abordadas no Referencial Teórico. \\
\hline $\begin{array}{l}\text { Quais são os pontos positivos } \\
\text { (oportunidades) e } \text { negativos } \\
\text { (desafios) de se } r \text { vender } \\
\text { inovação? }\end{array}$ & $\begin{array}{l}\text { Esclarecer as diferenças na venda de inovação e outros produtos já no início } \\
\text { da entrevista para direcionar o entrevistado ao tema. } \\
\text { Caso o entrevistado não o faça espontaneamente, especificar a pergunta } \\
\text { acerca de oportunidades e desafios, indicando o tema de modo } \\
\text { semiestruturado e exploratório. }\end{array}$ \\
\hline $\begin{array}{l}\text { Você usou algum modelo ou } \\
\text { metodologia para se basear no } \\
\text { lançamento do produto? }\end{array}$ & $\begin{array}{l}\text { Conhecer modelos não abordados no Referencial Teórico e identificar quais } \\
\text { modelos estão sendo efetivamente utilizados por empreendedores. }\end{array}$ \\
\hline $\begin{array}{l}\text { Você conhece o conceito de } \\
\text { startup enxuta? } \\
\text { Você já aplicou este ciclo? } \\
\text { Como foi esse processo? Qual a } \\
\text { sua opinião sobre ele? } \\
\text { Vocês criaram um MVP? }\end{array}$ & $\begin{array}{l}\text { Identificar se o entrevistado já utilizou o ciclo da startup enxuta (caso não o } \\
\text { tenha mencionado na pergunta anterior). Caso já o tenha utilizado, elencar } \\
\text { pontos positivos e negativos da experiência, assim como pontos críticos. }\end{array}$ \\
\hline $\begin{array}{l}\text { Este ciclo foi originado a partir } \\
\text { da experiência de um } \\
\text { empreendedor em uma startup. } \\
\text { Você acredita que seja possível } \\
\text { implantá-lo em uma empresa de } \\
\text { grande porte? E na sua opinião } \\
\text { seriam necessárias quais } \\
\text { adaptações para a sua adoção? }\end{array}$ & $\begin{array}{l}\text { Compreender a visão do empreendedor sobre o ciclo de inovação da startup } \\
\text { enxuta sob a perspectiva da corporação, comparando-a com a visão do gestor } \\
\text { corporativo e obtendo uma perspectiva crítica para o cenário. }\end{array}$ \\
\hline $\begin{array}{l}\text { O que você acha que seria } \\
\text { importante medir na entrada do } \\
\text { produto no mercado (na } \\
\text { estratégia do lançamento, antes } \\
\text { ou logo em seguida)? }\end{array}$ & $\begin{array}{l}\text { Visto que a métrica integra o ciclo da startup enxuta e há diferença entre } \\
\text { métricas para produtos novos e tradicionais, entender o que o entrevistado } \\
\text { propõe. }\end{array}$ \\
\hline $\begin{array}{l}\text { A última etapa do ciclo da } \\
\text { startup enxuta antes que ele seja } \\
\text { retroalimentado é 'validar o } \\
\text { aprendizado'. Isto é, o } \\
\text { aprendizado obtido com a } \\
\text { experiência - ainda que } \\
\text { frustrada - pode gerar uma } \\
\text { experiência que permite }\end{array}$ & $\begin{array}{l}\text { Levantar os destaques que cada entrevistado acredita ser importante no } \\
\text { lançamento de produtos, abordando seus principais aprendizados. }\end{array}$ \\
\hline
\end{tabular}




\begin{tabular}{|c|c|}
\hline $\begin{array}{l}\text { melhorias na próxima interação. } \\
\text { Quais os tipos de aprendizado } \\
\text { você acredita que são } \\
\text { necessários no lançamento de } \\
\text { produtos e inovação? }\end{array}$ & \\
\hline $\begin{array}{l}\text { Como você acredita que seria } \\
\text { possível acelerar o aprendizado } \\
\text { da equipe? }\end{array}$ & Elencar algumas propostas dos gestores para avaliação nas recomendações. \\
\hline $\begin{array}{l}\text { É importante entrar rápido no } \\
\text { mercado? } \\
\text { Sua startup participou de algum } \\
\text { programa de aceleração? } \\
\text { Por quê? }\end{array}$ & $\begin{array}{l}\text { Identificar relevância do tempo e as razões pelas quais as startups participam } \\
\text { ou não de programas de aceleração. }\end{array}$ \\
\hline $\begin{array}{l}\text { Caso positivo, como foi o } \\
\text { processo de aceleração? } \\
\text { Qual foi a duração aproximada } \\
\text { do programa? Durante o } \\
\text { programa de aceleração, quais } \\
\text { atividades foram realizadas? } \\
\text { Houve mentoria? Como ela } \\
\text { ocorre? } \\
\text { Como é o treinamento? Houve } \\
\text { Demo Day? }\end{array}$ & $\begin{array}{l}\text { Entender as fases e as atividades do programa de aceleração, a partir de } \\
\text { algumas etapas identificadas no Referencial Teórico, e compreender como } \\
\text { elas ocorrem para explorar oportunidades desses programas em corporações. }\end{array}$ \\
\hline $\begin{array}{l}\text { No que você acha que o } \\
\text { programa mais ajudou a } \\
\text { startup? } \\
\text { No que você acredita que o } \\
\text { programa poderia ajudar mais } \\
\text { na aceleração da startup? }\end{array}$ & $\begin{array}{l}\text { Identificar pontos positivos e negativos do programa sob a visão do } \\
\text { empreendedor. }\end{array}$ \\
\hline $\begin{array}{l}\text { Em sua experiência no } \\
\text { lançamento de produtos, quais } \\
\text { são as lições que você daria (de } \\
\text { experiências bem } \\
\text { malsucedidas)? }\end{array}$ & $\begin{array}{l}\text { Finalizar a entrevista com uma pergunta genérica de modo a deixar o } \\
\text { entrevistado dizer algo que ainda não tenha dito antes. }\end{array}$ \\
\hline
\end{tabular}

\section{Protocolo da entrevista com gestores de aceleradoras ou mentores}

O objetivo da entrevista com gestores de aceleradoras era primeiramente obter uma perspectiva externa do lançamento de produtos, quando comparada à opinião de entrevistados diretamente envolvidos com o lançamento. Embora com uma perspectiva externa, esse perfil de entrevistado já esteve envolvido em um grande número de lançamentos de produtos, uma vez que trabalha com um portfólio relativamente amplo e que se renova a cada novo programa (cuja duração vai de 3 a 12 meses, no caso dos entrevistados). Também buscou-se entender com mais profundidade os programas de aceleração, como eles funcionam, os métodos utilizados ao 
longo do programa e os principais desafios e oportunidades encontrados ao longo do processo de lançamento, com profissionais que já acompanharam um grande número de startups.

\begin{tabular}{|c|c|}
\hline Pergunta & Objetivo \\
\hline $\begin{array}{l}\text { A aceleradora na qual você } \\
\text { trabalha tem algum foco sobre } \\
\text { alguma indústria ou setor? }\end{array}$ & $\begin{array}{l}\text { Compreender o setor de atuação, se houver. Atentar ao fato de se incluírem } \\
\text { produtos de informação no portfólio. }\end{array}$ \\
\hline $\begin{array}{l}\text { Quais são os principais desafios, } \\
\text { na sua opinião, na venda de } \\
\text { produtos de inovação em sua fase } \\
\text { inicial (lançamento)? }\end{array}$ & $\begin{array}{l}\text { Pergunta exploratória com a busca de entender perspectivas não abordadas } \\
\text { no Referencial Teórico. }\end{array}$ \\
\hline $\begin{array}{l}\text { Quais são os pontos positivos } \\
\text { (oportunidades) e negativos } \\
\text { (desafios) de se vender inovação? }\end{array}$ & $\begin{array}{l}\text { Esclarecer as diferenças na venda de inovação e outros produtos já no início } \\
\text { da entrevista para direcionar o entrevistado ao tema. } \\
\text { Caso o entrevistado não o faça espontaneamente, especificar a pergunta } \\
\text { acerca de oportunidades e desafios, indicando o tema de modo } \\
\text { semiestruturado e exploratório. }\end{array}$ \\
\hline $\begin{array}{l}\text { O que é aceleração de startups e } \\
\text { como ocorre o processo de } \\
\text { aceleração? }\end{array}$ & Relacionar as etapas e atividades do processo de aceleração. \\
\hline $\begin{array}{l}\text { Houve mudanças neste processo } \\
\text { ao longo do tempo? } \\
\text { Por que é importante acelerar? E } \\
\text { ser rápido? }\end{array}$ & $\begin{array}{l}\text { Identificar se já foram verificadas e/ou realizadas melhorias no processo, a } \\
\text { partir de aprendizados passados. }\end{array}$ \\
\hline $\begin{array}{l}\text { A sua aceleradora segue algum } \\
\text { método ou teoria para o programa } \\
\text { de aceleração? Qual? }\end{array}$ & $\begin{array}{l}\text { Explorar métodos e referências utilizados, que ajudarão na construção das } \\
\text { recomendações. }\end{array}$ \\
\hline $\begin{array}{l}\text { Qual é a duração aproximada do } \\
\text { programa? Durante o programa de } \\
\text { aceleração, quais atividades são } \\
\text { realizadas? } \\
\text { Houve treinamento? Houve } \\
\text { mentoria? Houve Demo Day? }\end{array}$ & $\begin{array}{l}\text { Entender as fases e as atividades do programa de aceleração, a partir de } \\
\text { algumas etapas identificadas no Referencial Teórico, e compreender como } \\
\text { elas ocorrem para explorar oportunidades desses programas em } \\
\text { corporações. }\end{array}$ \\
\hline $\begin{array}{l}\text { O que você acredita que é o ponto } \\
\text { mais importante no processo de } \\
\text { aceleração? }\end{array}$ & $\begin{array}{l}\text { Definir como a aceleradora define o seu papel e situar o tempo neste } \\
\text { contexto. }\end{array}$ \\
\hline $\begin{array}{l}\text { Depois de startups escolhidas, o } \\
\text { que em geral mais as ajuda a } \\
\text { 'acelerar'? } \\
\text { Como vocês buscam ajuda-las } \\
\text { neste aspecto? } \\
\text { Com o que a aceleração mais ajuda } \\
\text { a startup? }\end{array}$ & $\begin{array}{l}\text { Identificar as melhores práticas de aceleração e explorar o conhecimento } \\
\text { dos entrevistados relacionado à aceleração da entrada de produtos no } \\
\text { mercado. }\end{array}$ \\
\hline $\begin{array}{l}\text { No que você acredita que o } \\
\text { programa poderia ajudar mais na } \\
\text { aceleração da startup (mas não } \\
\text { ajudou tanto)? }\end{array}$ & Identificar os obstáculos comuns que precisam ser aprimorados. \\
\hline $\begin{array}{l}\text { Há algum aspecto importante para } \\
\text { a startup sair bem-sucedida mas } \\
\text { que você considera difícil de } \\
\text { incentivar? Qual? }\end{array}$ & $\begin{array}{l}\text { Compreender desafios importantes de baixo potencial de solução por parte } \\
\text { das aceleradoras. }\end{array}$ \\
\hline
\end{tabular}




\begin{tabular}{|c|c|}
\hline $\begin{array}{l}\text { Você conhece o conceito de } \\
\text { startup enxuta? }\end{array}$ & $\begin{array}{l}\text { Identificar se o entrevistado já utilizou o ciclo da startup enxuta (caso não o } \\
\text { tenha mencionado na pergunta anterior). Caso já o tenha utilizado, elencar } \\
\text { pontos positivos e negativos da experiência, assim como pontos críticos. }\end{array}$ \\
\hline $\begin{array}{l}\text { Este ciclo é aplicado na } \\
\text { aceleradora? Qual a sua opinião } \\
\text { sobre ele? }\end{array}$ & $\begin{array}{l}\text { Compreender a visão do empreendedor sobre o ciclo de inovação da startup } \\
\text { enxuta sob a perspectiva da corporação, comparando-a com a visão do } \\
\text { gestor corporativo e obtendo uma perspectiva crítica para o cenário. }\end{array}$ \\
\hline $\begin{array}{l}\text { Este ciclo foi originado a partir da } \\
\text { experiência de um empreendedor } \\
\text { em uma startup. Você acredita que } \\
\text { seja possível implantá-lo em uma } \\
\text { empresa de grande porte? E na sua } \\
\text { opinião seriam necessárias quais } \\
\text { adaptacões para a sua adocão? }\end{array}$ & $\begin{array}{l}\text { Compreender a perspectiva do entrevistado sobre o ciclo de inovação da } \\
\text { startup enxuta e explorar aspectos importantes à sua adoção. }\end{array}$ \\
\hline $\begin{array}{l}\text { O que você acha que seria } \\
\text { importante medir na entrada do } \\
\text { produto no mercado (na estratégia } \\
\text { do lançamento, antes ou logo em } \\
\text { seguida)? }\end{array}$ & $\begin{array}{l}\text { Visto que a métrica integra o ciclo da startup enxuta e há diferença entre } \\
\text { métricas para produtos novos e tradicionais, entender o que o entrevistado } \\
\text { propõe. }\end{array}$ \\
\hline $\begin{array}{l}\text { O último ciclo da lean startup é } \\
\text { 'validar o aprendizado'. Isto é, o } \\
\text { aprendizado obtido com a } \\
\text { experiência - ainda que frustrada- } \\
\text { pode gerar uma experiência que } \\
\text { permite melhorias na próxima } \\
\text { interação. Quais os tipos de } \\
\text { aprendizado você acredita que são } \\
\text { necessários quando se fala em } \\
\text { inovação? }\end{array}$ & $\begin{array}{l}\text { Levantar os destaques que cada entrevistado acredita ser importante no } \\
\text { lançamento de produtos, abordando seus principais aprendizados. }\end{array}$ \\
\hline $\begin{array}{l}\text { Como você acredita que seria } \\
\text { possível acelerar o aprendizado da } \\
\text { equipe? }\end{array}$ & $\begin{array}{l}\text { Explorar mais especificamente o ponto do aprendizado e entender o que o } \\
\text { gestor acredita que precisa ser aprendido, abordando o terceiro ponto do } \\
\text { ciclo }\end{array}$ \\
\hline $\begin{array}{l}\text { Em sua experiência no lançamento } \\
\text { de produtos, quais são as lições } \\
\text { que você daria (de experiências } \\
\text { bem ou malsucedidas)? }\end{array}$ & $\begin{array}{l}\text { Finalizar a entrevista com uma pergunta genérica de modo a deixar o } \\
\text { entrevistado dizer algo que ainda não tenha dito antes. }\end{array}$ \\
\hline
\end{tabular}

